\title{
Memory distrust in the legal context
}

Citation for published version (APA):

van Bergen, S. H. E. M. (2011). Memory distrust in the legal context. [Doctoral Thesis, Maastricht University]. Datawyse / Universitaire Pers Maastricht. https://doi.org/10.26481/dis.20110610sb

Document status and date:

Published: 01/01/2011

DOI:

10.26481/dis.20110610sb

Document Version:

Publisher's PDF, also known as Version of record

\section{Please check the document version of this publication:}

- A submitted manuscript is the version of the article upon submission and before peer-review. There can be important differences between the submitted version and the official published version of record.

People interested in the research are advised to contact the author for the final version of the publication, or visit the DOI to the publisher's website.

- The final author version and the galley proof are versions of the publication after peer review.

- The final published version features the final layout of the paper including the volume, issue and page numbers.

Link to publication

\footnotetext{
General rights rights.

- You may freely distribute the URL identifying the publication in the public portal. please follow below link for the End User Agreement:

www.umlib.nl/taverne-license

Take down policy

If you believe that this document breaches copyright please contact us at:

repository@maastrichtuniversity.nl

providing details and we will investigate your claim.
}

Copyright and moral rights for the publications made accessible in the public portal are retained by the authors and/or other copyright owners and it is a condition of accessing publications that users recognise and abide by the legal requirements associated with these

- Users may download and print one copy of any publication from the public portal for the purpose of private study or research.

- You may not further distribute the material or use it for any profit-making activity or commercial gain

If the publication is distributed under the terms of Article $25 \mathrm{fa}$ of the Dutch Copyright Act, indicated by the "Taverne" license above, 
Memory Distrust

in the Legal Context 


\section{Colophon}

Graphic Design: Hugo Alberts

Production: Universitaire Pers Maastricht

(C) 2011 Saskia van Bergen, Maastricht

ISBN 9789461590572

All rights are reserved. No part of this book may be reproduced or transmitted in any form or by any means, without written permission from the author or, when appropriate, the publisher of the article. 


\section{Memory Distrust in the Legal Context}

\section{PROEFSCHRIFT}

ter verkrijging van de graad van doctor aan de Universiteit Maastricht, op gezag van de Rector Magnificus, Prof. mr. G.P.M.F. Mols volgens het besluit van het College van Decanen, in het openbaar te verdedigen op vrijdag 10 juni 2011 om 12.00 uur

door

Saskia Hubertina Eduarda Maria van Bergen

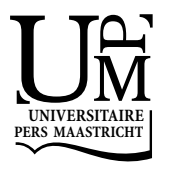




\section{Promotor}

Prof. dr. H.L.G.J. Merckelbach

\section{Copromotor}

Dr. M. Jelicic

\section{Beoordelingscommissie}

Prof. dr. P.J. van Koppen (voorzitter)

Prof. dr. I.M. Engelhard (Universiteit Utrecht)

Prof. dr. mr. E. Rassin (Erasmus University Rotterdam)

Prof. dr. C. de Ruiter

Dr. T. Smeets

The research presented in this dissertation was supported by the Netherlands Organisation for Scientific Research (NWO, The Hague), grant number 400.04.048 awarded to dr. M. Jelicic. 


\section{CONTENTS}

CHAPTER 1

General Introduction

7

PART 1

TRAIT MEMORY DISTRUST

CHAPTER 2

Assessing Trait Memory Distrust

25

CHAPTER 3

Related Concepts

39

CHAPTER 4

Memory Distrust and Misinformation

53

PART 2

STATE MEMORY DISTRUST

CHAPTER 5

Memory Distrust and Interrogation

69

Techniques

CHAPTER 6

Memory Distrust and False Confessions

83

CHAPTER 7

General Discussion

93

References

111

Summary

125

Samenvatting

Dankwoord

Curriculum Vitae

List of Publications

141 



\section{CHAPTER 1}

\section{GENERAL INTRODUCTION}

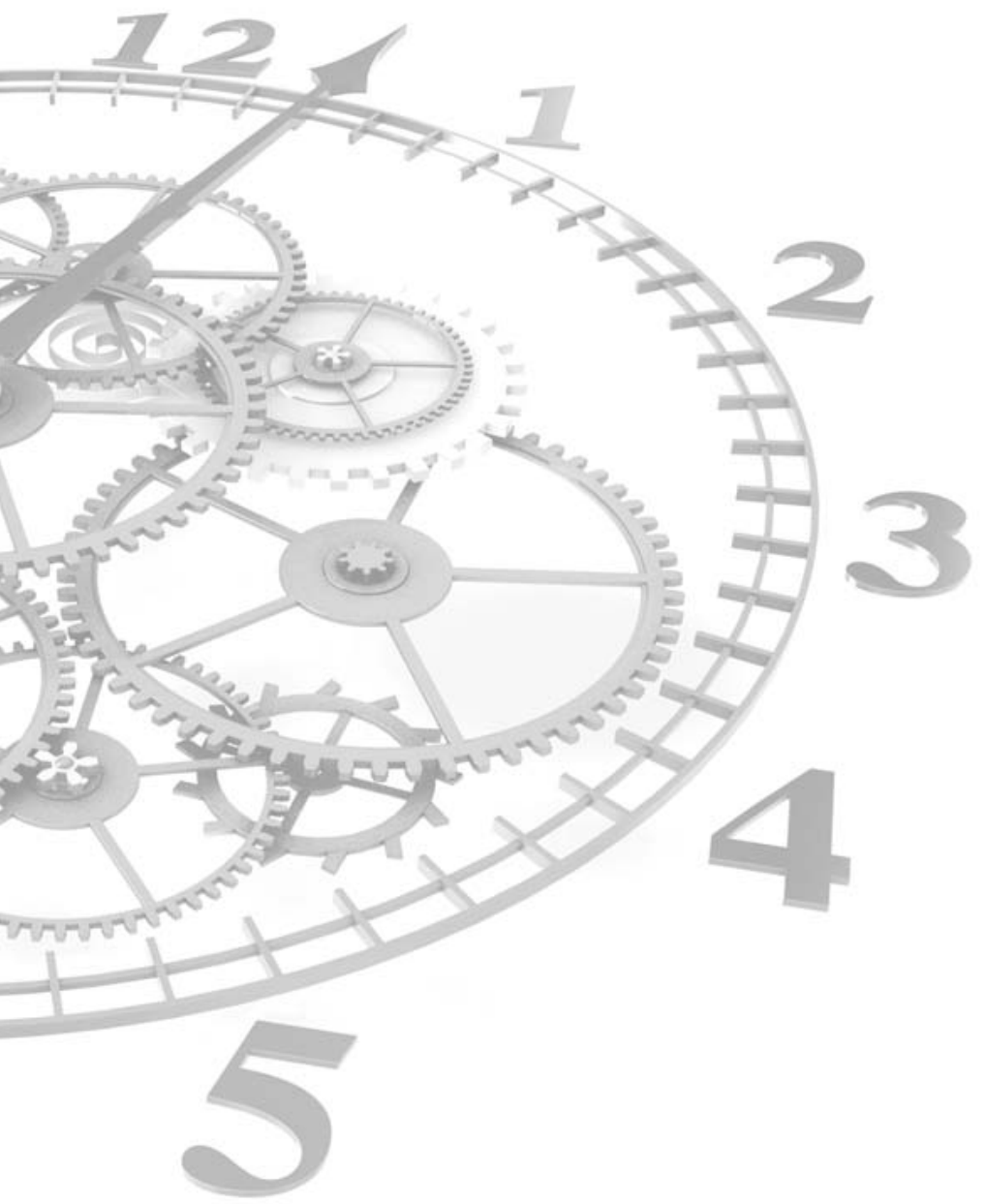

Van Bergen, S., Merckelbach, H., \& Jelicic, M. (2006). Je eigen geheugen wantrouwen: Een riskante zaak? [Memory distrust: Risky business?]. De Psycholoog, 41, 664-669. 
Memory distrust is a phenomenon that is familiar to most of us. Most people now and then start to doubt their own memory, for example, whether or not they have locked the door. Sometimes, memory distrust may cause real trouble. An anecdotal example of this is provided by the Olympic winter games of 2010, when Sven Kramer was heading for the golden medal in the $10 \mathrm{~km}$ distance speed-skating. At some point, just before a lane change, he received an instruction from his coach to go to the inner lane. In that split second, Kramer started to doubt his memory and made the wrong decision: he stayed in the same lane wrongly. If he had trusted his own memory, rather than that of his coach, then he would definitely have won the gold medal. Instead, Kramer was disqualified. This example shows that memory distrust, even amongst professionals, can have serious consequences. In this case, Kramer lost a gold medal. Of course, memory distrust may have even more serious consequences when legal matters are involved. This is demonstrated in case vignettes 1 and 2 .

\section{Case Vignette 1}

On June 7, 1972, 14-year old Judith Roberts was murdered in Staffordshire, England. The next day, Andrew Evans left the Army because of medical reasons. At that time, he was a 17-year old forgetful young man with low self-esteem. Because he had been stationed near the murder scene, Evans was asked by the police to complete a witness form a few weeks later. He testified that he had been inside the barracks during the whole day and that three other soldiers could confirm this. On October 8 , two police officers interrogated him about some inconsistencies in his testimony. From this moment on, Evans started to doubt his memory and developed memory distrust (Gudjonsson, 2003). According to the police, Evans behaved very nervously. The following night, Evans dreamt about a girl. This distressed him and he decided to go to the police station to ask for a photo of the murdered girl to check whether the two images would match. The descriptions he gave did not match those of the murdered girl. During subsequent interrogations, Evans behaved agitated. The girl's face continued to intrude his mind. He became convinced that he must have had something to do with her murder. Though he provided the police with specific information, he got many details wrong. Forty-eight hours after entering the police station, he confessed to the murder. The physicians who had examined Evans stated that his memories about the murder were poor. According to the doctors, this could be explained by psychogenic amnesia. Evans was convicted for murder on April 13, 1973. This conviction was mainly based on his confession. 
Twenty years after his conviction, Evans had become more and more convinced of his innocence. For the Appeal, the psychologist Gisli Gudjonsson and psychiatrist James MacKeith (Gudjonsson, 2003) examined him and concluded that it had been unsafe to rely on Evans' confession. Furthermore, there were good grounds that he did not suffer from psychogenic amnesia. Based on these testimonies, Evans was acquitted on December 3, 1997 after 25 years imprisonment (Gudjonsson, Kopelman, \& MacKeith, 1999).

\section{Case Vignette 2}

On May 6, 1995, 17-year old Brigitte Tengs was found murdered and sexually assaulted on Karmoy Island, Norway. Until January 1997, no substantial progress had been made in the investigation and the police decided to review all the material once again, before closing the case permanently. As a result, Mr $A^{l}$, the cousin of the victim and a highly intelligent man without any mental problems, was interrogated again. Two years earlier, he had been a suspect, because of reported sexually inappropriate behaviour with girls. However, he had denied continuously that he had anything to do with his cousin's murder. He even tracked down a witness who had seen him cycling home on the night of the murder, confirming his alibi. Unfortunately, this witness timed the cycling differently weakening $M r A^{\prime}$ s alibi. About this discrepancy in time, the police interrogated him thoroughly using psychological manipulations in order to break down Mr A's resistance. Together, these interrogations lasted for about 180 hours and seriously undermined his confidence in his memory. Moreover, he was isolated from his girlfriend and family. At last he confessed, despite having no memories of the crime. Nonetheless, he had a strong belief that he had killed his cousin. In detention, a few months later, he told his clinical psychologist that he had felt isolated and pressured to confess while being interrogated by the police. In addition, he became increasingly convinced that he had not killed his cousin. A polygraph test indicated that his denial of the murder was truthful. In spite of all that, he was convicted for rape and murder in November 1997 and sentenced to 14 years imprisonment.

During the appeal in 1998 Gudjonsson testified as a court appointed expert stating that "there was considerable evidence that at the time of making the confession [...], and for several months afterwards, Mr A was suffering from a memory distrust syndrome and had a grossly impaired capacity to

\footnotetext{
${ }^{1}$ The Norwegian Law specifies that the suspect's real name should not be disclosed in the public domain; therefore he is referred to as Mr A.
} 
distinguish facts from fantasy" (Gudjonsson, 2003, pp. 605-606). Gudjonsson was convinced that Mr A had made a coerced-internalised false confession. This time, the jury found Mr A not guilty of the criminal charges and he was released from prison. During the re-investigation of the case, Mr A was exonerated by DNA evidence and received compensation (Gudjonsson \& Sigurdsson, 2010).

Both cases were described in detail by Gisli Gudjonsson (Gudjonsson, 2003; Gudjonsson et al., 1999; Gudjonsson 8 Sigurdsson, 2010). ${ }^{2}$ These are not isolated cases. Similar cases can be found all over the Anglo-Saxon legal literature, especially the literature on so-called innocence projects (Doyle, 2005; Scheck, Neufeld, \& Dwyer, 2001). There are also some Dutch legal cases. A telling example is the Putten murder case in which a stewardess was raped and murdered (Blaauw \& Blaauw, 2009). After repeated and lengthy interrogations that undermined their memory confidence considerably, the two main suspects in this case confessed: 'Then we must have done it'. As a result, they were convicted to ten years imprisonment. In a retrial of the case after a review decision they were acquitted, but by then they already spent almost seven years in prison (Van Koppen, 2009). In 2009, the real perpetrator, Ronald P, was convicted on the basis of a DNA match. These cases illustrate that false confessions may result from false memories or beliefs that start with memory distrust.

Since the 1970s, a vast amount of research has been conducted on the origins of false memories. The American memory expert Elizabeth Loftus can be regarded as the initiator of this type of research. She showed in a series of innovative experiments that it is relatively easy to implant misinformation in people's memories, which they later recall with great confidence (Loftus, 1997). Since Loftus' pioneering studies, more and more research has been conducted in this field focusing on the different types of false memories. Although it is relatively easy to create false recollections, it is still unclear why individuals like Andrew Evans and Mr A falsely confessed. According to Gudjonsson and his colleagues (1999), a combination of Evans' initial uncertainty, repeated interrogations, and the use of 'truth serum', had created a state of cognitive chaos and disorientation. This resulted in total uncertainty about what was a true memory and what he had been told by or what he had inferred from the accounts of others. Memory distrust therefore seems to have paved the road for his confession. The same applies to $\mathrm{Mr} \mathrm{A}$, who

\footnotetext{
${ }^{2}$ Note that the false confession in Case Vignette 1 (Andrew Evans) was based on a false memory, whereas that in Case Vignette 2 ( $\mathrm{Mr} \mathrm{A}$ ) was based on a false belief. For more information about the distinction between false memories and false beliefs, see e.g., Scoboria, Mazzoni, Kirsch, \& Relyea (2004); Smeets, Merckelbach, Horselenberg, \& Jelicic (2005).
} 
was in a confusional state in which his memory confidence was seriously undermined by the interviewing officers, which in turn made him more prone to develop a false belief. Would Andrew Evans and Mr A also have confessed, had they not been psychologically manipulated during the interrogations and had they not had doubts about their original memories?

This dissertation addresses the phenomenon of memory distrust. Memory distrust was introduced in the scientific literature by Gudjonsson and MacKeith (1982). They defined the memory distrust syndrome as "some persons' tendencies to be persuaded that they might have committed a crime because they do not trust their own memory due to previous memory impairment" (p. 265). About 20 years later, Gudjonsson (2003) gave the syndrome a broader connotation, namely "a condition where people develop a profound distrust of their memory recollections, as a result of which they are particularly susceptible to relying on external cues and suggestions" (p. 196). This latter definition will be used in this dissertation for memory distrust.

In the literature, two types of circumstances are described in which the memory distrust syndrome may occur (Gudjonsson, 2003). In the first, suspects have no clear memory of what they were doing at the time of the alleged offence. ${ }^{3}$ This may be due to head injury or substance abuse (e.g., excessive alcohol use). As a result, suspects start to fill in their memory gap and come to believe that they must have committed the crime. In the second type of circumstances, suspects are completely convinced of their innocence at the beginning of the interrogation and later start to distrust their own memory due to psychological manipulations exerted by the interrogator.

Memory distrust may manifest itself in two different ways. Therefore, in this dissertation a distinction is made between trait memory distrust and state memory distrust. The first type refers to a habitual distrust in one's own memory. This type closely resembles a personality trait and is therefore more permanent by nature. The second type of memory distrust refers to a temporary state in which a person starts to distrust his/her memory due to external conditions. This happens, for example, in the two memory distrust evoking conditions that were described above.

\section{Attribution}

Not everybody distrusts their memory. Following their optimistic bias, many people (about 30\%) actually believe that they have better memory capabilities than others (Crombag, Merckelbach, $\delta$ Elffers, 2000). However, in pa-

\footnotetext{
${ }^{3}$ This may be true for both guilty and innocent suspects.
} 
tients visiting memory clinics such bias is usually absent. Much research has been conducted on memory performance of the elderly and their memory judgments (Ponds \& Jolles, 1996; Ponds, Van Boxtel, \& Jolles, 2000). Authors in this field point out that memory complaints of the elderly that emerged during stressful circumstances may last for a considerable period of time and are intensified by concern about dementia, excessive attention to memory failures, and negative expectations about one's own memory. Most authors use the term subjective forgetfulness to refer to these complaints, which comes close to the concept of memory distrust.

Two factors seem to play a role when considering memory distrust in the clinic: age and education (Commissaris, Ponds, \& Jolles, 1998). Both elderly people and lower educated individuals appear to blame their supposed memory complaints on internal causes, such as advanced age, health problems, and a chronic poor memory. In these cases, there is a strong connection between memory distrust and an internal attribution style, which resembles - what we would term - trait memory distrust. Young adults and higher educated persons, on the other hand, attribute their forgetfulness to external factors, such as stress, emotional problems, and lack of mental effort. These variables are more transient and therefore we refer to this type of memory distrust as state memory distrust.

In general, people are afraid of forgetting information. This fear grows exponentially with age; older persons are often worried about their deteriorating memory and about developing dementia. There is ground for these fears and worries, because the elderly have more difficulty with remembering than young individuals (Commissaris et al., 1998). However, in older individuals no direct relationship has been found between subjective memory complaints and objective memory performance (Ponds et al., 2000). This corresponds well with studies in the field of legal psychology that examined the relationship between confidence and accuracy of witnesses confronted with line-ups. Here, again, the correlation between subjective beliefs and objective performance is absent or modest at best (Brewer, 2006; Tomes $\&$ Katz, 2000). Thus, very confident eyewitnesses may be wrong. But the contrary is also true (Odinot \& Wolters, 2006), namely that eyewitnesses who have doubts about their memory can make correct identifications.

\section{Obsessive-Compulsive Disorder}

Memory distrust as a trait is also a well-studied phenomenon in the clinical literature. Specifically, it is one of the main features of Obsessive-Compulsive Disorder (OCD). This disorder is characterised by chronic doubts about one's own memory functioning (Tolin et al., 2001). These doubts are the driving 
forces behind compulsions. More specifically, the more often a patient checks an action (e.g., locking the door), the more familiar he/she becomes with this action. However, memories for such routine actions are less lively and detailed than other memories and they are therefore, relatively difficult to remember. This is a perfect breeding ground for memory distrust, which increases the need for checking. In short, repetitive checking causes memory distrust, which in turn causes even more checking (Van den Hout 8 Kindt, 2003a, 2003b). As with the elderly, this type of memory distrust does not necessarily co-occur with objective memory problems. For example, research has shown that OCD patients are rather good in reality monitoring tasks (McNally \& Kohlbeck, 1993; Merckelbach \& Wessel, 2000). In other words, they can accurately distinguish between memories of actions they have actually performed and memories of actions they have only imagined. Moreover, several studies show that OCD patients have intact memory in other respects as well (Radomsky $\&$ Rachman, 2004; Tolin et al., 2001; Van den Hout $\delta$ Kindt, 2004). For instance, OCD patients are better in remembering anxiety related information compared to patients who suffer from other anxiety disorders and healthy individuals. Nonetheless, they have more pessimistic views about their own memory than the other two groups.

\section{Metamemory}

This brings us to metamemory, which can be defined as beliefs that individuals have about the functioning and quality of their memory (Van Oorsouw, 2004). Memory distrust is evidently a component of metamemory, but the relation between metamemory and actual memory deficits is a rather complex one. When persons develop a strong metamemory for a particular event (which manifests itself in greater confidence, clarity, and more details), it is fairly simple to explore whether they have accurate memories for that specific event. Everyday psychology seems to dictate that people perfectly know whether or not they remember an event. However, if a person suffers from poor metamemory (low confidence, vagueness, or few details), he or she may have a difficult time to decide whether his or her memory is accurate. Doubt and insecurity can result in a self-fulfilling prophecy, wherein a person will make less effort to recall a memory. For example, OCD patients might be able to remember an action, but do not know that they do, and therefore do not try to remember the memory anyway (Radomsky \& Rachman, 2004). 


\section{Source Monitoring Errors}

Following the most recent definition, individuals who distrust their own memory are more likely to depend on suggestions or cues by others (Gudjonsson, 2003). This may lead to source monitoring errors, which occur when memories are attributed to the wrong source (e.g., a fantasy is taken as a genuine memory). Three different types of source monitoring exist (Johnson, Hashtroudi, \& Lindsay, 1993): Reality monitoring refers to distinguishing internally generated from externally derived information (Johnson \& Raye, 1981); external source monitoring pertains to discriminating between statements from two external sources; and internal source monitoring refers to internal discriminations, for example distinguishing between things said and thought.

Source monitoring errors can be elicited by many factors, for example, time pressure, high levels of stress, depression, distraction, alcohol and drug use, or brain damage (Johnson et al., 1993). Individuals who distrust their memory may also suffer from source monitoring errors. Examples are OCD patients who cannot remember whether they only thought about turning off the gas stove or actually performed this action, or suspects who have trouble distinguishing between information they heard from the police and their own memories of a crime. Reality monitoring problems were also evident in the cases of Andrew Evans and $\mathrm{Mr} \mathrm{A}$, who had great difficulty in distinguishing facts from fantasy (Gudjonsson, 2003).

Although it is thought that mostly persons who are insecure about their memories are more susceptible to suggestions by others, Hekkanen and McEvoy (2002) provide an alternative perspective on this issue. They claim that individuals who have an optimistic attitude about their own memory use less stringent criteria and are, as a result, more susceptible to pseudomemories. This would entail that individuals who distrust their memories are more critical towards new information and therefore set higher demands before they accept it as accurate information. As a result, memory distrust may immunise against the acceptance of suggestive information given by others. Apparently, the relation between memory distrust and susceptibility to suggestions (and source monitoring errors) is not clear-cut (see e.g., Liebman et al., 2002; Winograd, Peluso, \& Glover, 1998).

\section{Forensic Practice}

Manoeuvring suspects or eyewitnesses in a certain situation can undermine their metamemory and can increase the chance of making source monitoring errors. When this happens during suspect interrogations involving dubi- 
ous interrogation techniques, this may lead to false confessions (Van Bergen, 2009b). False confessions can be defined as "an admission ('I did it') plus a post-admission narrative (a detailed description of how and why the crime occurred) of a crime that the confessor did not commit" (Leo, 2009, p. 333). Though false confessions seem counter-intuitive to most individuals, they are not uncommon. In 15 to 25 percent of the DNA exoneration cases, false confessions were the main cause of the wrongful conviction (Kassin et al., 2010; Leo, 2009; Saks \& Koehler, 2005; The Innocence Project, 2010). Note that there are probably more miscarriages of justice caused by false confessions than these exoneration cases. However, it is unknown how large these numbers are.

Kassin (2008; see also Kassin \& Wrightsman, 1985) proposed a taxonomy of three types of false confessions: voluntary, coerced-compliant, and coerced-internalised false confessions. Most voluntary false confessions are given to protect somebody else, to attract media attention, to expiate feelings of guilt, or due to confusing facts with fantasy (a common feature of major psychiatric illness). In any case, they are made without any pressure from the police. Conversely, coerced-compliant and coerced-internalised false confessions are made by individuals due to police pressure. Coercedcompliant false confessions are given for instrumental gain; they are made for tactical reasons that have to do with suspects wanting to escape from a stressful and unbearable situation in the short term, and assuming that innocence will be proven in the long term. Coerced-internalised false confessions are given when suspects come to believe that they have committed the crime they are accused of.

Although the typology of Kassin and Wrightsman (1985) has proven to be useful in forensic practice and research, critiques and suggestions for refinements have also been given (Gudjonsson, 2003; McCann, 1998; Ofshe $\delta$ Leo, 1997). One of these, the proposed modified framework by Gudjonsson (2003), needs to be mentioned briefly (see also Table 1.1). Germane to this refinement is that the word coerced is changed into pressured when there is clear evidence of coercion. In all other cases, this term should be omitted. Furthermore, this framework also classifies the source of the pressure experienced by the individual, namely a distinction between custodial, noncustodial, and internal pressure. Altogether this contributes to a bivariate classification system, which is summarised in Table 1.1. 
Table 1.1

Proposed Framework for Classifying False Confessions (Gudjonsson, 2003)

\begin{tabular}{l|l}
\hline Type of false confession & Source of pressure \\
\hline $\begin{array}{l}\text { 1. Voluntary } \\
\text { 2. Pressured-compliant }\end{array}$ & Internal \\
\hline 3. Pressured-internalised & Custodial / Non-custodial \\
\hline
\end{tabular}

What characteristics contribute to false confessions? Until now, research investigating the predictive value of traditional personality characteristics (e.g., neuroticism) has yielded equivocal results (Horselenberg, Merckelbach, \& Josephs, 2003; Israëls \& Horselenberg, 2010). However, studies have shown that individuals who are highly suggestible and compliant (e.g., juveniles, mentally ill or developmentally disabled persons) might be more prone to falsely confess (Kassin \& Gudjonsson, 2004). Nonetheless, it should be noted that most of the police-induced confessions are made by mentally normal persons (Leo, 2009). In one study, this figure was even higher than $70 \%$ (Drizin \& Leo, 2004). Thus, not only personality factors render us vulnerable to falsely confess, but also situational factors. One of the main situational factors is a lengthy and psychologically coercive interrogation (Kassin, 2005; Leo, 2009). The aim of such an interrogation is to undermine the suspect's confidence causing him/her to doubt his/her memory which facilitates confession. Research on memory distrust may put a different light on this issue and might turn out to be a relevant antecedent of false confessions (Gudjonsson, 2003; Gudjonsson \& MacKeith, 1982). The close relationship between memory distrust and false confessions has already been suggested by forensic cases such as the two case vignettes described above (Gudjonsson, 2003; Gudjonsson et al., 1999; Gudjonsson \& Sigurdsson, 2010). The figure below (Gudjonsson $\&$ Sigurdsson, 2010, p. 101) gives a schematic summary of variables that played a role in case vignette 2 . It clearly illustrates the prominent role of memory distrust.

\section{Memory Distrust in the Lab}

Besides case studies, there is also some evidence from experimental research showing a relationship between memory distrust and false confessions (Duijf, 2005; Gudjonsson, Young, \& Bramham, 2007). A case in point is a study in which guilty students $(n=40)$ were instructed to steal money from a wallet (and keep it), while innocent students $(n=40)$ were instructed to 


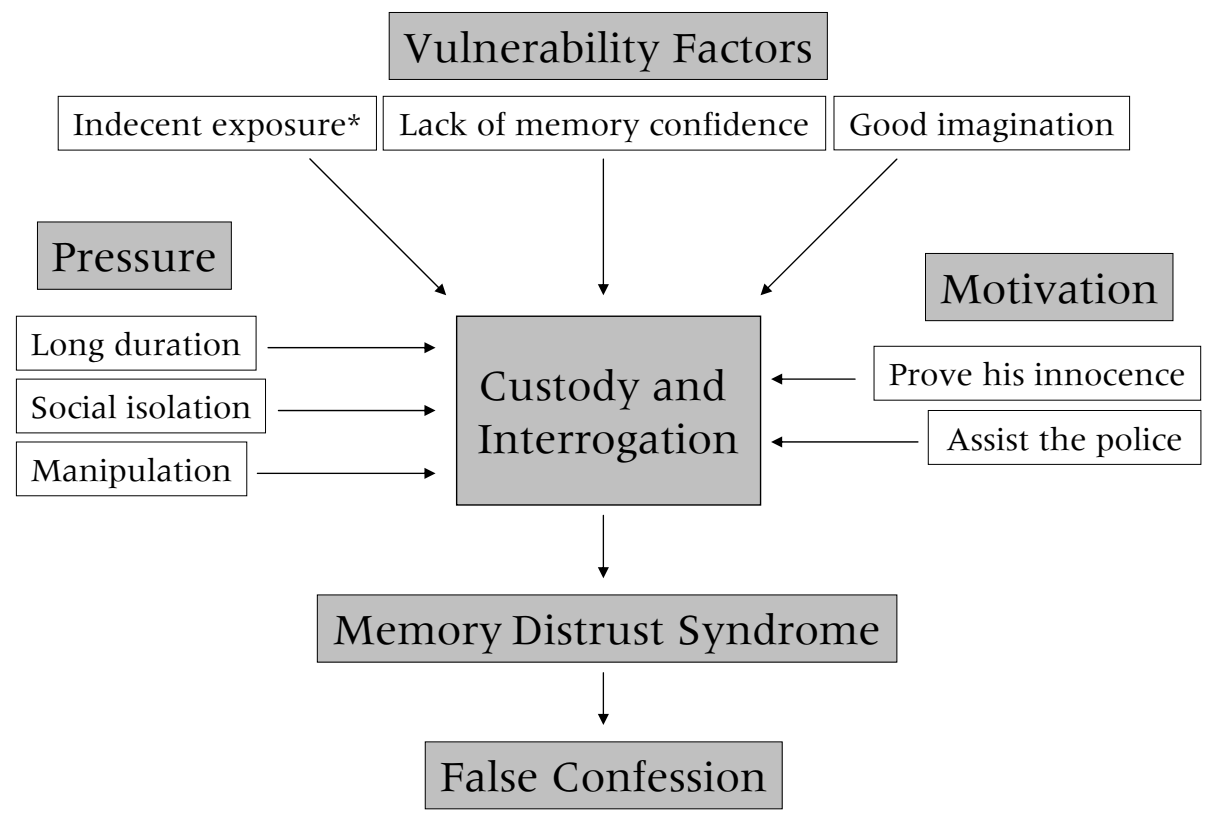

Figure 1.1. Graphic representation of the false confession of Mr A. This figure is adopted from Gudjonsson and Sigurdsson (2010, p. 101).

* Mr A's sexually inappropriate behaviour that was reported in the past.

collect the money and give it back to the experimenter (Duijf, 2005). Both groups were interrogated in ways that may induce memory distrust, such as providing false evidence ('There was a camera in the room, so if you stole the wallet, we will find out soon'), maximising the crime ('The person whose wallet you stole is very poor and is now in deep trouble since the money in the wallet you stole was about the last he had'), suggesting memory problems ('I think that you have a poor memory but are not aware of that. Therefore you are not responsible for what you have done'), incriminating evidence ('Your fingerprints have been found on the stolen wallet'), and showing absolute certainty ('You have stolen a large amount of money from someone else's wallet; I know that for sure. There is no doubt about this and by denying it, you are only showing us that you are a liar'). After each intervention, students had to indicate on a 10-point Likert scale their tendency to confess to the crime (anchors: $1=$ 'totally not willing to confess'; $10=$ 'totally willing to confess'). The effect of the interventions on the willingness to confess differed per group. The results show why such interventions are popular among police officers: they increase the readiness of guilty students to confess (see Figure 1.2). This study, however, also shows that 
innocents start to doubt their innocence. This finding underscores the danger of these interventions: they may lead to false confessions.

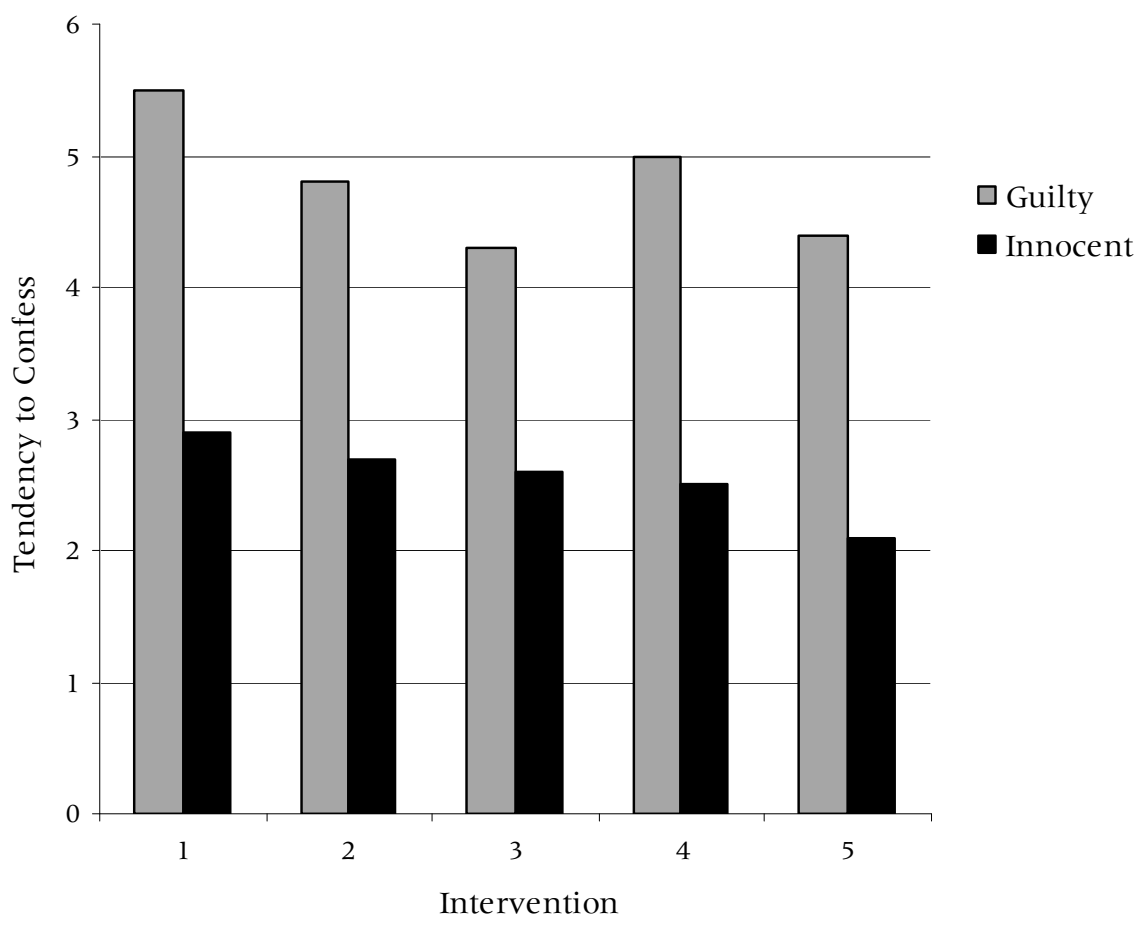

Figure 1.2. Tendency to confess (scale $0-10)$ for the guilty and innocent student group separately per intervention (i.e., $1=$ false evidence, $2=$ maximising, 3 = suggesting memory problems, $4=$ incriminating evidence, $5=$ absolute certainty).

Some false confessions can be seen as special types of pseudo-memories (Horselenberg et al., 2003). This is the case with coerced-internalised false confessions (i.e., false confessions in which persons believe that they have committed the crime). The scenario, on which this type of false confessions is based, typically consists of a suspect who has doubts about his/her memory making him/her more susceptible to suggestions offered by others (e.g., police officers). Thus, it appears that memory distrust is closely related to the phenomenon of suggestibility. The standard instrument to measure suggestibility is the Gudjonsson Suggestibility Scale (GSS; Gudjonsson, 1997; see for the Dutch version: Merckelbach, Muris, Wessel, \& Van Koppen, 1998; Smeets, 2008). This is a structured procedure in which a short story is read out loud to participants. Subsequently, 20 questions are asked, of which 15 
are misleading questions. Then, participants receive negative feedback ('You did not do very well') and are asked to answer the questions again. One of the GSS parameters - the Shift score - indicates the extent to which individuals change their answers as a result of negative feedback. According to Gudjonsson (2003), this parameter can be conceptualised as an estimate of the degree of memory distrust.

The crucial factor in memory distrust is that giving false feedback makes people feel insecure. Evidence for this comes from research that showed a strong relationship between the extent to which persons were negative about their memory (indexed by the Cognitive Failures Questionnaire; CFQ; Broadbent, Cooper, Fitzgerald, \& Parkes, 1982) and their susceptibility to misleading information as indexed by the GSS (Merckelbach et al., 1998). The type of memory distrust that is tapped by the GSS has both a state and trait component. The former is induced by the negative feedback, whereas the latter refers to memory distrust that might have already been present in an individual regardless of the feedback. In the forensic setting, the combination of trait and state memory distrust is also typically found. An example is that of a key witness who awoke from a coma, was subsequently interrogated in a suggestive way by the police, and finally gave a supposedly false incriminatory testimony about the suspect (Merckelbach $\&$ Jelicic, 2005). In this case, the trait component relates to the cognitive restraints of the witness that made it impossible to reconstruct the facts of the crime. And exactly in this situation, suggestive manoeuvres - producing the state component of memory distrust - may result in pseudo-memories. See for a similar case, the analysis of the Schiphol fire (Wagenaar, 2010).

Besides providing false feedback such as in the GSS, other manipulations can also elicit memory distrust. Winkielman and colleagues (1998) developed a method to manipulate the confidence people have about their memory capabilities. In their original study, participants had to recall either 4 or 12 childhood memories. Subsequently, they were asked whether they had forgotten large parts of their childhood. One would expect that participants who were able to recall many childhood memories would answer this negatively, because the task should have made them feel more confident about their autobiographical memory. However, the opposite was true; participants gave a more negative memory judgment after completing a difficult task (i.e., retrieving 12 memories) than after an easy task (i.e., retrieving 4 memories). This finding has been replicated in several studies (Merckelbach, Wiers, Horselenberg, \& Wessel, 2001; Van Oorsouw, 2006).

This is a paradoxical phenomenon because participants, who had to complete the difficult task, most of the times recalled more than 4 memories and therefore performed better than participants who were given an easy task. This finding suggests that individuals base their memory confidence on 
the degree of effort (i.e., more effort, less confidence) and not on the superior performance that results from a lot of effort (i.e., more effort, more confidence). This can be explained by the availability heuristic (Tversky \& Kahneman, 1973): participants blame the difficulty of the task on the poor state of their memory. This phenomenon has practical implications. Imagine, for instance, a therapy session in which a patient has to recall many childhood memories, followed by questions like 'what was your childhood like?', 'how did your parents react?', leading to a negative judgment about the patient's autobiographical memory, and in some cases, a feeling of having amnesia for the past.

When going through a procedure like that described by Winkielman and colleagues (1998), individuals can easily be made insecure about their childhood memories. This could elicit state memory distrust. It should be noted, though, that this type of distrust focuses on a specific memory aspect, namely childhood memories. But does this make individuals also more susceptible to suggestive manipulations, such as imagination inflation? Based on previous research (for an overview see Garry \& Polaschek, 2000), one would expect a strong relationship between memory distrust and susceptibility to develop false memories, but more recent research has shown that this link is not that straightforward. In two lab studies (Franssens \& Peters, 2004; Van Bergen $\&$ Jelicic, 2007), the Winkielman procedure, or an equivalent procedure, was followed by an imagination inflation session (Garry, Manning, Loftus, \& Sherman, 1996). During this session, students were instructed to imagine about implausible childhood events. Before and after the session, they were asked to indicate how confident they were that those and other events had taken place before their $10^{\text {th }}$ birthday. The prediction was that the students, who were instructed to recall more events or who obtained negative feedback (that would make them less confident), would rate unlikely events they had imagined as more plausible than students who had recalled fewer events. This was, however, not found. An explanation for the absence of such effect might be that state memory distrust as induced by the Winkielman procedure in intelligent, healthy participants is not strong enough to make them more susceptible to suggestive manipulations. Further research is needed to test this proposition.

\section{Concluding Remarks}

Memory distrust seems to manifest itself both within clinical and forensic settings. To accumulate solid knowledge about the issue of memory distrust, proper scales and questionnaires should be developed. When studying state memory distrust, existent methods such as the Winkielman procedure have 
not turned out to be successful. This can be explained to a great extent by the weakness of the manipulation. Providing negative feedback may be a better way to elicit state memory distrust. According to Gudjonsson (2003), the Shift score of the GSS - which indicates the extent to which persons are influenced by negative feedback - is a good parameter of state memory distrust. Furthermore, questionnaires may help inform researchers about trait memory distrust. The CFQ gives, for instance, an indication of subjective memory deficits during daily routines. It seems logical to assume that individuals who distrust their memory also report more cognitive failures on this questionnaire. The CFQ, however, also taps other aspects of subjective cognitive functioning, such as perception and attention. The Squire Subjective Memory Questionnaire (SSMQ; Squire, Wetzel, \& Slater, 1979) might be a better instrument to measure memory distrust because it focuses on the global judgments people have about their own memory. It is anticipated that individuals who distrust their memory generally have a low score on this questionnaire. Both the CFQ and SSMQ measure trait-like characteristics, which make it possible to map potential relationships between memory distrust and other individual differences.

The literature on memory distrust is very scattered and the concept is not well-developed and under-researched. However, when proper scales and questionnaires are developed and tested, they can be used to examine whether individuals actually suffer from memory distrust. Next, and more interestingly, the consequences of memory distrust can be experimentally studied and interventions can be tested that possibly diminish the probability of false confessions.

\section{Outline of this Thesis}

The central aim of this thesis is to systemically explore memory distrust in the legal domain. Its focus is on the issue whether memory distrust is an antecedent of pseudo-memories and false confessions. To explore this issue the following specific questions will be examined first: What is memory distrust? What are related concepts of memory distrust? How can memory distrust be measured best? Are individuals suffering from trait memory distrust susceptible to developing false memories, or false confessions? These questions will all be addressed in the chapters that follow. Apart from a General Introduction (Chapter 1) and a General Discussion (Chapter 7), this thesis is divided into two parts.

Part 1 focuses on trait memory distrust and consists of three chapters. Chapter 2 describes a validation study of a questionnaire that measures trait memory distrust, the SSMQ (Squire et al., 1979). In this chapter, the psy- 
chometric properties of the Dutch version of the SSMQ will be explored and discussed. Chapter 3 aims to explore the underlying concepts of memory distrust. More specifically, it examines memory distrust, as indexed by the SSMQ, and how it relates to concepts such as suggestibility, compliance, false memories, and objective memory performance. Chapter 4 continues to focus on the relationship between memory distrust, suggestibility, and false memories by using a more ecologically valid design, the misinformation paradigm. This chapter examines whether persons suffering from memory distrust accept misinformation more easily than individuals who are confident in their memory.

Part 2 focuses on state memory distrust that might be experienced in the interrogation room and consists of two chapters. Chapter 5 examines whether the tendency to distrust memory is related to the tendency to falsely confess, by using different interrogation techniques. Chapter 6 elaborates on the preceding chapter by examining the causal relationship between memory distrust and false confessions. In the study that is described in this chapter, memory distrust was elicited by providing negative feedback.

The thesis concludes with a General Discussion (Chapter 7) that gives an overview of the results presented in the preceding chapters. It also addresses how these findings can be useful for clinical and forensic practice and suggests some directions for future research. 

CHAPTER 2

\section{ASSESSING TRAIT MEMORY DISTRUST}

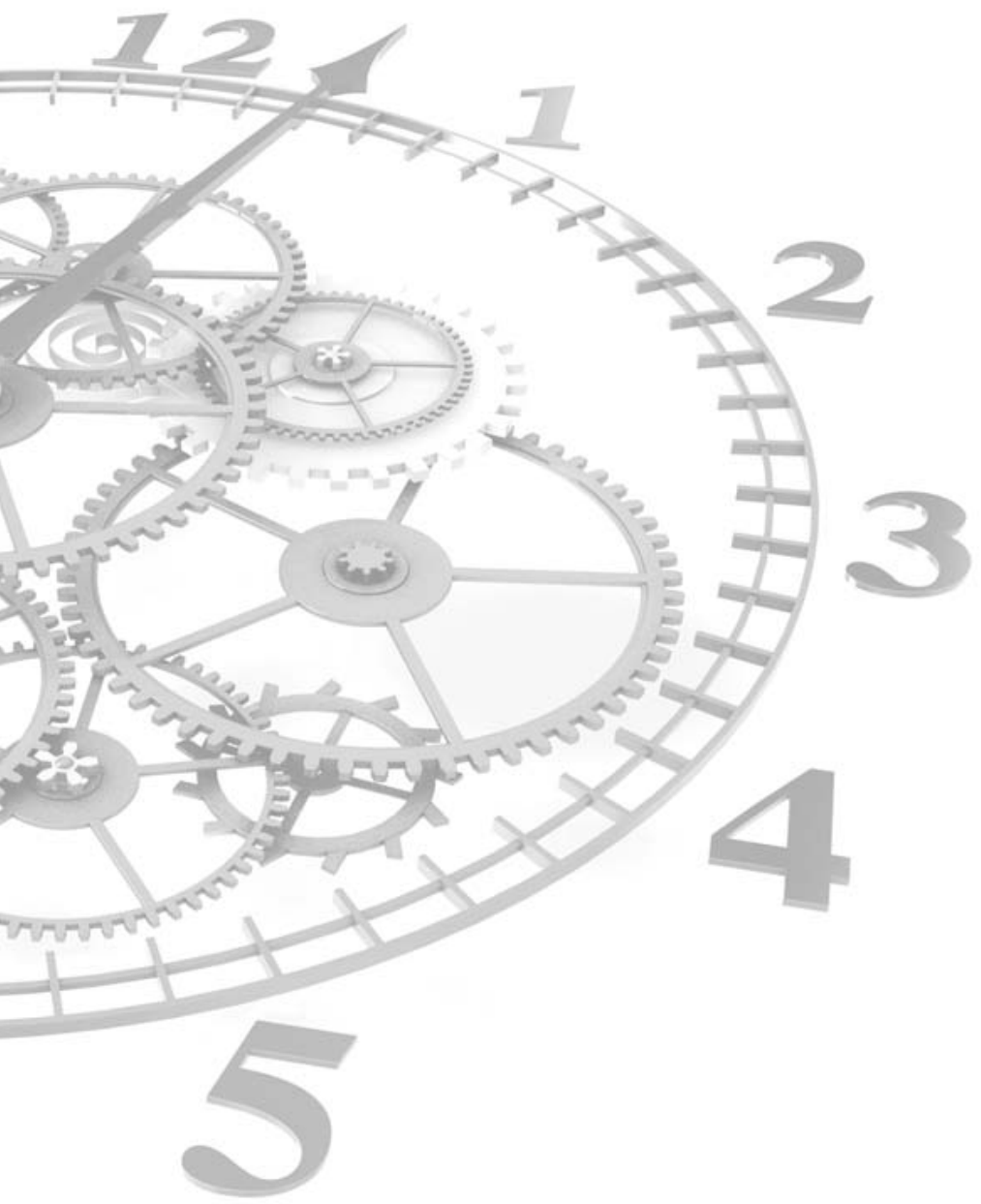

Van Bergen, S., Brands, I., Jelicic, M., \& Merckelbach, H. (2010). Assessing trait memory distrust: Psychometric properties of the Squire Subjective Memory Questionnaire. Legal and Criminological Psychology, 15, 373-384. 


\begin{abstract}
When people suffer from memory distrust, they evaluate their memory in negative terms. Memory distrust plays an important role in police interrogations because it may underlie false confessions. The Squire Subjective Memory Questionnaire (SSMQ; Squire, Wetzel, \& Slater, 1979) intends to be a simple measure of subjective memory functioning. To our knowledge, no data have been published about the psychometric properties of the SSMQ. Relying on five samples ( $n s=70-819$ ) of healthy individuals and patients, we studied the psychometric characteristics of the SSMQ. Principal component analysis showed that the SSMQ has a one-dimensional structure referring to subjective memory evaluation. The SSMQ was found to have adequate reliability and good construct validity. Furthermore, it appears to correlate in a theoretically meaningful way with age and cognitive failures. All together, the SSMQ is a psychometrically sound screening tool that can be helpful in assessing subjective memory evaluations in the legal domain. In this way, vulnerable suspects can be identified in an early stage.
\end{abstract}

\title{
Introduction
}

Distrusting one's own memory may have far-reaching consequences. A case in point is when defendants begin to question their own memory capabilities (i.e., distrust their memory) during lengthy police interrogations. As a result, they may become more susceptible to misleading information suggested by police officers (Gudjonsson, 2003). This, in turn, may lead to false confessions (Gudjonsson et al., 1999). The type of memory distrust that is evoked by social pressure and that can be found in some forensic case vignettes is a state phenomenon. However, memory distrust can also manifest itself in another form, namely that of a personality trait (Van Bergen, Jelicic, \& Merckelbach, 2009). This type of memory distrust, which we refer to as trait memory distrust, may be present in defendants before they enter the interrogation room. A combination of trait memory distrust and interrogative pressure may increase the psychological vulnerability of the defendant tremendously. Whereas state memory distrust is impossible to evaluate before the interrogation takes place, this is not the case for trait memory distrust. The latter can, in principle, be quantified with self-report scales designed to measure beliefs about one's own memory capabilities, with negative memory evaluations corresponding to high levels of memory distrust.

There are many tests that can be used to assess a person's objective memory performance, but the number of instruments designed to measure subjective memory evaluations is limited. Some clinicians use the Cognitive 
Failures Questionnaire (CFQ; Broadbent et al., 1982) for this purpose. This questionnaire is a simple, but relatively broad measure of metacognition, because it not only includes subjective memory items, but also items that pertain to perceptual and attentional errors. Other questionnaires that may be relevant focus on multiple aspects of metamemory. Examples are the Metamemory in Adulthood Questionnaire (MIA; Dixon \& Hultsch, 1983) and the Prospective and Retrospective Memory Questionnaire (PRMQ; Smith, Della Sala, Logie, \& Maylor, 2000). One limitation of the MIA is that it consists of a large number of items (i.e., 108 items), making it less suitable for forensic settings in which there is often not much time to evaluate a defendant's vulnerability. Furthermore, this questionnaire consists of several subscales, some of which bear little relevance to subjective memory beliefs of defendants. The PRMQ, on the other hand, is short. Half of this scale, however, addresses prospective memory, i.e., events that may happen in the future (Crawford, Smith, Maylor, Della Sala, \& Logie, 2003). As beliefs about prospective memory are not helpful for establishing defendants' vulnerability in interrogation settings, this scale seems to be a less promising tool for evaluating memory distrust in the legal arena.

A self-report instrument that measures subjective memory complaints and does not suffer from the limitations mentioned above, is the Squire Subjective Memory Questionnaire (SSMQ; Squire et al., 1979). Originally, this 18-item questionnaire was developed to differentiate memory complaints related to depression before electroconvulsive therapy (ECT) from memory complaints associated with amnesia after ECT. Yet, Squire and co-workers suggested that this questionnaire might also be useful in other settings, in which subjective memory functioning is relevant. Because the psychometric properties of the original SSMQ have not been examined before, the present study sought to evaluate them in healthy adults and patients.

To test the dimensionality of the questionnaire, principal component analysis was conducted. Furthermore, we investigated the reliability of the SSMQ by studying its test-retest stability and internal consistency. We also examined its construct validity by comparing the SSMQ scores of healthy people to those of clinical patients with cognitive complaints. Finally, we explored the links (i.e., convergent validity) between the SSMQ and scales that measure concepts related to trait memory distrust in the legal context. To begin with, we explored to what extent the SSMQ is related to the CFQ (Broadbent et al., 1982). As the CFQ taps subjective reports of one's own cognitive functioning, we hypothesised that both measures would overlap to a considerable extent. The CFQ was chosen as a measure of concurrent validity because it is a brief scale of which the Dutch psychometric properties have been well researched (Merckelbach \& Muris, 2008; Merckelbach, Muris, Nijman, \& De Jong, 1996). Like the SSMQ, it focuses on retrospective 
functioning. As well, it is widely used in the Netherlands, both in clinical and research domains. Second, we examined how trait memory distrust is related to compliance as indexed by the Gudjonsson Compliance Scale (GCS; Gudjonsson, 1989). Based on case reports by Gudjonsson (2003) indicating that people suffering from memory distrust rely more on external cues and suggestions, we expected that these people would also be more compliant than others. Third, we studied the association between subjective memory complaints and depressive symptoms as measured with Beck's Depression Inventory (BDI-II; Beck \& Steer, 1996). Given that depressive symptoms are often accompanied by pessimistic beliefs, we hypothesised that the SSMQ and the BDI-II would be related. Fourth, we examined the relationship between memory distrust and objective memory functioning as indexed by the Auditory Verbal Learning Test (AVLT; Rey, 1964). Note that studies about the relationship between subjective memory complaints and objective memory performance have come up with mixed findings. Some studies (e.g., Brewin \& Stokou, 2002) found that these two variables are related, such that there is a fundamental integrity to subjective memory beliefs. Other studies, however, reported that particularly in older adults, subjective memory complaints may be completely unrelated to intact memory performance (e.g., Ponds et al., 2000).

\section{Methods}

\section{Participants}

The SSMQ and several other measures were administered to the following Dutch samples. Note that all samples were independent.

Sample 1 consisted of 819 undergraduate students of Maastricht University (594 women; $M=19.6 ; S D=2.2$; range $=16-39$ ). These students completed the SSMQ during a mass screening session at the beginning of the first year of their psychology study.

Sample 2 was a community sample of 70 adults (51 women; $M=32.5$; $S D=8.6$; range $=17-54)$. These participants were recruited through advertisements in local newspapers. In these advertisements, we invited people to come to our lab when they believed their memory to be either poor or excellent. This resulted in a 'poor memory group' consisting of 33 participants (25 women; $M=33.2 ; S D=9.5$; range $=17-44$ ) and an 'excellent memory group' comprising 37 participants (26 women; $M=31.8$; $S D=7.8$; range = 19-45). The two groups did not differ significantly in age $[t(68)<1$, ns] or gender $\left[\chi^{2}(1)=.27, \mathrm{~ns}\right]$. 
Sample 3 comprised a community sample of 128 adults (95 women; $M=$ 33.6; $S D=8.4$; range $=16-45)$. The participants of this sample completed a web-based format of the SSMQ via the Internet. A selection of this web sample $(n=70)$ was invited to participate in a follow-up study in which several other tests were administered.

Sample 4 was a community sample of 79 adults (53 women; $M=33.6$; $S D=9.5$; range $=18-49$ ). As was the case for sample 2, this sample was recruited through advertisements in various newspapers. However, the advertisements for sample 4 contained a slightly different formulation than those for sample 2; this time we invited people who distrusted their memory and people who were very confident in their memory capabilities to participate in our study. ${ }^{4}$ This resulted in two groups: a 'memory distrust group' ( $n$ $=40 ; 27$ women; $M=38.6 ; S D=7.9$; range $=19-49$ ) and a 'memory confidence group' ( $n=39 ; 26$ women; $M=28.5 ; S D=8.4$; range $=18-46)$. The memory distrust group was older than the memory confidence group $[t(77)$ $=5.48, p<.05]$, but the two groups did not differ in their gender distribution $\left[\chi^{2}(1)=.01, \mathrm{~ns}\right]$.

Sample 5 consisted of 75 outpatients from the Neuropsychology Unit of Zuwe Hofpoort Hospital/Regional Psychiatric Centre Woerden (41 women; $M=56.6 ; S D=15.5$; range $=14-82)$. The majority of these patients was referred by neurologists because of memory-related complaints (e.g., amnesia, forgetfulness), mild cognitive impairments, cerebrovascular accidents, or dementia and most of them also reported mood and/or anxiety symptoms.

\section{Instruments}

\section{SSMQ}

The SSMQ intends to measure subjective memory functioning. The original version consists of 18 items that are rated on a 9-point Likert scale, with answer options ranging from 'worse than ever before' $(-4)$ to 'better than ever before' (+4). The large majority of these items refer to retrospective memory and the current situation. Examples of items are shown in Table 2.1. A total score can be obtained by summing SSMQ scores across items. Accordingly, the SSMQ total score ranges from -72 to +72 , with negative scores indicating memory distrust.

The original SSMQ was linked to the context of ECT and depressive disorder. It was designed such that it can be administered during two or three test sessions, more specifically, before and after ECT. However, in many

\footnotetext{
${ }^{4}$ This sample was not collapsed with sample 2, as the wording used in the advertisements may have attracted different research participants.
} 
other domains, there is no need for repeated testing. For example, forensic psychologists often only need a rough indication of defendant's trait memory distrust levels before the police start their interrogation. For that reason, a single test session will often be sufficient. Therefore, with some slight reformulations of the original SSMQ items, we tried to transform the SSMQ into a more general measure of subjective memory functioning. Thus, we changed the answer options of the 9-point Likert scale into 'disastrous' (-4) and 'perfect' (+4). Also, pilot work with the Dutch version of the original SSMQ showed that participants found the negation embedded in the original item 6 confusing. Consequently, we decided to reformulate this item in the positive, which also solved the issue of recoding. Table 2.1 gives our adjusted version of the SSMQ. A back-translation check made sure that our Dutch translation was a perfect equivalent of this version.

\section{Other tests}

To explore construct and concurrent validity, we administered a series of other self-report scales and tasks to our samples. All these measures tap concepts that are related to trait memory distrust in the legal context (e.g., cognitive failures, compliance). Although some traits seem more clinical by nature (e.g., depressive disorder), they often play a role in the legal domain as well, for example in cases of vulnerable suspects (Gudjonsson, 2003).

All samples were administered the Cognitive Failures Questionnaire (CFQ; Broadbent et al., 1982; Merckelbach et al., 1996). The CFQ comprises 25 items that pertain to the frequency of everyday failures in memory, attention, and action. Sample items are 'Do you forget appointments?' and 'Do you fail to notice signposts on the road?'. Participants have to indicate how often they have experienced these errors and slips in the past months on a 5-point Likert scale (anchors: $0=$ 'never'; $4=$ 'very often'). Scores are summed to obtain CFQ total scores, with higher scores reflecting more selfreported cognitive failures.

To samples 2, 3, and 4, we also administered the Gudjonsson Compliance Scale (GCS; Gudjonsson, 1989; Horselenberg et al., 2006) that gives an indication of how compliant a person is. This scale consists of 20 items in a true-false format. Illustrative items are 'I give in easily to people when I am pressured' and 'I try to please others'. After recoding items 17, 18, and 19, scores are summed. The higher the GCS total score, the more compliant a person is.

In samples 1 and 5, depressive symptomatology was measured with Beck's Depression Inventory II (BDI-II; Beck \& Steer, 1996). This scale consists of 21 items that are scored on a 4-point Likert scale (anchors: $0=$ 'symptom is not present'; $3=$ 'symptom is severe'). Items refer to typical depressive symptoms like gloominess, aversion, and suicidal thoughts. A 
BDI-II total score can be obtained by summing individual item scores, with higher scores reflecting higher levels of depression.

To measure objective memory performance, the Auditory Verbal Learning Test (AVLT; Deelman, Brouwer, Van Zomeren, \& Saan, 1980; Rey, 1964) was administered to samples 2, 3, and 5. The AVLT consists of 15 monosyllabic meaningful words that are read out loud by the experimenter on five trials. After each trial, participants are instructed to reproduce these words (immediate recall). This gives an indication of short term verbal memory. Although the task is also designed to measure delayed recall and recognition, the present study only addressed immediate recall.

\section{Results}

\section{Item Analysis}

Inspection of the data showed that there were four outliers in the distribution of the SSMQ total scores (i.e., deviating more than 3 standard deviations from the mean): three students (sample 1) and one patient of the Neuropsychology Unit (sample 5). Their records were excluded from further analyses. The distribution $(N=1167)$ had a unimodal left-skewed shape. The skewness $(-.70 ; S E=.07)$ and kurtosis $(.83 ; S E=.14)$ were not within the normal range, due to the large proportion of undergraduate students in the overall sample, who generally scored high on the SSMQ (i.e., had favourable opinions about their memory functioning). Table 2.1 gives the mean scores, standard deviation, corrected item-total correlation, and squared multiple correlation (i.e., explained variance) per SSMQ item for the total sample ( $N$ = 1167). As none of the corrected item-total correlations was smaller than .3 , there was no need to exclude any SSMQ item. Thus, all items tap related conceptual domains. Cronbach's $\alpha$ for the whole set of items was .93.

\section{Table 2.1}

Mean Scores (M), Standard Deviations (SD), Corrected Item-Total Correlations $(r)$, and Squared Multiple Variance $\left(r^{2}\right)$ for each SSMQ Item $(N=$ 1167). Loadings ( $L)$ are given of the One-Dimensional Structure in Community and Clinical Samples (Samples 2-5, N=351)

\begin{tabular}{|l|c|c|c|c|c|}
\hline $\begin{array}{l}\text { Items } \\
\text { My ability to search through my mind and } \\
\text { recall names or memories I know are there } \\
\text { is }\end{array}$ & 0.89 & 1.76 & .71 & .50 & .82 \\
\hline
\end{tabular}




\begin{tabular}{|c|c|c|c|c|c|}
\hline Items & $M$ & $S D$ & $R$ & $r^{2}$ & $L$ \\
\hline $\begin{array}{l}\text { I think my relatives and acquaintances now } \\
\text { judge my memory to be }\end{array}$ & 1.35 & 1.62 & .67 & .45 & .81 \\
\hline My ability to recall things when I really try is & 1.08 & 1.67 & .72 & .52 & .86 \\
\hline $\begin{array}{l}\text { My ability to hold in my memory things I } \\
\text { have learned is }\end{array}$ & 1.31 & 1.54 & .68 & .46 & .82 \\
\hline $\begin{array}{l}\text { If I were asked about it a month from now, } \\
\text { my ability to remember facts about this form } \\
\text { I am filling out would be }\end{array}$ & 0.31 & 1.75 & .68 & .46 & .85 \\
\hline $\begin{array}{l}\text { My ability to make a past memory that is on } \\
\text { 'the tip of my tongue' available is }\end{array}$ & 0.19 & 1.63 & .48 & .23 & .74 \\
\hline $\begin{array}{l}\text { My ability to recall things that happened a } \\
\text { long time ago is }\end{array}$ & 0.93 & 1.69 & .62 & .38 & .70 \\
\hline $\begin{array}{l}\text { My ability to remember the names and faces } \\
\text { of people I meet is }\end{array}$ & 0.85 & 1.88 & .58 & .34 & .74 \\
\hline $\begin{array}{l}\text { My ability to remember what I was doing } \\
\text { after I have taken my mind off it for a few } \\
\text { minutes is }\end{array}$ & 0.88 & 1.61 & .66 & .44 & .82 \\
\hline $\begin{array}{l}\text { My ability to remember things that have } \\
\text { happened more than a year ago is }\end{array}$ & 0.91 & 1.66 & .74 & .55 & .82 \\
\hline $\begin{array}{l}\text { My ability now to remember what I read } \\
\text { and what I watch on television is }\end{array}$ & 1.05 & 1.60 & .69 & .48 & .84 \\
\hline $\begin{array}{l}\text { My ability to recall things that happened } \\
\text { during my childhood is }\end{array}$ & 0.57 & 1.92 & .50 & .25 & .60 \\
\hline $\begin{array}{l}\text { My ability to know when the things I am } \\
\text { paying attention to are going to stick in my } \\
\text { memory is }\end{array}$ & 0.93 & 1.44 & .62 & .38 & .77 \\
\hline $\begin{array}{l}\text { My ability to make sense out of what people } \\
\text { explain to me is }\end{array}$ & 1.62 & 1.42 & .58 & .34 & .69 \\
\hline $\begin{array}{l}\text { My ability to reach back in my memory and } \\
\text { recall what happened a few minutes ago is }\end{array}$ & 1.38 & 1.56 & .66 & .44 & .81 \\
\hline $\begin{array}{l}\text { My ability to pay attention to what goes on } \\
\text { around me is }\end{array}$ & 1.52 & 1.43 & .61 & .37 & .76 \\
\hline $\begin{array}{l}\text { My general alertness to things happening } \\
\text { around me is }\end{array}$ & 1.48 & 1.48 & .55 & .30 & .68 \\
\hline $\begin{array}{l}\text { My ability to follow what people are saying } \\
\text { is }\end{array}$ & 1.56 & 1.39 & .58 & .34 & .74 \\
\hline
\end{tabular}




\section{Principal Component Analysis}

To explore the dimensions underlying the SSMQ, we performed principal component analysis on SSMQ scores of samples 2 through 5 ( $n=351$; see Table 2.1 for factor loadings). We did not include sample 1, because this large sample consisted of undergraduate students who generally have a favourable opinion of their own memory. Including this sample would have biased the dimensional structure. The point here is that our community and clinical samples are more representative of the defendants generally interrogated by the police. Visual inspection of the scree plot (see Figure 2.1) suggested one general dimension. This dimension had an eigenvalue of 10.77, explaining $59.8 \%$ of the total variance, and included all 18 SSMQ items. We labelled this dimension 'subjective memory evaluation'.

\section{Scree Plot}

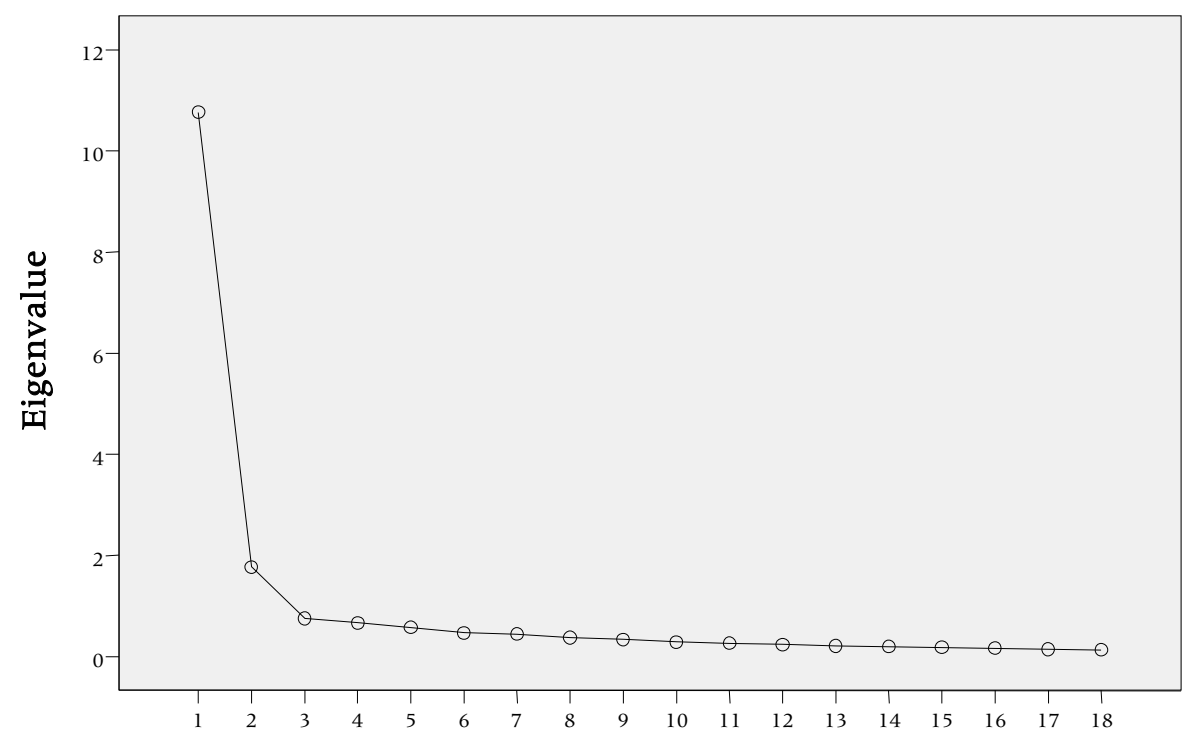

Figure 2.1. Scree-plot of eigenvalues obtained from principal component analysis of 18 SSMQ items.

\section{Reliability}

Test-retest stability was measured (in terms of Pearson product-moment $r$ ) by administering the SSMQ twice to two samples. More than half of sample $2(n=38)$ completed the SSMQ for a second time and returned it by mail, 
approximately three months after the first test session. A test-retest stability of .87 was found. In sample 3, participants were asked to complete the SSMQ on the Internet. A subgroup of this sample $(n=70)$ was selected for a follow-up study, in which the SSMQ was given for a second time. This time, a test-retest stability of .90 was found, with an interval of approximately six weeks between both test sessions.

Furthermore, as can be seen in Table 2.2, internal consistency (in terms of Cronbach's $\alpha$ ) was excellent and varied from .88 to .96 per sample.

\section{Validity}

\section{Construct validity}

Because the five samples were quite heterogeneous by nature, we expected that they would differ with respect to SSMQ total scores. Indeed, an oneway Analysis of Variance showed a significant group difference $[F(4,1162)=$ $41.81, p<.001]$. Bonferroni corrected post-hoc analyses revealed that the undergraduate sample (sample 1) had the highest SSMQ scores and in this way differed significantly from all other samples (all $p s<.01$ ). Furthermore, the community samples (samples 2, 3, and 4) had significantly higher SSMQ scores (all $p s<.001)$ than the clinical sample (sample 5). Thus, undergraduate students were, not surprisingly, most optimistic about their own memory, followed by people from the community, followed by outpatients. Table 2.2 gives an overview of the mean SSMQ total scores per sample.

\section{Table 2.2}

Sample Size (n), Mean Total Score (M), Standard Deviation (SD), Range, and Internal Consistency (Cronbach's $\alpha$ ) of the SSMQ, for each Sample

\begin{tabular}{|l|c|c|c|c|c|}
\hline Samples & $n$ & $M$ & $S D$ & Range & $\alpha$ \\
\hline 1 - Undergraduate students & 816 & 22.59 & 14.79 & $-18-64$ & .88 \\
\hline 2- Community sample & 70 & 14.36 & 22.13 & $-30-57$ & .94 \\
\hline 3 - Community sample & 128 & 13.88 & 23.67 & $-46-59$ & .96 \\
\hline $4-$ Community sample & 79 & 12.80 & 26.71 & $-59-62$ & .96 \\
\hline 5 - Patients & 74 & -3.71 & 27.24 & $-64-55$ & .96 \\
\hline
\end{tabular}

As an additional test of construct validity, we compared the two memory groups in samples 2 and 4. As one might have expected, SSMS scores corresponded with the general memory beliefs that people had and which formed the basis for their assignment to the conditions. Thus, for sample 2, the excellent memory group had significantly higher scores on the SSMQ than the 
poor memory group [t(68) $=10.41, p<.001$, Cohen's $d=2.49]$, means being $30.62(S D=14.03)$ and $-3.88(S D=13.62)$, respectively. This pattern was replicated in sample 4 . That is, people who were very confident in their own memory showed significantly higher SSMQ scores than people reporting that they suffered from memory distrust $[t(77)=11.95, p<.001$, Cohen's $d=2.70$ ], means being $34.46(S D=14.33)$ and -8.32 $(S D=17.32)$, respectively. Even when age was included as a covariate, group differences with regard to SSMQ total scores remained significant (both $p s<.001$ ).

Not surprisingly, when all samples were collapsed, age correlated negatively with SSMQ total scores $(r=-.34, p<.001)$. That is, older adults were more pessimistic about their own memory capabilities than young adults. Also, men tended to have slightly lower SSMQ scores than women [t(1161) $=1.71, p=.09$; two-tailed $]$, means being $17.24(S D=21.61)$ and $19.41(S D$ $=18.74)$, respectively. However, analysis of covariance showed that after correcting for age, this borderline gender difference disappeared $[F(1,1109)$ $=.62, p=.42]$.

\section{Convergent validity}

To assess the concurrent validity of the SSMQ, we correlated SSMQ scores with scores on other relevant questionnaires and tests (see Table 2.3). ${ }^{5}$ In some samples, we identified outliers (i.e., deviating more than 3 standard deviations from the mean). They were removed and are therefore not included in the following analyses. Also, incomplete records were excluded from data analysis, which explains the fluctuations in degrees of freedom.

First, in the community samples (samples 2, 3, and 4), the CFQ correlated substantially but negatively with the SSMQ. In the student group (sample 1) and the clinical sample (sample 5), these correlations were somewhat lower. They were, however, still in the predicted direction and reached significance. Second, the relationship between subjective memory complaints and compliance was inconsistent. In sample 3, we found that the more negative participants scored on the SSMQ, the more compliant they were, but this significant relationship was not replicated in samples 2 and 4 . Third, with respect to the BDI-II, we found in sample 1 that the more depressed participants were, the lower they scored on the SSMQ. Yet, in sample 5, this relationship failed to reach significance. Fourth, we found that the SSMQ and AVLT were positively correlated in the healthy samples (samples

\footnotetext{
${ }^{5}$ We used Pearson product-moment correlations because with the exception of the student sample 1, all samples displayed a normal SSMQ distribution. For sample 1, we also calculated the non-parametric correlation statistics Kendall's tau and Spearman's rho. Although these statistics differed in a subtle way from the Pearson correlations, the overall levels of significance remained basically the same.
} 
2 and 3), whereas a non-significant but positive correlation was obtained in the clinical sample (sample 5). When samples 2, 3, and 5 were collapsed, we found a significant positive correlation between subjective (SSMQ) and objective (AVLT) memory $\left(n=182 ; r=.31 ; r^{2}=.09\right)$.

\section{Table 2.3}

Pearson Product-Moment Correlations between SSMQ Total Scores and Construct-Related Variables (for each Sample)

\begin{tabular}{|c|c|c|c|c|c|}
\hline Tests & Sample 1 & Sample 2 & Sample 3 & Sample 4 & Sample 5 \\
\hline CFQ & $\begin{array}{c}-.43 \\
(n=494)\end{array}$ & $\begin{array}{c}-.72 \\
(n=67)\end{array}$ & $\begin{array}{c}-.70 \\
(n=70)\end{array}$ & $\begin{array}{c}-.73 \\
(n=77)\end{array}$ & $\begin{array}{c}-.60 \\
(n=69)\end{array}$ \\
\hline GCS & - & $\begin{array}{c}-.08 \\
(n=69)\end{array}$ & $\begin{array}{c}-.33^{*} \\
(n=70)\end{array}$ & $\begin{array}{c}-.15 \\
(n=75)\end{array}$ & - \\
\hline BDI-II & $\begin{array}{c}-.14^{*} \\
(n=448)\end{array}$ & - & - & - & $\begin{array}{c}-.18 \\
(n=44)\end{array}$ \\
\hline AVLT & - & $\begin{array}{c}.31^{*} \\
(n=70)\end{array}$ & $\begin{array}{c}.25^{*} \\
(n=70)\end{array}$ & - & $\begin{array}{c}.19 \\
(n=43)\end{array}$ \\
\hline
\end{tabular}

Note. $\mathrm{CFQ}=$ Cognitive Failures Questionnaire; GCS = Gudjonsson Compliance Scale; BDI-II = Beck's Depression Inventory-II; AVLT = Auditory Verbal Learning Test.

$* p<.05$.

\section{Discussion}

All in all, our findings indicate that the SSMQ has solid psychometric properties. A one-dimensional structure was found that makes conceptual sense. In various samples, we found evidence for satisfactory test-retest stability and excellent internal consistency. With respect to construct validity, the SSMQ distinguished very well between different samples (i.e., students, community samples, and outpatients) and different memory groups (e.g., memory distrust vs. memory confidence). Furthermore, the questionnaire appeared to correlate in a theoretically meaningful way with age and cognitive failures, although the correlational pattern for compliance, depression, and objective memory performance was less compelling.

In line with its name, the SSMQ was found to consist of one dimension reflecting beliefs that people have about their memory functioning (i.e., subjective memory). Indeed, inspection of the SSMQ items also makes clear that they pertain to subjective memory evaluation. It is not surprising, therefore, that we found an overlap between the SSMQ and CFQ in all samples. Note, 
however, that the CFQ contains heterogeneous items alluding to memory, attention, and motor efficiency (Broadbent et al., 1982).

We found that SSMQ scores differentiate between a priori beliefs that people have about their own memory functioning, with scores being higher for those who have favourable opinions about their memory than those who evaluate it in negative terms. One could counter that this is a weak approach to measure construct validity. While it is true that finding a null result would have been more diagnostic for the (lack of) construct validity than finding a connection between a priori beliefs and SSMQ scores, one should also take effect sizes - which were considerable - into account. Meanwhile, beliefs that people have about their own cognitive functioning need not to parallel their actual memory performance. Thus, subjective memory confidence and objective memory functioning were significantly and positively correlated in samples 2 and 3 (i.e., community samples), but not in sample 5 (i.e., clinical sample). Even in samples 2 and 3, the proportion of explained variance was by all standards modest (.06 and .09, respectively). So, the link between subjective and objective memory turned out to be fragile, but this is not an unusual theme in the literature. Several studies (Ponds \& Jolles, 1996; Ponds et al., 2000) reported similar findings among the elderly. These studies bear strong relevance to our results, as the patients in our clinical sample were significantly older than the people in our community samples 2 and 3 . Hence, it seems that young and middle-aged adults are more accurate in estimating their own memory functioning than older adults. An explanation might be that older people, who experience more cognitive problems in daily life, are more often preoccupied with their memory problems and therefore overestimate these problems in self-report questionnaires, while in fact their objective memory performance is not as poor as they think. Another possibility is that the lack of association between objective memory performance and subjective memory complaints in sample 5 was due to health problems experienced by the patients in this sample. However, because of the heterogeneity of the memory complaints, health problems, and mood and anxiety disorders involved, no hard conclusions can be drawn about the effect of health problems on subjective memory complaints.

Two further remarks are in order about the correlates of the SSMQ. We expected that compliance would be intimately linked to negative beliefs about one's own memory. This expectation was not fully borne out by the data. In general, we found a negative correlation between subjective memory evaluation and compliance. In other words, the more people distrust their memories, the more they comply with others. This is the pattern one would expect, because memory distrust almost by definition implies that people suffering from it rely on cues or suggestions provided by others. However, the memory distrust-compliance link was only evident for the 
community sample 3. Apparently, the relationship between memory evaluation and compliance is not as straightforward as anticipated. Using other samples in future research, such as alleged false confessors or forensic patients, might shed a different light on this link, because in general, they tend to have higher compliance scores. Evidently, this link is most relevant among forensic groups, while it might be less obvious in community and clinical samples due to, for example, restriction of range phenomena.

Surprisingly, the predicted relationship between depression and negative beliefs about one's memory was less evident in the clinical sample. Although the correlation in this sample failed to reach significance, it was in the predicted direction, with more depressive symptoms being associated with more pessimistic thoughts about one's own memory, and consistent with mixed findings in other studies examining the relationship between depression and metamemory beliefs (Kalska, Punamäki, Mäkinen-Pelli, \& Saarinen, 1999; Ponds \& Jolles, 1996)

In sum, the SSMQ appears to be a reliable and valid instrument measuring subjective beliefs about one's own memory. Because memory distrust can be seen as an antecedent of false confessions (Gudjonsson 8 MacKeith, 1982), the SSMQ may be a valuable tool for estimating the vulnerability of suspects or eyewitnesses before interrogation. By administering the SSMQ, forensic psychologists may obtain an indication of the potential risk of memory distrust and inform police officers to exercise caution when questioning a suspect or eyewitness. In particular, very low scores on the SSMQ might be indicative of high vulnerability of trait memory distrust. Meanwhile, the precise connection between the SSMQ scores and compliance requires further study. Thus, it may well be the case that pessimistic beliefs about one's own memory only go along with compliance to the extent that the person has other characteristics that make him or her vulnerable (e.g., depression, external locus of control). Besides assisting forensic psychologists in assessing the vulnerability of suspects and eyewitnesses, this instrument may also facilitate empirical research on the concept of memory distrust. 


\section{CHAPTER 3}

\section{RELATED CONCEPTS}

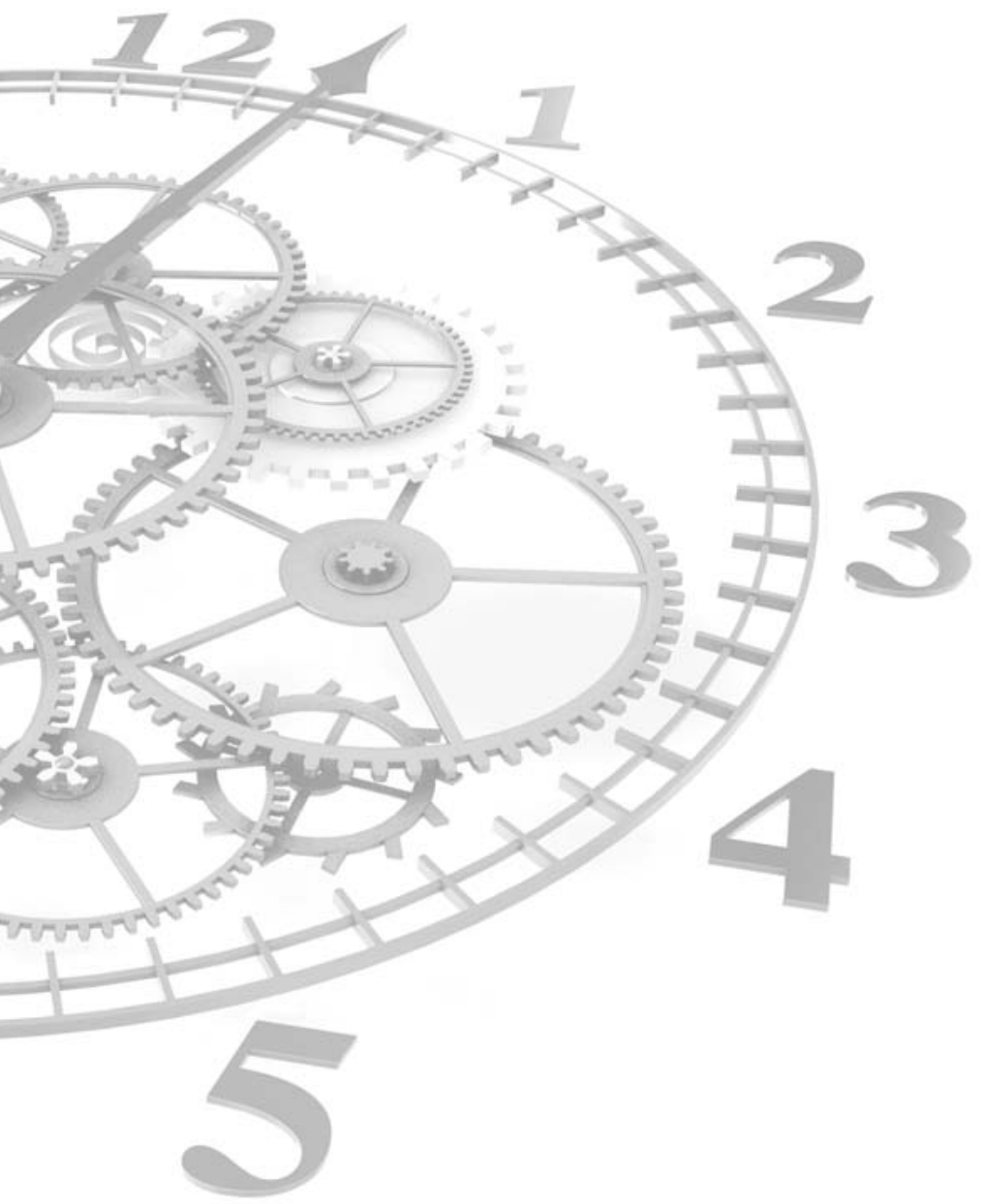

Van Bergen, S., Jelicic, M., \& Merckelbach, H. (2009). Are subjective memory problems related to suggestibility, compliance, false memories, and objective memory performance? American Journal of Psychology, 122, 249257. 


\begin{abstract}
The relationship between subjective memory beliefs and suggestibility, compliance, false memories, and objective memory performance was studied in a community sample of young and middle-aged people $(N=142)$. We hypothesised that people with subjective memory problems would exhibit higher suggestibility and compliance levels and would be more susceptible to false recollections than those who are optimistic about their memory. In addition, we expected a discrepancy between subjective memory judgments and objective memory performance. We found that subjective memory judgments correlated significantly with compliance, with more negative memory judgments accompanying higher levels of compliance. Contrary to our expectation, subjective memory problems did not correlate with suggestibility or false recollections. Furthermore, participants were rather accurate in estimating their objective memory performance.
\end{abstract}

\title{
Introduction
}

There are large individual differences in how people evaluate their own memory. While most of us tend to be quite optimistic about the power of our memory, some people believe their memory is much poorer compared to that of people from their own age group (Crombag et al., 2000; Magnussen et al., 2006). However, subjective ideas about memory do not always correspond to objective memory performance (Ponds \& Jolles, 1996; Ponds et al., 2000). For example, healthy older people (more than 55 years old) who rate their memory as very poor, often exhibit normal performance on standard memory tasks (Ponds \& Jolles, 1996; Ponds et al., 2000). In a forensic setting, pessimistic ideas about one's own memory might have farreaching consequences. Given the weight that triers of fact attach to confidence (Leippe, Manion, \& Romanczyk, 1992), individuals with such pessimistic ideas may erroneously be treated as less credible eyewitnesses or suspects.

There are hints in the literature suggesting that negative ideas about one's own memory are associated with elevated suggestibility levels and an enhanced susceptibility to false recollections. People who judge their own memory as very poor because they suffer from the memory distrust syndrome, are thought to be especially prone to memory distortions (Gudjonsson \& MacKeith, 1982). According to Gudjonsson (2003, p. 196), memory distrust is "a condition where people develop profound distrust of their memory recollections, as a result of which they are particularly susceptible to relying on external cues and suggestions". Gudjonsson describes a number 
of court cases in which defendants suffering from memory distrust, developed false memories, eventually resulting in false confessions (Gudjonsson, 2003; Gudjonsson et al., 1999). Note that such isolated single cases do not provide hard evidence for a close connection between pessimistic opinions about one's own memory and suggestibility. Furthermore, we believe that a distinction should be drawn between state and trait memory distrust, with the former referring to the cases described in the literature and the latter manifesting itself as a personality trait. In this chapter, we will focus on trait memory distrust which can be seen as a negative subjective memory judgment.

Compliance is a concept related to suggestibility. It can be defined as "a tendency of the individual to go along with propositions, requests or instructions, for some immediate instrumental gain" (Gudjonsson, 2003, p. 370). Whereas suggestibility assumes that people accept the information provided, this does not apply to compliance. Nonetheless, the consequences of complying can be far-reaching in some settings. Think for example of complying with statements about a murder expressed by a police officer or complying with a therapist's suggestion that you might have been sexually abused. Research has shown that people with poor self-esteem are highly compliant (Gudjonsson, Hannesdottir, Petursson, \& Bjornsson, 2002). As self-esteem and judgments about one's memory seem to be related, a measure of compliance was included in our study.

To our knowledge, the relationship between judgments of one's own memory on the one hand, and suggestibility, compliance, false recollections, and objective memory performance on the other hand has not yet been studied systematically. Therefore, we designed a study to examine these associations. Following the ideas of Gudjonsson (2003), we hypothesised that participants with subjective memory problems would exhibit higher levels of suggestibility and compliance and would be more susceptible to false recollections than those who reported to have excellent memory capabilities. The idea here is that people who have pessimistic ideas about their own memory will be more willing to comply with the suggestive cues given by others. Furthermore, based on the work of Crombag et al. (2000), we expected that people would overestimate their own memory functioning. This hypothesis is consistent with research demonstrating that in healthy elderly, subjective evaluations of memory do not appear to be associated with objective memory performance (Ponds \& Jolles, 1996; Ponds et al., 2000). We decided to select a sample of young and middle-aged participants, so as to be sure that the subjective memory judgments we measured were not linked to age-related memory problems. 


\section{Method}

\section{Participants}

Our sample consisted of 142 young and middle-aged research participants (105 women), who were recruited through advertisements in a regional newspaper. Their mean age was 34.23 years $(S D=8.06$, range $=17-46)$. The participants were told that they would be administered several memory tasks and questionnaires. They were given a financial compensation (€25) for participating in our study. The research was approved by the standing ethical committee of the Faculty of Psychology and Neuroscience, Maastricht University.

\section{Instruments}

\section{Subjective memory}

A Dutch translation of the Squire Subjective Memory Questionnaire (SSMQ; Squire et al., 1979; Van Bergen, 2008; Van Bergen, Brands, Jelicic, \& Merckelbach, 2010a; Cronbach's $\alpha=.94)$ was used to measure subjective memory. This self-report questionnaire consists of 18 items, which are answered on a 9-point Likert scale (anchors: $-4=$ 'disastrous'; $+4=$ 'perfect'). Sample items are 'My ability to recall things when I really try is' and 'My ability to remember things that have happened more than a year ago is'. Scores are summed to obtain an SSMQ total score (varying from -72 to +72 ), with a negative score indicating a negative subjective evaluation of one's own memory. The SSMQ has good test-retest stability $(r=.89 ; n=113$; Van Bergen et al., 2010a).

To test the concurrent validity of the SSMQ, we administered another index of subjective memory functioning; the Dutch translation of the Cognitive Failures Questionnaire (CFQ; Broadbent et al., 1982; Merckelbach et al., 1996; Cronbach's $\alpha=.92$ ). The CFQ consists of 25 items that measure selfreported frequency of everyday lapses and errors in memory, perception/attention, and action. Illustrative items are 'Do you forget where you put something like a newspaper or a book?', 'Do you fail to notice signposts on the road?', and 'Do you drop things?'. Participants are asked to indicate on a 5-point Likert scale how often they have experienced each cognitive failure during the past months (anchors: $0=$ 'never'; $4=$ 'very often'). Scores are summed to obtain a CFQ total score, with higher scores indicating more self-reported cognitive failures. The Dutch translation of the CFQ has adequate psychometric properties (Merckelbach et al., 1996). 


\section{Suggestibility and compliance}

A Dutch translation of the Gudjonsson Suggestibility Scale (GSS; Gudjonsson, 1984) was used to measure suggestibility. The GSS consists of a story that is read out loud by the experimenter. In the free recall phase, participants are asked to write down what they can remember from the story. Fifty min later, participants are given a second free-recall test. Subsequently, they are asked a series of 20 questions. Fifteen of these questions contain misleading elements in the sense that they suggest things that are not mentioned in the story, whereas five other questions are factual memory questions. After they have answered the questions, participants receive negative feedback irrespective of their performance (i.e., 'You have made a number of errors. It is therefore necessary to go through the questions once more, and this time, try to be more accurate' $)$. Next, the questions are repeated.

The GSS yields several parameters. First, with regard to the free recall, the number of correctly reproduced story elements is counted (maximum = 40). This is done for both immediate and delayed recall. The corresponding inter-rater reliability parameters were .95 and .93, respectively (both $p s<$ $.001)$. Also, four suggestibility parameters can be derived from the GSS. Yield 1 refers to the number of misleading elements that the participant accepts during the first set of questions (maximum $=15$ ). Yield 2 reflects the number of accepted misleading elements during the second set of questions (maximum $=15)$. Shift refers to the number of answers that the participant changes as a result of the negative feedback (maximum $=20$ ). The GSS total score is the sum of Yieldl and Shift, with higher scores indicating higher suggestibility levels. Research has shown that the Dutch version of the GSS is a psychometrically sound instrument (Merckelbach et al., 1998). More specifically, Merckelbach et al. reported sufficient internal consistency, with Cronbach's as being .79 (Yield1), .75 (Shift), and .82 (GSS total score). Testretest stability was modest $(r=.55)$. They also found indications for the predictive validity of the Yield scales.

The Gudjonsson Compliance Scale (GCS; Gudjonsson, 1997; Cronbach's $\alpha=.75$ ) is a self-report measure consisting of 20 items which all tap compliant behaviour, in other words, the tendency to give in to another's opinion. Examples of GCS items are 'I give in easily when I am pressured', 'People in authority make me feel uncomfortable and uneasy', and 'I try to please others'. The items have a true-false format. After recoding, scores are summed (range $=0-20$, with higher scores reflecting more compliant behaviour. In the present study, we employed a Dutch translation of the GCS, which has good psychometric properties (Smeets, 2008). 


\section{False recollections}

To measure individual differences in the tendency to develop false recollections, we employed the Deese-Roediger/McDermott (DRM) paradigm (Roediger \& McDermott, 1995). The 10 wordlists that were used comprised 15 Dutch words each. Each list contained words (e.g., drowsy, bed, dream) that were associated with a non-presented theme word (e.g., sleep). This word is called the critical lure. Extensive pilot studies by Peters, Jelicic, Haas, and Merckelbach (2006) have shown that proportions of recall and recognition of these wordlists are comparable to those reported by Roediger and McDermott. Participants were told that they would hear several wordlists and would be tested immediately after hearing each list by writing down all the words they could remember. They were instructed not to guess. The lists were read out loud by the experimenter at a pace of 1 word per second with an inter-stimulus interval of 1 second. After each list, participants were given 2 min to write down all the words they could remember. Split-half reliability was excellent for correctly recalled words (Spearman-Brown coefficient = .92 ) and moderate for the critical lures (Spearman-Brown coefficient $=.54$ ).

After all lists had been presented, a recognition test was given. This test consisted of 30 old words and 30 new words. Three items per list corresponding with serial positions 1, 8 and 10, were selected as old words. Ten of the new words were critical lures and the other 20 words were derived from other wordlists that were not used during this experiment.

\section{Objective memory performance}

The Dutch version of the Auditory Verbal Learning Test (AVLT; Deelman et al., 1980; Rey, 1964) was used to determine objective memory performance. This test consists of 15 monosyllabic meaningful words that are presented on five successive trials. Participants are asked to recall the words after each trial (immediate recall). Delayed recall is measured after an interval of approximately $15 \mathrm{~min}$ during which participants complete non-verbal filler tasks. The present study focused on both immediate and delayed recall. Research has shown that the AVLT has high internal consistency, with Cronbach's $\alpha$ being .95 (Deelman et al., 1980). Test-retest stability was acceptable, varying from .64 (for long intervals) to .85 (for intervals less than 1 hour).

Recognition was also measured by reading a list of 30 words out loud, consisting of 15 old and 15 new words. For each word, participants had to indicate whether or not the word had appeared on the study list and true positive, false positive, and false negative scores were scored. 


\section{Procedure}

Participants were tested individually in a quiet laboratory room. Upon arrival, they were first asked to give informed consent. Next, the GSS was administered, followed by the DRM recall task. After this, participants completed several questionnaires (including the SSMQ, CFQ, and the GCS) and they were given the recognition part of the DRM task. Immediately after this task, they were asked to write down the GSS story for a second time. Participants were asked 20 questions about the story and, after they had been given false feedback on their performance, they were instructed to answer the 20 questions again. Next, the AVLT was administered. In the time interval between immediate recall and delayed recall followed by recognition, participants completed several unrelated filler questionnaires.

\section{Results}

Table 3.1 shows the mean scores, standard deviations and ranges of the selfreport questionnaires, the GSS, the false memory task (DRM), and the AVLT.

\section{Subjective Memory}

As can be seen in Table 3.1, the SSMQ total scores ranged from -46 to +57 . This indicates that both people with negative and positive impressions of their memory participated in our study. There was a significant negative correlation between subjective memory evaluation and cognitive failures $(r$ $=-.72, p<.05)$, showing that more optimistic views about one's own memory were associated with fewer self-reported cognitive failures. This underlines the concurrent validity of the SSMQ.

\section{Suggestibility and Compliance}

Both immediate and delayed recall on the GSS were positively correlated with subjective memory beliefs (both $r s=.30$, both $p s<.05$ ). However, none of the correlations between SSMQ and other GSS parameters attained significance (see Table 3.2). Furthermore, we found a negative correlation between the GCS and the SSMQ $(r=-.22, p<.05)$, suggesting that more optimistic opinions about one's memory are associated with less compliance. 
Table 3.1

Mean Scores, Standard Deviations and Ranges of the Questionnaires and Tests in a Community Sample $(N=142)$

\begin{tabular}{|c|c|c|c|c|c|}
\hline \multicolumn{3}{|c|}{ Instruments } & $M$ & $S D$ & Range \\
\hline \multicolumn{3}{|c|}{ Squire Subjective Memory Questionnaire } & 11.39 & 22.55 & $-46-57$ \\
\hline \multicolumn{3}{|c|}{ Cognitive Failures Questionnaire } & 40.59 & 14.42 & $12-79$ \\
\hline \multicolumn{3}{|c|}{ Gudjonsson Compliance Scale } & 10.40 & 3.92 & $2-18$ \\
\hline \multirow[t]{6}{*}{ GSS } & \multicolumn{2}{|c|}{ Immediate recall } & 16.85 & 6.01 & $4.5-33$ \\
\hline & \multicolumn{2}{|c|}{ Delayed recall } & 15.80 & 6.05 & $3-34.5$ \\
\hline & \multicolumn{2}{|c|}{ Yield 1} & 3.62 & 2.61 & $0-12$ \\
\hline & \multicolumn{2}{|l|}{ Yield2 } & 4.77 & 3.29 & $0-13$ \\
\hline & \multicolumn{2}{|l|}{ Shift } & 3.25 & 2.56 & $0-10$ \\
\hline & \multicolumn{2}{|c|}{ GSS total score } & 6.87 & 4.40 & $0-20$ \\
\hline \multirow[t]{4}{*}{ DRM } & Recall & Correct & 91.07 & 16.17 & $53-128$ \\
\hline & & False - critical lures & 4.97 & 2.23 & $0-10$ \\
\hline & Recognition & Correct - old words & 23.94 & 3.69 & $10-30$ \\
\hline & & False - critical lures & 8.35 & 2.21 & $1-10$ \\
\hline \multirow[t]{7}{*}{ AVLT } & $\begin{array}{l}\text { Immediate } \\
\text { recall }\end{array}$ & Correct & 46.46 & 11.10 & $21-69$ \\
\hline & & Incorrect & 1.27 & 1.97 & $0-10$ \\
\hline & $\begin{array}{l}\text { Delayed } \\
\text { recall }\end{array}$ & Correct & 9.75 & 3.41 & $1-15$ \\
\hline & & Incorrect & 0.37 & 0.67 & $0-3$ \\
\hline & Recognition & True positive & 13.97 & 1.69 & $4-15$ \\
\hline & & False positive & 0.27 & 0.72 & $0-6$ \\
\hline & & False negative & 1.04 & 1.69 & $0-11$ \\
\hline
\end{tabular}

\section{False Recollections}

Although the number of correctly recalled words in the DRM task correlated significantly to SSMQ scores $(r=.36, p<.05)$, there was no link between SSMQ scores and endorsement of critical lures during the free recall phase $(r$ $=-.04, p=.62$ ). As for the recognition parameters, the SSMQ was only partly related to false recollections. More specifically, a significant negative correlation was found between old words that were correctly remembered as old words and the SSMQ $(r=-.19, p<.05)$. Such a relationship was absent for the SSMQ and critical lures that were remembered as old words $(r=-.12$, $p=.16)$. 


\section{Table 3.2}

Pearson's Product-Moment Correlations between Subjective Memory (indexed by the SSMQ) and Other Tests in a Community Sample $(N=142)$

\begin{tabular}{|c|c|c|c|}
\hline \multicolumn{3}{|l|}{ Instruments } & SSMQ \\
\hline \multicolumn{3}{|c|}{ Cognitive Failures Questionnaire } & $-.72 *$ \\
\hline \multicolumn{3}{|c|}{ Gudjonsson Compliance Scale } & $-.22 *$ \\
\hline \multirow[t]{6}{*}{ Suggestibility } & \multicolumn{2}{|l|}{ Immediate recall } & $.30 *$ \\
\hline & \multicolumn{2}{|l|}{ Delayed recall } & $.30^{*}$ \\
\hline & \multicolumn{2}{|l|}{ Yield 1} & .13 \\
\hline & \multicolumn{2}{|l|}{ Yield2 } & .01 \\
\hline & \multicolumn{2}{|l|}{ Shift } & .11 \\
\hline & \multicolumn{2}{|l|}{ GSS total score } & .14 \\
\hline \multirow[t]{4}{*}{ False recollections } & Recall & Correct & $.36 *$ \\
\hline & & False - critical lures & -.04 \\
\hline & Recognition & Correct - old words & $.19 *$ \\
\hline & & False - critical lures & -.12 \\
\hline \multirow[t]{7}{*}{ Objective memory } & Immediate recall & Correct & $.29 *$ \\
\hline & & Incorrect & -.12 \\
\hline & Delayed recall & Correct & $.29 *$ \\
\hline & & Incorrect & .00 \\
\hline & Recognition & True positive & $.24^{*}$ \\
\hline & & False positive & -.09 \\
\hline & & False negative & $-.25 *$ \\
\hline
\end{tabular}

Note. The application of a Bonferroni correction did not change the general pattern.

${ }^{*} p<.05$.

\section{Objective Memory Functioning}

Table 3.2 shows Pearson's product-moment correlations of the SSMQ with objective memory indices. Subjective memory judgments (indexed by the SSMQ) and objective memory functioning (measured by the AVLT) correlated significantly, both for immediate and delayed correct recall (both is = .29 , both $p s<.05)$. As for word recognition, the SSMQ correlated significantly with true positives (i.e., correct identification of studied words). In other words, participants with higher SSMQ scores correctly recognised more old words as previously presented $(r=.24, p<.05)$. Similarly, SSMQ scores were negatively correlated with false negatives $(r=-.25, p<.05)$. No 
significant correlation emerged between SSMQ and false positives, that is falsely recognising words that were not studied $(r=-.09, p=.30)$.

\section{Extreme Values}

As correlational analyses assume linearity, and this assumption might not be true for our sample, we conducted additional analyses for which we created two groups consisting of participants with extreme SSMQ values: a poor memory group, with the $25 \%$ lowest SSMQ scores $(n=35)$ and an excellent memory group, with the $25 \%$ highest SSMQ scores $(n=38)$. Independent samples $t$-tests revealed a similar pattern as was obtained with Pearson product-moment correlations, except for the GCS [Ms being 11.34 (SD = 3.98) and $10.05(S D=3.76)$, respectively; $t(71)=1.43, p=.16$ ].

In other words, we found significant differences between the poor and excellent memory group on all objective memory parameters and the questionnaire tapping cognitive failures (both $p s<.05$ ). But no group differences on suggestibility, compliance, and false recollection parameters emerged.

\section{Inter-correlations between the Questionnaires}

To get more insight in the relationships between the concepts that were examined in this study, we examined the inter-correlation matrix (see Table 3.3). Suggestibility was positively correlated to false memories $(r=.19, p<$ $.05)$. In addition, false memories and objective memory performance were negatively correlated $(r=-.34, p<.05)$. The other inter-correlations failed to reach significance.

Table 3.3

Correlation Matrix of Test (Total) Scores in a Community Sample $(N=142)$

\begin{tabular}{|l|c|c|c|c|}
\hline Tests & GSS & GCS & DRM & AVLT \\
\hline Cognitive Failures Questionnaire & -.14 & .12 & -.01 & -.14 \\
\hline Gudjonsson Suggestibility Scale & - & -.06 & $.19^{*}$ & -.17 \\
\hline Gudjonsson Compliance Scale & & - & .05 & -.10 \\
\hline Deese-Roediger/McDermott Task & & & - & $-.34^{*}$ \\
\hline
\end{tabular}

Note. DRM = Recall of Critical Lures; and AVLT = Correct Immediate Recall.

$* p<.05$. 


\section{Discussion}

The findings of the present study can be summarised as follows. Firstly, participants who were pessimistic about their memory reported more cognitive failures and higher levels of compliance. Secondly, beliefs about one's own memory were not related to suggestibility and false recollections. Thirdly, participants with more optimistic opinions about their memory exhibited better objective memory performance.

Gudjonsson has described a number of cases suggesting that memory distrust may contribute to false memories and false confessions (Gudjonsson, 2003; Gudjonsson et al., 1999). He argued that people with subjective memory problems have a tendency to rely on external cues and suggestions, making them vulnerable to false memories. Our results do only partly support this line of reasoning. Thus, we found that the SSMQ was negatively associated with the GCS: the more pessimistic a person's own memory beliefs, the more compliant he/she is. This is understandable when one assumes that people suffering from memory distrust (i.e., who evaluate their memory as poor) are more susceptible to the authority of others. As a result, they perceive the opinion of others as more important than their own opinions. However, as this relationship was only based on correlations, the causal relationship between these two concepts cannot be established. One could also argue that people start to distrust their memory because they are more easily intimidated by authorities who might have played an active role in undermining the confidence in one's memory abilities. This points out that the relationship between memory distrust and compliance could go both ways.

In this study, we failed to find a significant correlation between the SSMQ and false recollections (i.e., critical lures) elicited by the DRM task. This finding could be explained by the moderate split-half reliability of the critical lures of the DRM task in this study. Furthermore, following Gudjonsson's line of reasoning, one would also expect elevated suggestibility levels in people with negative memory beliefs (Gudjonsson, 2003). Contrary to our expectation, we did not find evidence to support this hypothesis. Thus, no significant correlations were found between the SSMQ and suggestibility. However, it should be noted that levels of interrogative pressure during the GSS procedure are very modest. In the forensic cases involving memory distrust (Gudjonsson, 2003; Gudjonsson et al., 1999), all suspects had been exposed to extremely high levels of interrogative stress. Therefore, our results do certainly not preclude the possibility that when people suffering from memory distrust are exposed to high interrogative pressure, they become suggestible. We also found that the inter-correlation between false recollections and suggestibility was positive and reached significance. This 
was not surprising as other studies have indicated that highly suggestible people are more prone to develop false memories (see e.g., Geraerts, Smeets, Jelicic, Van Heerden, \& Merckelbach, 2005; Gudjonsson, 2003).

Our finding that self-reported memory capabilities in young and middle aged participants correspond with their objective memory performance contrasts with research showing that older participants who believe their memory is poor perform as well as elderly people with optimistic views of their memory (Ponds \& Jolles, 1996; Ponds et al., 2000). It seems that our participants were more accurate in evaluating their own memory than older participants with self-reported memory problems. Interestingly, our results fit nicely with those of Brewin and Stokou (2002), who found that individuals who judge themselves to have poor childhood memory perform worse on a standardised autobiographical memory test compared to those who report normal childhood memories. It is difficult to say why some of the older people believe to have poor memory capabilities, while there is nothing wrong with their memory. Perhaps, these individuals had been confronted with cases of dementia in their relatives and friends. Such experiences may lead one to interpret normal age-related memory decline as a form of pathological aging (Commissaris et al., 1998). Our younger and middle-aged participants may not have had these experiences and this may help to explain why in this group, subjective and objective memory parameters are not dissociated to such an extent as is often seen in older participants. Our sample may also have more realistic memory beliefs because they are more often exposed to feedback information about their memory performance (e.g., in the context of their work or education), which could promote a better calibration.

In addition, we found that poor memory performance (indexed by immediate recall on the AVLT) was related to more false recollections (i.e., more critical lures). However, this was to be expected as "[...] (partial) amnesia is a necessary condition for the development of a full-blown false autobiographical memory" (Smeets, Merckelbach, Horselenberg, \& Jelicic, 2005, p. 925).

There are several limitations in the present study that deserve some comment. First, although the correlations between subjective memory judgments and objective memory parameters were significant, they were by all standards modest. This may have to do with the fact that the sample did not involve patients or older persons (i.e., participants with more extreme opinions about their memory). Furthermore, the modest correlations may have to do with the fact that the test we used to measure objective memory performance, the AVLT, only taps a specific type of memory (i.e., learning of new verbal information). Second, another weakness of the present study is that for technical reasons, scales and tasks were given in a fixed order and 
this may have introduced carry-over effects. Finally and most importantly, in our study, people with low SSMQ scores might not necessarily suffer from a full-blown memory distrust syndrome. It may be that some participants with pessimistic views about their own memory suffered from trait memory distrust. However, this may not be true for the large majority of participants scoring low on the SSMQ. Furthermore, in Gudjonsson's forensic cases, memory distrust is described as a confusional state. As the SSMQ taps a quality that is more trait than state by nature, our results can not be easily generalised to memory distrust cases. Therefore, future studies should look at whether individuals suffering from state memory distrust are prone to create false memories and have high suggestibility levels. It would be interesting to examine how memory distrust is related to other types of tasks, notably tasks in which external pressure is high. An example is the computer crash paradigm (Horselenberg et al., 2003; Horselenberg et al., 2006; Kassin \& Kiechel, 1996). In this paradigm, innocent participants are accused of being responsible for a computer crash. The question rises whether people with negative opinions about their own memory would be more ready to confess than those with favourable opinions about their memory.

For the forensic setting, our results imply that people who have optimistic ideas about their memory generally show better memory performance and lower compliance scores than those with pessimistic views. However, these correlations are modest. Furthermore, people with optimistic beliefs about their memory are not less susceptible to suggestions and false recollections than people with pessimistic beliefs about their own memory. Therefore, one should not regard their testimonies as more reliable. 



\section{CHAPTER 4 \\ MEMORY DISTRUST and MISINFORMATION}

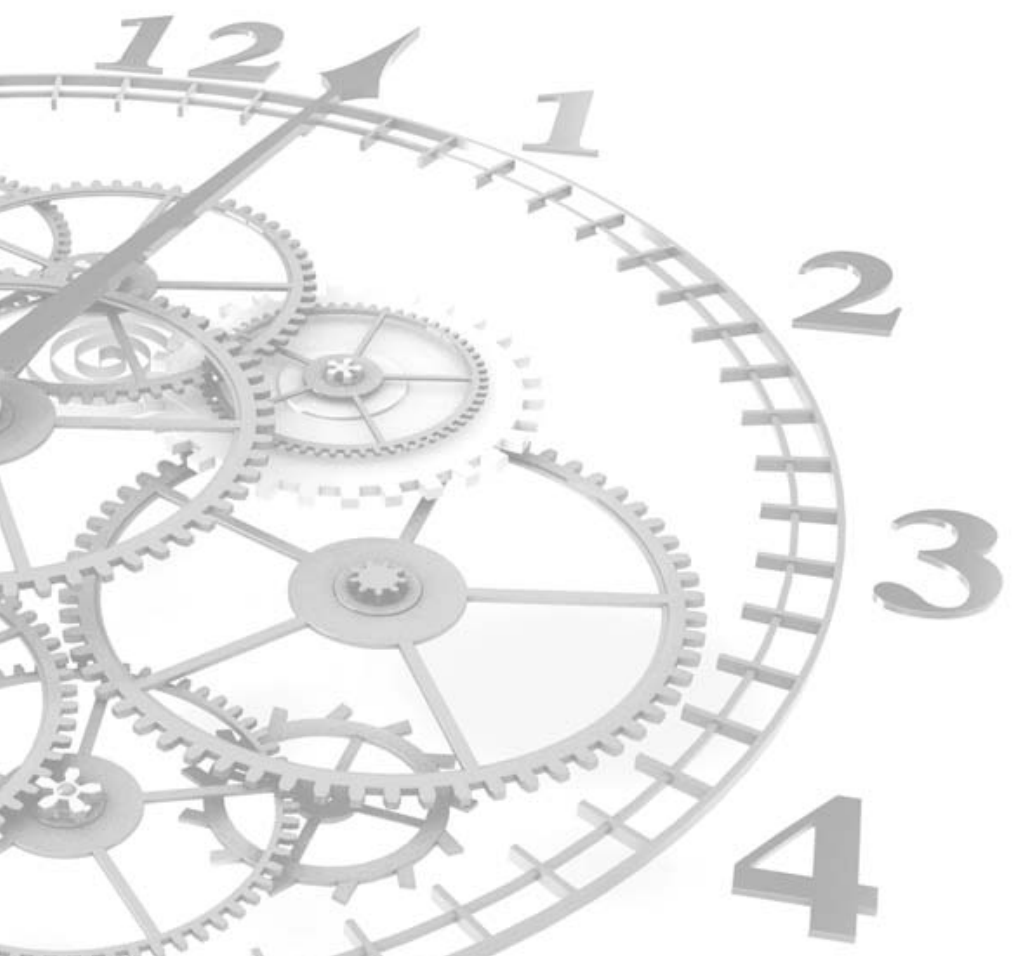

Van Bergen, S., Horselenberg, R., Merckelbach, H., Jelicic, M., \& Beckers, R. (2010). Memory distrust and acceptance of misinformation. Applied Cognitive Psychology, 24, 855-896. 


\begin{abstract}
Relying on a community sample $(N=80)$, the present study examined whether memory distrust is related to an increased tendency to accept misinformation and whether it interacts with the passage of time. Participants were shown video footage of an armed robbery. Approximately 30 min later, they were asked to describe as accurately as possible what they had seen. Either 1 day or 2 weeks later they were presented with their own statements, to which five misinformation items had been added. The results showed that people suffering from memory distrust accepted more misinformation than those with optimistic beliefs about their memory. In addition, both age and free recall seemed to modulate this relationship. However, memory evaluation did not interact with time interval.
\end{abstract}

\title{
Introduction
}

Eyewitness testimony is of crucial importance to the legal system. Judges and juries often heavily rely on such testimony when deciding on a case, even though they know that eyewitness evidence may not be accurate (Doyle, 2005). Indeed, a substantial number of studies has shown that people's memories can easily be distorted when incorrect post-event information or feedback is presented (e.g., Wade, Garry, Read, \& Lindsay, 2002; Wright, Loftus, \& Hall, 2001). Post-event information can be given through leading questions (e.g., during police interrogations), through statements made by authorities (e.g., in the media), or through co-witnesses (Morris, Laney, Bernstein, \& Loftus, 2006).

Exposure to misleading post-event information may affect people's memory reports in either of two ways. First, people may have failed to attend to the event and, therefore, may have poor memories. As a result, they are unable to come up with contradictory arguments when they are exposed to misinformation, making them vulnerable to incorporate the misinformation (Loftus, 2005). Second, post-event information might suggest a more accurate or complete version of the event than one's own memory, resulting in an increased willingness to accept the misinformation (Sutherland $\delta$ Hayne, 2001). There is some debate about how post-event misinformation affects the original memory: whether the original information is completely and permanently lost (Loftus, 2005; Loftus $\&$ Palmer, 1974) or is retained, but has become (partly) inaccessible (McCloskey \& Zaragoza, 1985).

Either way, exposure to misinformation may lead people to incorporate incorrect information into their memories (Sutherland $\delta$ Hayne, 2001). These incorrect elements are often endorsed with high levels of confidence 
(Loftus, 2005). Moreover, recent research has shown that once an inaccurate memory has been formed on the basis of misleading post-event information, it remains stable across time (Devilly, Varker, Hansen, \& Gist, 2007; but see Huffman, Crossman, \& Ceci, 1997). The relevance of the misinformation effect to the legal domain is almost self-evident: it may distort eyewitness testimony, such that it could potentially lead to wrongful convictions (Doyle, 2005).

Many situational factors modulate the misinformation effect (see e.g., Sutherland \& Hayne, 2001). A case in point is the passage of time. Research has shown that people are more susceptible to misinformation when time has had the chance to weaken the memory trace (Loftus, 2005). Thus, the longer the interval between the original event and exposure to post-event misinformation, the higher the probability that misinformation will be incorporated into memory. Another important factor is the way misinformation is presented. Within a social context (e.g., conversation) people are more likely to accept misinformation than when confronted with written statements (Gabbert, Memon, Allan, \& Wright, 2004). Protocol presentation also affects misinformation detection. It appears that misinformation is detected more often when eyewitnesses read their own statements after the interview than when the statements were read out loud by a police officer (Christianson, Engelberg, \& Gustafson, 2007).

Besides situational factors, individual differences appear to influence the misinformation effect. For example, younger children are more susceptible to misinformation than older children and adults (Bruck \& Ceci, 1999; Otgaar, Candel, Merckelbach, $\&$ Wade, 2009). Also, gender seems to play a role with women being more likely to accept and incorporate misinformation than men (Tomes \& Katz, 1997). Furthermore, high scores on personality characteristics such as empathy, imagery ability, dissociation, and introversion have been found to predict a larger misinformation effect (Loftus, 2005; Ward \& Loftus, 1985).

A less researched characteristic that may be relevant in this context is memory distrust (Gudjonsson \& MacKeith, 1982). Gudjonsson (2003) argued that people who distrust their memories tend to rely on external sources and cues. Memory distrust is conceptualised as a phenomenon that is closely related to source amnesia, since people suffering from memory distrust often find it difficult to distinguish between information that is internally generated and information that is externally suggested (Gudjonsson et al., 1999). According to Gudjonsson (2003), memory distrust may result from memory problems during encoding and consolidation or from police interrogations in which confidence in one's memory is undermined. Another distinction is that between state memory distrust and trait memory distrust (Van Bergen, Jelicic, \& Merckelbach, 2008). State memory distrust 
refers to a particular situation in which one experiences a lack of trust in one's memory as a result of, for example, interrogative stress and health problems. People with trait memory distrust, on the other hand, show a stable tendency to distrust their memory (Van Bergen et al., 2009). This latter type of memory distrust is not uncommon in the general population with at least 10 percent of various age groups showing pessimistic memory evaluations (Crombag et al., 2000).

In legal settings, eyewitnesses who distrust their own memories (i.e., who lack confidence in their memories) are often treated as less credible than people who present their eyewitness accounts in a confident manner (Gudjonsson \& MacKeith, 1982). This practice is contradicted by extensive research showing that there is no clear-cut relationship between memory confidence and accuracy (e.g., Brewer, 2006; but see Odinot $\&$ Wolters, 2006). Meanwhile, it is not clear whether eyewitnesses who suffer from memory distrust are more vulnerable to developing memory distortions when confronted with post-event information (e.g., during police interrogations) than those who are confident in their memory.

With these considerations in mind, the present study examined the relationship between subjective memory evaluation and the acceptance of misinformation. In addition, following suggestions made by Christianson et al. (2007), it tested whether memory distrust interacted with the passage of time. During a first session, participants watched a video fragment of an armed robbery. Afterwards, they had to give an account of the event they had witnessed. In a second session that took place either 1 day or 2 weeks after the first session, they had to check the written version of their account to which five misinformation items had been added. We opted for adding items to a statement because in several European countries, including the Netherlands, it is standard practice that the verbal statements are not directly written down. Statements are later interpreted and formulated by the interrogator (Van Koppen, 2007; Van Koppen \& Penrod, 2003). In this way, it is not unlikely that misinformation ends up in written statements.

Following Gudjonsson's line of reasoning (2003), we expected people suffering from memory distrust to accept misinformation more easily than those with high memory confidence, especially after a long time interval (i.e., 2 weeks). A subsidiary aim of the present study was to explore how beliefs about one's memory functioning are related to self-report indices of cognitive failures, compliance, and interrogative suggestibility. We expected that those with pessimistic beliefs about their memory would report more everyday lapses and cognitive blunders and would be more compliant and suggestible (i.e., would be more willing to rely on external sources) than those who are more confident in their own memory. 


\section{Methods}

\section{Participants}

Our sample consisted of 80 adults ( 54 women). Their age varied between 18 and 49 years $(M=33.6 ; S D=9.5)$. Participants were recruited through advertisements in local newspapers, as well as through flyers distributed in a shopping mall and announcements on billboards at Maastricht University. During a telephone interview, they were asked to evaluate their memory functioning and to rate it in terms of a 10-point Likert scale (anchors: $1=$ 'very poor'; $10=$ 'excellent'). Those people who were very confident (i.e., gave subjective evaluations $\geq 7$ ) and those who were doubtful about their memory (i.e., gave subjective evaluations $\leq 4$ ) were selected and assigned to the memory confidence and the memory distrust group, respectively. They were given a small financial compensation for participating. The study was approved by the standing ethical committee of the Faculty of Psychology and Neuroscience, Maastricht University.

\section{Materials}

\section{Video footage}

Participants were presented with 2 min video footage of a simulated armed robbery at a wine shop. Participants were instructed to pay close attention to what happened. The fragment showed a wine shop with some customers and the owner. Suddenly, a man flourishing a gun entered the shop. He ordered the customers to lie down on the floor, while the owner was forced to hand over the money. Finally, the robber fled the store.

\section{Eyewitness accounts}

Immediately after having seen the video fragment, participants were asked to provide a free recall about what they had seen. Their statements were recorded using a digital voice recorder. Subsequently, each free recall was written out verbatim and five misinformation items were added, consisting of altered and new information. These items were selected on the basis of a pilot study, in which six people were asked to give a detailed description of the fragment. From their descriptions, we chose two items that were recalled most often and therefore most plausible to be recalled by our future participants. These altered items were 'the attacker wore a cap' and 'the total number of people was 6'. We replaced the first item by 'the attacker wore a hood' and the second by 'the total number of people was 7'. When participants recalled an incorrect number of people, we added one more person to the number they had mentioned. In some cases, this resulted in changing 
the number of people into the correct number. Note that, also in this case, the correct number of people that was reported should have been detected, as it differed from the number originally mentioned by the participant. The other three misinformation items added completely new elements because they were not part of the fragment and were never mentioned by any of the pilot participants. These items were 'the robber nearly fell', 'the robber put the plastic bag containing the money in his pocket', and 'the robber held the customers continuously at gunpoint'. Corresponding with the procedure by Christianson et al. (2007), and because the altered and new items correlated highly $(r=.53, p<.05)$, they were collapsed into a single variable (i.e., misinformation detection), ranging from 0 to 5 . The written eyewitness account was designed in such way that it looked like an official police document.

\section{Free recall scoring}

To score free recall, we used a procedure that was similar to that of Smeets, Candel, and Merckelbach (2004). During the pilot study, the video footage was shown to six people. They were instructed to give a detailed description. The items that were mentioned by at least four people were added to a scoring list. The final list consisted of 20 critical details of the video fragment. Free recall was scored by summing the number of list items mentioned by the participant, ranging from 0 to 20 .

\section{Questionnaires and tests}

We administered five tests to the participants. The first was the Dutch version of the Squire Subjective Memory Questionnaire (SSMQ; Squire et al., 1979; Van Bergen, 2008; Van Bergen et al., 2010a; Cronbach's $\alpha=.96$ ). This is a self-report scale consisting of 18 items tapping subjective evaluations of one's own memory. Items are scored on a 9-point Likert scale $(-4=$ disastrous; $+4=$ perfect $)$. Sample items are 'My ability to remember things that have happened more than a year ago is' and 'My ability to recall things when I really try is'. Scores are summed to obtain an SSMQ total score varying from -72 to +72 , with negative scores corresponding with pessimistic judgements about one's own memory and positive scores reflecting optimistic memory evaluations.

The second questionnaire was the Dutch version of the Cognitive Failures Questionnaire (CFQ; Broadbent et al., 1982; Merckelbach et al., 1996; Cronbach's $\alpha=.92)$. The CFQ is a self-report scale that taps failures in everyday actions, perception and attention, and memory over the last month. It consists of 25 items that are scored on a 5-point Likert scale (anchors: $0=$ 'never'; 4 = 'very often'). Illustrative items are 'Do you fail to notice signposts on the road?' and 'Do you forget where you put something like a newspaper or a book?' Scores were summed to obtain a CFQ total score 
varying from 0 to 100 , with higher scores indicating more self-reported cognitive failures.

The third questionnaire was the Dutch version of the Gudjonsson Compliance Scale (GCS; Gudjonsson, 1989; Smeets, 2008; Cronbach's $\alpha=.81$ ). This self-report instrument measures people's levels of compliance. It focuses on two types of behaviour, namely eagerness to please others, and avoidance of conflicts. The scale consists of 20 items using a true-false format. Examples are 'I give in easily to people when I am pressured' and 'I try hard to do what is expected of me'. After recoding items 17 to 19, a GCS total score varying from 0 to 20 can be obtained by summing the number of true responses, with higher scores indexing more compliant behaviour.

To measure interrogative suggestibility, the participants were given the Gudjonsson Suggestibility Scale (GSS; Gudjonsson, 1997; Merckelbach et al., 1998). The GSS consists of a story that is read out loud by the experimenter. Participants have to answer 20 questions of which 15 are misleading and 5 are neutral and address factual details of the story. After participants have answered the questions, they receive negative feedback about their performance. They are asked to answer the questions one more time and to be more accurate this time. Thus, all questions are answered twice and in this way several GSS parameters can be calculated. First, Yieldl refers to the number of misleading questions that the participant accepts during the first round (range $=0-15)$. Second, Yield2 refers to the number of misleading questions accepted during the second round (range $=0-15$ ). Third, Shift refers to the number of changes that participants make in their answers after having received negative feedback (range $=0-20$ ). Finally, the GSS total score is the sum of Yieldl and Shift, with higher scores reflecting higher levels of interrogative suggestibility ( range $=0-35$ ).

The fifth test was the Dutch version of the National Adult Reading Test (NART; Nelson, 1982; Schmand, Lindeboom, \& Van Harskamp, 1992), that gives an estimate of verbal intelligence (correlation with Wechsler Adult Intelligence Scale ranging from .74 to .85 among healthy controls; Bright, Jaldow, \& Kopelman, 2002; Schmand et al., 1992). The NART consists of 50 irregularly spelled words that have to be pronounced. An example item is the word 'enzyme'. Words can either be pronounced correctly (score $=2$ ), spuriously (score $=1)$, or incorrectly $($ score $=0)$. Scores are summed to obtain a NART score varying from 0 to 100 . This score is then transformed into an IQ score, with a higher score reflecting a higher IQ.

\section{Design and Procedure}

Testing occurred in two sessions: either 1 day or 2 weeks after the participants had seen the video of the robbery. More specifically, half of the mem- 
ory distrust group $(n=20)$ and half of the memory confidence group $(n=$ 20) were asked to return to the lab 1 day after the first session. The other participants $(n=40)$ were asked to return after 2 weeks. Thus, our design was basically a 2 (memory group: memory distrust vs. memory confidence) x 2 (time interval: 1 day vs. 2 weeks) between-subjects set-up.

During the first session, participants were asked to give informed consent. Subsequently, the video footage was presented to them. Next, participants were asked to complete the SSMQ, CFQ, GCS, and NART, as well as some filler tasks. The order in which the tests were given was counterbalanced across participants. Approximately $30 \mathrm{~min}$ after they had seen the video footage, participants were asked to recall everything they could remember. After the first session, the recorded free recall was written out by the experimenter. During the second session, participants were confronted with their written accounts. We chose to present their accounts in this way since written statements play an important role in the legal system. Moreover, research has shown that people are more easily misled when postevent information is presented in a written form (Itsukushima, Nishi, Maruyama, \& Takahashi, 2006). We asked participants to check their testimony carefully. The experimenter stressed that the statements had to be correct. In case participants had doubts about some of the statements, they were instructed to underline these sentences so that these could be discussed later. Participants were asked to sign the testimony if they approved with its content. ${ }^{6}$ Finally, participants had to complete some filler tasks and the GSS.

\section{Results}

\section{Demographic Data and Tests}

Table 4.1 shows demographic data and mean scores on self-report tests of the two memory groups. The memory distrust group was significantly older than the memory confidence group $[t(78)=5.51, p<.05]$. There were no gender differences between the memory groups. As expected, the memory distrust group had significantly lower scores on the SSMQ than the memory confidence group $[t(77)=11.95, p<.05] .{ }^{7}$ By the same token, participants distrusting their memory scored significantly higher on the CFQ than participants who were very confident in their memory $[t(75)=6.72, p<.05]$.

\footnotetext{
${ }^{6}$ Of the 80 participants, 31 participants signed the testimony. Despite the instruction, this group of 31 individuals consisted of both participants who detected misinformation and/or rejected accurate information and participants who did not.

${ }^{7}$ The degrees of freedom vary due to missing values.
} 
Regarding the GCS and the GSS total score, no significant group differences were found $[t(74)=1.45, p=.15$ and $t(78)=1.23, p=.22$, respectively]. Neither were there group differences for any of the GSS subscales (i.e., Yield1, Yield2, Shift; all $p$ ns). Furthermore, both memory groups differed in IQ scores $[t(77)=2.24, p<.05]$, with the memory confidence group outperforming the memory distrust group on the NART. Finally, participants suffering from memory distrust had poorer free recall (i.e., objective memory performance) than participants who were very confident in their memory $[t(78)=2.29, p<.05]$.

\section{Table 4.1}

Demographic Data and Mean Total Scores on Self-Report Tests of the Two Memory Groups (Standard Deviations are presented in Parentheses)

\begin{tabular}{|l|c|c|}
\hline Demographic data/tests & Memory distrust & Memory confidence \\
\hline Gender & 13 male/27 female & 13 male/27 female \\
\hline Age & $38.55(7.87)$ & $28.60(8.27)$ \\
\hline SSMQ & $-8.32(17.31)$ & $34.46(14.33)$ \\
\hline CFQ & $49.10(12.53)$ & $31.13(10.86)$ \\
\hline GCS & $10.84(4.08)$ & $9.38(4.63)$ \\
\hline GSS (total score) & $8.13(4.09)$ & $7.05(3.70)$ \\
\hline IQ (based on NART) & $100.70(7.81)$ & $104.26(6.16)$ \\
\hline Free recall & $9.45(2.79)$ & $10.94(3.01)$ \\
\hline
\end{tabular}

\section{Misinformation Detection}

Figure 4.1 shows the extent to which the two groups detected misinformation at the two time delays. A two-way Analysis of Variance (ANOVA) revealed a non-significant interaction effect of memory group and time interval $(p=.31)$. After removing the interaction term, two significant main effects were found. People suffering from memory distrust detected significantly less misinformation than people who were confident in their memory $\left[F(1,77)=5.15, p<.05, \eta_{p}^{2}=.06\right]$. Furthermore, participants who were tested after 1 day detected more misinformation than those who were tested after 2 weeks $\left[F(1,77)=14.31, p<.05, \eta_{p}^{2}=.16\right]$. 


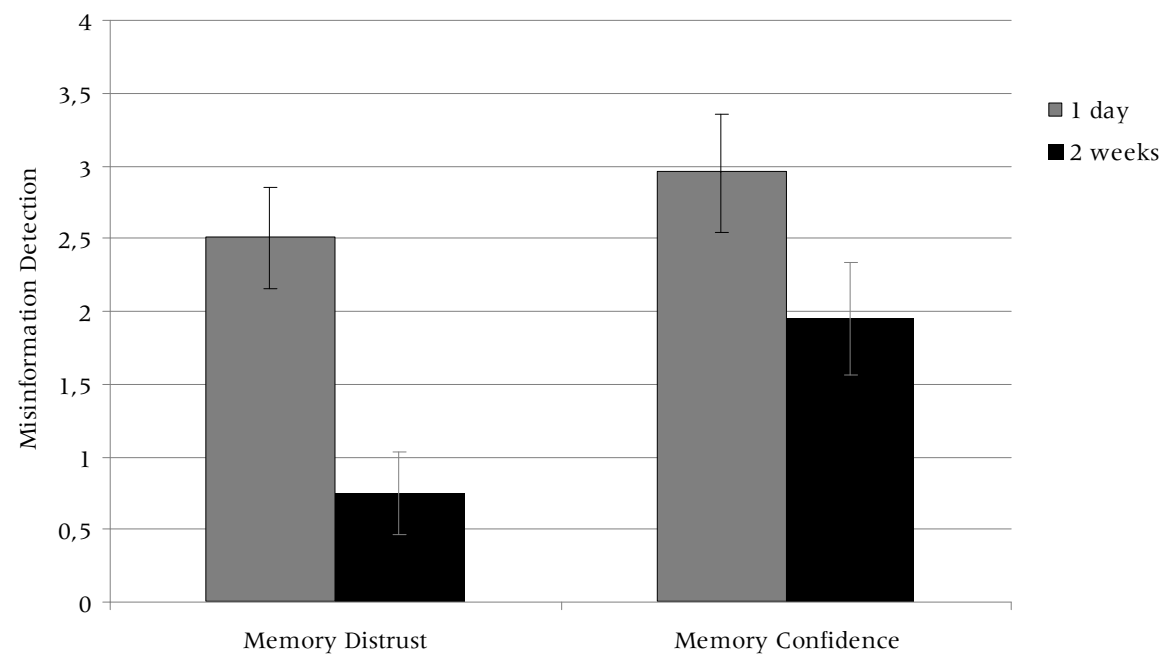

Figure 4.1. Average amount of misinformation detection of the memory groups (i.e., memory distrust and memory confidence) at the two time intervals (i.e., 1 day and 2 weeks).

\section{Covariates}

A close examination of the correlation matrix showed that misinformation detection correlated significantly with age $(r=-.26, p<.05)$ and free recall $(r$ $=.22, p=.05)$. As these factors might have confounded the obtained results, Analysis of Covariance (ANCOVA) was conducted. After removing the nonsignificant interaction term between memory group and time interval, both age and free recall failed to reach significance $(p=.27$ and $p=.28$, respectively). However, it should be noted that due to the inclusion of age and free recall, the main effect of memory group disappeared $[F(1,75)=1.13, p=$ .29]. The main effect of time interval was not affected by the inclusion of the covariates and remained significant $[F(1,75)=14.19, p<.05]$.

\section{Rejected Accurate Information}

We also performed an ANOVA on the number of items that participants indicated to be incorrect, when in fact they were correct (i.e., rejected accurate information). The two-way ANOVA showed no significant interaction effect between memory and time $(p=.26)$ and this interaction was therefore removed from the model. The main effect of memory group was significant $\left[F(1,77)=4.81, p<.05, \eta_{p}{ }^{2}=.06\right]$. The participants who were confident in their memory more often rejected correct items $(M=.90, S D=1.74$, range $=$ 
$0-7)$ than those suffering from memory distrust $(M=.28, S D=.55$, range $=$ $0-2) .{ }^{8}$ The main effect of time interval failed to reach significance $[F(1,77)=$ $2.78, p=.10] .^{9}$

\section{Discussion}

Our findings can be summarised as follows. First, participants who suffer from memory distrust accept more misinformation than those who report to be confident in their memory. Second, this effect does not become stronger over time (i.e., no memory group x time interaction). Third, a longer time interval between sessions promotes acceptance of misinformation. Fourth, age and free recall performance seem to modulate the relationship between memory group and misinformation acceptance. Fifth, people who are confident in their memory more frequently reject accurate information than people who distrust their memory.

That our recruitment procedure was successful is shown by the fact that the memory distrust group reported more negative subjective memory evaluations (indexed by the SSMQ) and more cognitive failures (indexed by the $\mathrm{CFQ}$ ) than the memory confidence group. Furthermore, the two groups differed with regard to the proxy measure of IQ (i.e., NART) and free recall performance, an issue to which we will return.

The finding that people who believe to have poor memory abilities show more difficulty to detect misinformation corresponds well with our first hypothesis. Apparently, people who distrust their memory more readily rely on external cues and suggestions, as has been proposed by Gudjonsson (2003). Consequently, they run a risk of incorporating misinformation into their memory. Conversely, confidence in one's own memory is associated with less misinformation incorporation probably because it does not go along with an increased sensitivity to external cues. Note also that there is a fundamental integrity to memory confidence evaluations. That is, those who distrusted their memory exhibited poorer free recall performance than those who were

\footnotetext{
${ }^{8}$ These data contain outliers. However, they were included because they reveal relevant information. Note that after excluding these outliers the main effect of memory group remains significant, means being $.00(S D=.00)$ for the memory distrust group (i.e., they did not reject any accurate information) and $.39(S D=.60$; range $=0-2)$ for the memory confidence group $\left[F(1,64)=12.87, p<.05, \eta_{p}^{2}=.17\right]$.

${ }^{9}$ Performing an ANCOVA on these data showed the same results as for misinformation detection. More specifically, the covariates age and free recall were both non-significant ( $p=.81$ and $p=.69$ ). Therefore, they were removed from the model. Note that including the covariates in the model affected the main effect of memory group (which disappeared), but not that of time interval (which remained non-significant).
} 
confident in their memory. Overall, our findings are in line with a recent study by Van Bergen and colleagues (2009) showing that subjective memory evaluation is positively related with objective memory performance.

We anticipated that the memory distrust group's tendency to accept misinformation would increase with the passage of time, but this interaction was not borne out by the data. It would be premature though to conclude that memory distrust and the passage of time are independently operating factors. The reason is that a ceiling effect at the two-week session (i.e., many participants accepting the misinformation elements) might have overruled an interaction effect. Thus, this issue warrants further study, probably with a measure of misinformation that allows for more variability.

Indeed, we found that, after a relatively long time interval, the chance to detect discrepancies between authentic memory representations and misinformation decreases. This effect holds true both for people who are confident in their memory and those who distrust their memory. The effect size associated with this main effect of time was relatively large. Misinformation will be incorporated more easily when time passes by, because after a while it makes the impression of providing a more complete version of what has happened than one's own recollections (Lee, 2004).

While neither age nor free-recall was a significant covariate, together they seemed to be relevant, since their inclusion in the model resulted in the disappearance of a significant main effect of memory group. Why this occurred becomes more comprehensible when looking at the zero-order correlations between subjective memory evaluation and age $(r=-.53, p<.05)$, between memory evaluation and free recall $(r=.25, p<.05)$, and between age and free recall $(r=-.40, p<.05)$. That older people more frequently distrust their memory has been reported a number of times (Commissaris et al., 1998; Ponds \& Jolles, 1996; Ponds et al., 2000). We do not think that age has a direct influence on the acceptance of misinformation in memory. Rather, it seems that when people grow older, some of them will start to attribute memory difficulties to internal (organic) factors, rather than blaming such problems on external (situational) factors (Commissaris et al., 1998). As a result, memory distrust is more frequent in older than in younger people, even though our group of participants suffering from memory distrust is still considerably younger than the samples described in the above mentioned studies.

The fact that free recall together with age moderates the relationship between memory group and acceptance of misinformation is interesting. According to the discrepancy detection principle (Schooler $\&$ Loftus, 1993; Tousignant, Hall, \& Loftus, 1986), having detailed and accurate memories about an event allows people to detect discrepancies between the original event and misinformation that is provided about that event. So, poor free 
recall performance will on the one hand, fuel one's negative memory evaluations (see also: Van Bergen et al., 2010a; Van Bergen et al., 2009), and on the other hand, it will make one vulnerable to accepting misinformation.

This study also looked at the rejection of accurate information. Interestingly, participants with memory distrust less often rejected accurate information than participants who were confident in their own memory. At first sight, this seems to contradict the pattern that we found for the detection of misinformation. Thus, while participants were less correct when it came to accepting misinformation, they were more accurate in rejecting accurate information, relative to the memory confidence group. An obvious explanation for this is that our participants were confronted with an external source claiming to reflect their written statements. Compared to the memory confidence group, memory distrust individuals were less likely to express doubts about their statements, whether these were true or false. As scores on the self-report tests show, this difference is unlikely to be a product of group differences in compliance or interrogative suggestibility. As a matter of fact, participants suffering from memory distrust did not have higher scores on the GCS and the GSS than memory confidence participants. Previous studies have shown that the relationship between subjective memory evaluations and memory accuracy is a complex one (e.g., Odinot $\delta$ Wolters, 2006; Sporer, Penrod, Read, \& Cutler, 1995). Our finding that memory distrust is accompanied by both heightened levels of misinformation acceptance and lowered levels of incorrect rejections further underlines this point. To put this finding into perspective, note that the highest average amount of rejected accurate information (i.e., in the memory confidence group) was still lower than 1. Furthermore, both in the memory distrust group and memory confidence group the majority of participants did not reject any accurate information $(77.5 \%$ vs. $60 \%$, respectively).

There is reason to believe that levels of misinformation acceptance might be even higher if misinformation had been introduced in a more social way, for example during a conversation with a confederate (Gabbert et al., 2004). We anticipate that the increase of the effect would be higher in the memory distrust group since people suffering from memory distrust are more prone to rely on suggestions by others (Gudjonsson, 2003).

The limitations of the present study deserve some comment. First, an ad hoc criterion was adopted to recruit participants for one of the two memory groups. In future research, it might be of interest to use multiple criteria and to select more extreme groups. Second, there was a significant age difference between both memory groups. Therefore, future studies on memory distrust and misinformation should match for age. In doing so, they will be able to avoid that age becomes a difficult covariate to interpret, as was the case in the present study. Finally, the current study was correlational by nature and 
so it remains to be seen whether poor free recall performance is the principle driver of memory distrust and heightened levels of misinformation acceptance. A closer look at participants' memory functioning would therefore be useful in future studies. Studies in which this causal interpretation can be directly tested would further increase our understanding.

As eyewitness testimonies bear strong relevance to forensic settings, it is important to examine factors that might affect their reliability. Since eyewitnesses who distrust their memory are often considered to be more susceptible to memory distortions, they will be treated as less credible than people without memory complaints (Gudjonsson \& MacKeith, 1982). The present study shows that there is some wisdom to this because people suffering from memory distrust are indeed more vulnerable to misinformation than those who are very confident in their memory. The most important implication of our study, however, is that eyewitnesses or suspects suffering from memory distrust should be interviewed or interrogated in a prudent way. 



\section{CHAPTER 5 MEMORY DISTRUST and INTERROGATION TECHNIQUES}

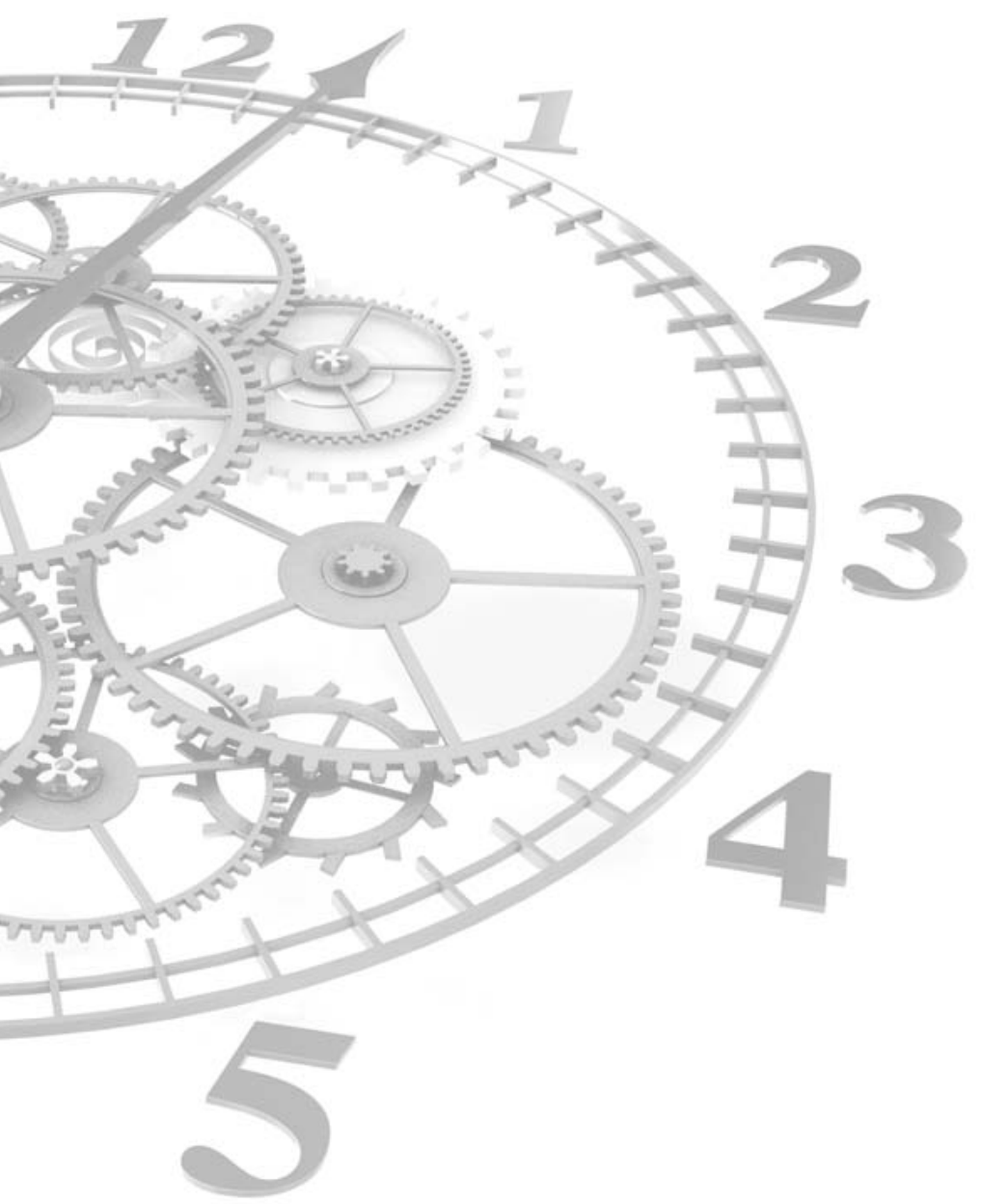

Van Bergen, S., Jelicic, M., \& Merckelbach, H. (2008). Interrogation techniques and memory distrust. Psychology, Crime \& Law, 14, 425-434. 


\begin{abstract}
Extensive research has shown that certain interrogation techniques may lead to false confessions. Gudjonsson and MacKeith (1982) argued that the memory distrust syndrome could underlie some of these false confessions. In the current study, we examined the relation between memory distrust, false confessions, and several interrogation techniques, by accusing innocent undergraduate students $(N=50)$ of exam fraud. To this end, we used five interrogation techniques, namely providing false technical evidence, providing false eyewitness evidence, minimising, maximising, and suggesting memory problems. We found that suggesting memory problems had the largest impact on memory distrust. Furthermore, it appeared that people were most willing to confess when false technical evidence was provided. Although we found that in all interrogation techniques, memory distrust scores correlated highly with false confession scores, they did not have a uniform effect. Several explanations for, and implications of these findings, are discussed.
\end{abstract}

\title{
Introduction
}

Police interrogations often consist of a variety of interrogation techniques. In worst case scenarios, suspects are exposed to suggestive questions, false evidence, and several other ploys. A well-known procedure in the interrogation literature is the Reid technique (Inbau, Reid, Buckley, \& Jayne, 2001). This technique consists of nine steps, which all aim at obtaining a confession from the suspect. The main objection to this technique is the high level of pressure that suspects are exposed to, sometimes giving room to false confessions (Gudjonsson, 2001). To protect the interrogated individual, the Reid technique is prohibited in several European countries (Vrij, 1998). However, some of these techniques and many others, that can be harmful to the suspect too, are still found in the interrogation room (Pearse \& Gudjonsson, 1999).

In some of these techniques false evidence is presented to the suspect (Leo, 1996). This may vary from footage of non-existing cameras, false testimonies of eyewitnesses, to non-existent fingerprints found at the crime scene. Although prohibited in several countries, using false evidence is quite powerful in evoking false confessions. Other techniques basically consist of active persuasion. For example, interrogators may communicate absolute certainty that a suspect is guilty (Henkel $\delta$ Coffman, 2004). In this way, suspects come to believe that denying their involvement in the crime is pointless and tend to confess. In another example of maximisation, the consequences of the crime are exaggerated by the interrogator (Hartwig, Gran- 
hag, \& Vrij, 2005; Kassin \& McNall, 1991). This often results in strong feelings of guilt in suspects. Minimisation, on the other hand, intends to reduce the responsibility of the suspect. As a result, suspects may trivialise the crime and will more easily confess to the crime (Hartwig et al., 2005; Kassin $\delta$ McNall, 1991). Another way of manipulating suspects, is undermining their confidence in their memories (Henkel \& Coffman, 2004). Of course, the techniques mentioned above are just a minority of all the interrogation techniques that are used by the police.

Extensive research has shown that false confessions resulting from questionable interrogations are a common phenomenon (e.g., Kassin 8 Gudjonsson, 2004; Kassin \& Kiechel, 1996). These false confessions can be divided into three different types: voluntary false confessions, coerced-compliant false confessions, and coerced-internalised false confessions (Kassin $\delta$ Wrightsman, 1985). Voluntary false confessions occur without any external pressure from the police and the motives behind them have to do with, for example, the suspect's desire for notoriety. Coerced-compliant and coercedinternalised false confessions, on the other hand, result from interrogative pressure. In cases of coerced-compliant false confessions, suspects remain convinced of their innocence, despite their confessions. Their confessions can best be seen as an attempt to escape from the interrogation situation or to avoid being locked up in police custody. In cases of coerced-internalised false confessions, individuals come to believe that they have committed the crime. They hold on to their confession even though they lack crime-related knowledge (Gudjonsson, 2003).

Gudjonsson and MacKeith (1982) argue that the memory distrust syndrome could underlie this last category of false confessions. This syndrome can be defined as "a condition where people develop profound distrust of their memory recollections, as a result of which they are particularly susceptible to relying on external cues and suggestions" (Gudjonsson, 2003, p. 196). The memory distrust syndrome is associated with two different conditions: a) memory problems related to faulty encoding or consolidation during the criminal events (e.g., due to drug or alcohol use); b) manipulation and undermining of the suspect's confidence in his memory during police interrogations (Gudjonsson, 2003). This chapter only deals with the latter condition, as the confidence of participants was also challenged by the interrogation techniques that were used in the current experiment.

Gudjonsson has described several cases of false confessions in which memory distrust seems to play a crucial role (Gudjonsson, 2003). Typically, suspects' statements in these cases develop from "I have not committed this crime" to "I do not know if I did this", and "I could have done this", into "I must have done it" (e.g., Gudjonsson et al., 1999, p. 456). Case studies on memory distrust and false confessions can be taken to imply that memory 
distrust is a state-like characteristic, which is usually temporary and results from a disturbed thinking process (Gudjonsson, 2003).

In the present study, we wanted to explore to what extent memory confidence of healthy and intelligent young people can be undermined by interrogation techniques that are suspected of evoking false confessions. Therefore, we selected interrogation techniques that we expected to be most promising in creating memory distrust. Furthermore, we were interested in the relation between memory confidence and the tendency to confess. On the basis of cases described by Gudjonsson (e.g., Gudjonsson et al., 1999), it was expected that memory distrust and tendency to falsely confess would co-occur. To increase the ecological validity of the experiment, we chose for a setting in which undergraduate students were accused of exam fraud.

\section{Methods}

\section{Participants}

Our sample consisted of 50 undergraduate psychology students (36 women) of Maastricht University. Their mean age was 20.04 years $(S D=1.41$; range $=18-24)$. The participants were naive as to the real purpose of the experiment. They were told that they had to perform a series of cognitive tasks and complete several questionnaires. The session lasted for one hour. They were compensated with research credits for participating in our study. The research was approved by the standing ethical committee of the Faculty of Psychology and Neuroscience, Maastricht University.

\section{Procedure}

The experiment took place in a small laboratory room which was designed to resemble an interrogation room. Upon arrival, participants signed informed consent. Following this, they had to organise two files of forensic cases that were deliberately mixed up. We told them that we were interested in how accurate and fast they would be able to do this. While participants were busy with this task, a paper with the upcoming exam of the current curriculum module was left on their table and the experimenter left the room.

After approximately $5 \mathrm{~min}$, the experimenter returned in distress, searched for the exam paper and when found, left the room again, but did not close the door entirely. In this way, the participant was able to hear a conversation in which the experimenter told another person, who was waiting in the corridor, that the participant may have looked into the exam. 
When returning to the room again, the experimenter still appeared distressed. After the participants had organised the files, they were given a paper that stated: 'From this moment on you are suspected of exam fraud. Imagine that you are seated in an interrogation room. You will be given descriptions of a couple of situations and I would like to ask you to put real effort in imagining those situations. You are suspected of looking into the exam of the current curriculum module. This is a violation according to the Rules and Regulations of the Act on Higher Education and Research. Try to imagine the given situation as clearly as possible, before answering the questions'.

After reading this instruction, the participants were confronted with five different interrogation situations. In between these interrogation situations they completed several questionnaires that served as fillers. The interrogation situations and questionnaires were counterbalanced across participants.

A hidden camera was used to check whether the participants had looked in the exam paper. The footage showed that all participants were innocent of committing exam fraud.

\section{Instruments}

\section{Interrogation techniques}

We selected those techniques described by Henkel and Coffman (2004) that might bear relevance to memory distrust.

One of the interrogation descriptions included false technical evidence. It was stated that a camera had recorded the person skipping through the test: 'A hidden camera in this room registered that you grabbed the exam and looked into it'. Another interrogation description involved a false eyewitness testimony, which read as followed: 'Fred Dragstra, one of the assistants, just walked by and looked into the room. He saw you looking into the exam'. A third strategy aimed at minimising the offence: 'I can imagine why you have looked into this exam. I probably would have done the same, if it would be lying here on this table. Any person would have done that. And naturally, you want to have a good grade for your next exam'. A fourth situation was based on the maximising strategy: 'The problem is that you might share its content with other students. The course coordinator is therefore obliged to make a completely new exam. The course coordinator is, however, not able to do this, as his wife just gave birth to a baby with a heart defect'. A fifth interrogation description suggested memory problems and read as follows: 'It happens quite regularly that healthy people cannot remember certain actions. This usually happens in case of an automatic action. It is very plausible that this also applies to you and that you, automatically but unconsciously, looked at that exam, so that you cannot vividly remember it anymore'. 
All five descriptions were followed by two questions: 'To what extent would you distrust your memory right now?' and 'To what extent would you be willing to confess that you have inspected the exam paper?'. Participants had to answer these questions on 100mm Visual Analogue Scales (VASs; anchors: $0=$ 'not at all'; $100=$ 'totally'). As answering the first question may lead participants to be more inclined to answer the second question in the same way, we presented the questions on separate pages.

\section{Subjective cognitive functioning}

The Dutch version of the Squire Subjective Memory Questionnaire (SSMQ; Squire et al., 1979; Van Bergen, 2008; Van Bergen et al., 2010a; Cronbach's $\alpha=.87)$ was used to measure confidence in memory functioning. This selfreport questionnaire consists of 18 items, which are scored on a 9-point Likert scale (anchors: $-4=$ 'disastrous'; $+4=$ 'perfect'). Sample items are 'My ability to recall things when I really try is' and 'My ability to remember things that have happened more than a year ago is'. Scores were summed to obtain an SSMQ total score varying from -72 to +72 , with negative scores indicating memory distrust. This questionnaire was part of a survey which was performed several weeks before the experiment.

As another index of subjective memory functioning, we administered the Dutch version of the Cognitive Failures Questionnaire (CFQ; Broadbent et al., 1982; Merckelbach et al., 1996; Cronbach's $\alpha=.84)$. The CFQ consists of 25 items, which measure self-report frequency of everyday failures in memory, perception/attention, and action. Illustrative items are 'Do you forget where you put something like a newspaper or a book?', 'Do you fail to notice signposts on the road?', and 'Do you drop things?'. Participants are asked to indicate on a 5-point Likert scale how often they have experienced each cognitive failure during the past months (anchors: $0=$ 'never'; $4=$ 'very often'). Scores are summed to obtain a CFQ total score, with higher scores reflecting more self-reported cognitive failures.

\section{Attribution style}

The Attribution Style Questionnaire (ASQ; Peterson et al., 1982; Cronbach's $\alpha=.69$ ) was used to get a better impression of the participants' attribution styles. That is, whether they tend to attribute negative and positive situations either externally or internally. They were given 10 situations. Sample items are 'You run into an acquaintance who compliments you on your looks' and 'You give an important presentation for a group, but the audience reacts negatively'. These items were followed by several questions. We were particularly interested in the answer they gave to the question 'Could this cause be attributed to you or to other people or situations?'. The answers are rated on 7-point Likert scales (anchors: 1 = 'totally attributed to other people and situations'; 7 = 'totally attributed to myself'). Scores are summed with a 
lower score indicating an external attribution style, and a higher score reflecting an internal attribution style.

Other questionnaires

Apart from these questionnaires, we used several other questionnaires that will not be described here because they are theoretically irrelevant to the issue under consideration. These filler questionnaires had two goals: first, to conceal the real purpose of the experiment, and second, to avoid cross-over effects of the interventions.

\section{Results}

\section{Questionnaires}

Table 5.1 shows total scores and standard deviations of participants on the SSMQ, CFQ, and ASQ. In general, mean total scores come close to what has been found in other studies relying on undergraduate samples (Merckelbach et al., 1996; Peterson et al., 1982; Van Bergen et al., 2010a). Table 5.1 also presents Pearson product-moment correlations between these measures. As can be seen, the correlational pattern is in the expected direction. That is, memory confidence (i.e., SSMQ) correlated significantly with cognitive failures (i.e., CFQ). Furthermore, internal attribution (i.e., ASQ) was related to lower levels of subjective confidence in one's own memory functioning (i.e., SSMQ).

All relevant questionnaires were included as covariates in the analyses below. However, they were all non-significant and therefore excluded from the data analyses. Thus in what follows, results of analyses without these covariates are presented.

\section{Table 5.1}

Mean Total Scores and Standard Deviations of Participants' Scores on all Relevant Questionnaires, followed by Pearson Product-Moment Correlation Coefficients

\begin{tabular}{|l|c|c|c|c|}
\hline Questionnaires & $M$ & $S D$ & $C F Q$ & $A S Q$ \\
\hline Squire Subjective Memory Questionnaire & 18.04 & 15.75 & $-.39 *$ & $-.32^{*}$ \\
\hline Cognitive Failures Questionnaire & 39.36 & 10.48 & - & .03 \\
\hline Attribution Style Questionnaire & 45.39 & 6.94 & & - \\
\hline
\end{tabular}

${ }^{*} p<.05$. 


\section{Interrogation Techniques and Memory Distrust}

A repeated measures analysis of variance (ANOVA) showed that there was a significant within-subject difference among interrogation techniques: $F(4,196)=3.05, p<.05$ (see Table 5.2). Bonferroni corrected post-hoc analyses showed that this effect was caused by the difference between the minimising manipulation and the suggesting memory problems manipulation on memory distrust scores $(p<.05, d=.42)$. In other words, minimising evoked significantly lower levels of memory distrust than suggesting memory problems.

To assure that the scores of participants were caused by the interrogation techniques and not by trait memory distrust, we also measured baseline memory distrust in a control group of undergraduates $(N=35)$ who had not participated in the experiment. In other words, they had to estimate the tendency to distrust their memory, imagining a situation in which they were accused of exam fraud while in fact they were innocent. The reason why we opted for undergraduates who did not participate in the study, was to overcome potential crossover effects between baseline ratings and the other ratings of the five interrogation situations during the experiment. The baseline rating was also scored on a $100 \mathrm{~mm}$ VAS. The average of the VAS scores was $7.97(S D=8.56)$. One sample $t$-tests showed that the tendency to distrust your memory in each interrogation situation differed significantly from baseline (all $p s<.05)$.

\section{Table 5.2}

Mean Scores and Standard Deviations of Participants' Tendencies to distrust their Memory for all Interrogation Descriptions, followed by the Number (and Percentage) of Participants scoring above Midpoint

\begin{tabular}{|l|c|c|c|}
\hline Interrogation description & $M$ & $S D$ & Score $>50$ \\
\hline Technical evidence & 26.38 & 32.43 & $13(26 \%)$ \\
\hline Eyewitness testimony & 23.96 & 26.99 & $10(20 \%)$ \\
\hline Minimising & 17.68 & 18.78 & $4(8 \%)$ \\
\hline Maximising & 20.38 & 24.20 & $9(18 \%)$ \\
\hline Suggesting memory problems & 28.14 & 29.95 & $14(28 \%)$ \\
\hline
\end{tabular}

Another way to approach the issue of how interrogation affects memory distrust is to look at the number of participants who rated their memory distrust higher than 50. This refers to the number of participants who scored higher than midpoint on the VAS, and therefore showed a noteworthy increase in memory distrust. Table 5.2 also shows these frequencies. As can be 
seen, in each interrogation situation at least some of the participants tended to distrust their memory (varying from 4 participants in the minimising manipulation to 14 participants in the suggesting memory problems manipulation).

\section{Interrogation Techniques and Confessions}

A repeated measures ANOVA performed on confession ratings yielded also significant differences between interrogation techniques: $F(4,196)=12.47, p$ $<.05$. As can be seen in Table 5.3, the interrogation description that elicited the strongest tendency to falsely confess was the false technical evidence description. Bonferroni corrected post-hoc analyses indicated that this technique differed significantly from all the others. That is, false technical evidence induced higher false confession ratings than false eyewitness testimony $(p<.05, d=.48)$, minimising $(p<.05, d=.66)$, maximising $(p<.05$, $d=.50)$, and suggesting memory problems $(p<.05, d=.88)$.

Again, baseline measurements were performed to assure the impact of the interrogation techniques. The average tendency to confess without any interrogation technique was $6.34(S D=8.30)$. One sample $t$-tests showed that tendency to confess in all interrogation techniques differed significantly from this baseline measurement (all $p s<.05$ )

\section{Table 5.3}

Mean Scores and Standard Deviations of Participants' Tendencies to falsely confess for all Interrogation Descriptions, followed by the Number (and Percentage) of Participants scoring above Midpoint

\begin{tabular}{|l|c|c|c|}
\hline Interrogation description & $M$ & $S D$ & Score $>50$ \\
\hline Technical evidence & 51.16 & 38.49 & $28(56 \%)$ \\
\hline Eyewitness testimony & 34.16 & 31.99 & $18(36 \%)$ \\
\hline Minimising & 28.42 & 30.04 & $12(28 \%)$ \\
\hline Maximising & 33.52 & 31.26 & $17(34 \%)$ \\
\hline Suggesting memory problems & 22.48 & 25.51 & $7(14 \%)$ \\
\hline
\end{tabular}

Table 5.3 also shows the frequency of confession ratings exceeding midpoint (> 50) per interrogation description. This refers to the number of participants who scored higher than midpoint on the VAS, and therefore showed a remarkable tendency to falsely confess. As can be seen in this table, in all interrogation descriptions quite a few participants had a tendency to falsely 
confess. When exposed to false technical evidence, more than half of the people $(56 \%)$ exceeded the midpoint.

\section{Memory Distrust and False Confessions}

Table 5.4 shows $r^{2}$ indices, which represent the amount of variability in false confessions that is explained by memory distrust for each interrogation situation. These indices were obtained by squaring the Pearson's correlation coefficients between memory distrust and false confession tendency. In general, we found that memory distrust scores significantly correlated with false confession scores among all interrogation techniques ( $r$ s varied from .31 to $.54)$, yet the amount of explained variance $\left(r^{2}\right)$ varied from a low $10 \%$ to a high $29 \%$.

\section{Table 5.4}

Explained Variance $\left(r^{2}\right)$ Coefficients between Tendency to Distrust Memory and the Tendency to falsely confess for each Interrogation Technique separately

\begin{tabular}{|l|c|}
\hline Interrogation description & $r^{2}$ \\
\hline Technical evidence & 9.6 \\
\hline Eyewitness testimony & 17.6 \\
\hline Minimising & 29.2 \\
\hline Maximising & 19.4 \\
\hline Suggesting memory problems & 24.0 \\
\hline Note. All $p s<.05$. & \\
\hline
\end{tabular}

\section{Discussion}

It is well documented that a confession is the strongest type of evidence and triers of fact tend to perceive it as ultimate proof of guilt (Kassin $8 \mathrm{Neu}$ mann, 1997; Vrij, 1998). Gudjonsson and MacKeith (1982) argued that people with memory distrust might be more prone to falsely confess. The results of this study show that memory distrust is not always a static, trait-like phenomenon. Rather, under the influence of interrogation techniques, people may vary in their tendency to distrust their memory. We found that suggesting memory problems increases people's tendency to distrust their memory most. Presenting false technical evidence (i.e., camera footage), on the other hand, resulted in the strongest tendency to falsely confess. Thus, interrogation techniques do not have a uniform effect on memory distrust and false 
confessions. Indeed, the relationship between memory distrust and false confession tendencies is far from perfect.

Although confronting suspects with false evidence is prohibited in several countries outside the United States, it is not uncommon (Pearse $\delta$ Gudjonsson, 1999). Even if false evidence is not explicitly mentioned during an interrogation, police officers may insinuate that evidence is available. Furthermore, little is known about the techniques which are used during offthe-record interviews (Vrij, 1998). In accordance with the work by Kassin and Wrightsman (1985), our results show that techniques capitalising on false evidence promote false confessions. People may start to believe that there might be incriminating evidence and therefore tend to confess (Vrij, 1998).

The memory distrust measured in this experiment can be seen as state memory distrust. Table 5.1 shows that the mean SSMQ total score before any manipulation was above midpoint, meaning that our participants did not generally distrust their memory. So they cannot be classified as people with trait memory distrust. Only three individuals scored lower than midpoint on the SSMQ before the experiment. However, as can be seen in Table 5.2, the number of participants that started to distrust their memory after the manipulations was higher. This type of memory distrust is equivalent to memory distrust described in Gudjonsson's cases (Gudjonsson, 2003).

Our results indicate that suggesting memory problems results in the strongest tendency to distrust one's own memory. In a way, this was to be expected, as the content of the memory problem technique corresponds to the question that is asked later (i.e., whether people distrust their memory). The crux of the memory problem technique is that people are given an explanation as to why they have forgotten their illegal behaviour. In a way, this technique can be conceptualised as a minimising technique. However, as can be seen in Table 5.2, the suggesting memory problems technique and the minimising technique differed significantly in the extent to which they affect memory distrust scores. Indeed, there is an important difference between these two strategies. In the suggesting memory problems description, people were told explicitly that they might have looked into the exam paper, due to a process that happens automatically. On the other hand, the minimising technique implied that a person should have been fully aware of the violation. Of course, memory distrust will be strongest for actions that are not monitored consciously. The confidence undermining power of suggesting memory problems is also illustrated in case studies on false confessions (Gudjonsson, 2003).

With respect to the relationship between memory distrust and false confessions, we can conclude that for each interrogation technique, these two concepts are positively, but far from perfectly, correlated in each interroga- 
tion technique (see Table 5.4). In other words, if distrust in your memory increases, you will be more likely to confess and vice versa, but there also seem to be other factors that play a role in false confessions. Also, no conclusions can be drawn about causal direction of the link between memory distrust and false confessions. On theoretical grounds, it would be most logical to assume that memory distrust results in false confessions (Gudjonsson, 2003; Gudjonsson et al., 1999), but this issue needs further study.

To investigate this causal issue, one could elicit memory distrust in one of two groups, and then subject both groups to a false confession paradigm (e.g., Kassin \& Kiechel, 1996; Russano, Meissner, Narchet, \& Kassin, 2005). If creating memory distrust would result in a significant group difference, this would be strong evidence for memory distrust as an antecedent of false confessions.

A number of limitations of this study deserve comments. First, due to constraints imposed by our ethical committee, this experiment was designed as a thought experiment. That is, instead of being accused directly, people had to imagine the situations. This imaginative character may have reduced our effects. Still, the results indicate that some interrogation techniques make healthy, intelligent students susceptible to distrust their memory and to confess to violations that they have not committed. Also, we believe that the results may be generalised to real-life situations, as former studies have already shown that imagination may be strong enough to have behavioural consequences (Bernstein, Laney, Morris, \& Loftus, 2005; Scoboria, Mazzoni, \& Jarry, 2008). Moreover, Scoboria et al. (2008) state that suggestions about past events may have more persistent effects on behaviour than on selfreports. This confirms our expectation that the self-reported scores on the VASs are an underestimation of the effects in real life interrogation settings.

A second limitation concerns the ecological validity of our experiment. As there was no real pressure exerted during our experiment, it was not representative as a real interrogation setting. In addition, the descriptions of the scenarios were rather short. More extensive scenarios could have attributed to a more complete impression of an interrogation setting and as would have accounted for larger effects; on the other hand, in real life interrogations, police officers most often use manipulations consisting of only short messages.

Third, a within-subject design was used in this experiment. We chose for this design to increase ecological validity, as in police interrogations most of the times, more than one technique is used. However, in future studies, it might be interesting to use a between-subjects design. An argument favouring this design is that we expect that it would evoke larger differences between the interrogation techniques, as people would probably not give answers that contradict each other, which happens in a within-subject design. 
On the other hand, research has shown that in real interrogations, suspects stick to their starting position most of the time (Baldwin, 1993).

Fourth, but related to the first limitation, the participants in this experiment were all undergraduate students. There is reason to believe that undergraduates will be less susceptible to distrust their memory, as they are intelligent people who have good memory in general, compared to others. Some groups of individuals, for example, people with Attention Deficit Hyperactivity Disorder (ADHD) have been found to be more susceptible to memory distrust as a result of the little confidence they have in their memory (Gudjonsson et al., 2007). Furthermore, other studies have shown that undergraduates do not differ from prison inmates and people in the general community with regard to false confessions (Horselenberg, Smeets, \& Zonnenberg, 2007). This indicates that our results found in undergraduate students can at least be seen as a realistic mirror of the effects in real life interrogations, as they do not differ a lot from the general public. Therefore, we believe that the results obtained in this study can be generalised to the general public, however, we expect that in a real-life setting in which more pressure is exerted on other groups of individuals (e.g., people with ADHD), the effect of suggesting memory problems or memory distrust would be even larger. 



\section{CHAPTER 6 \\ MEMORY DISTRUST and FALSE CONFESSIONS}

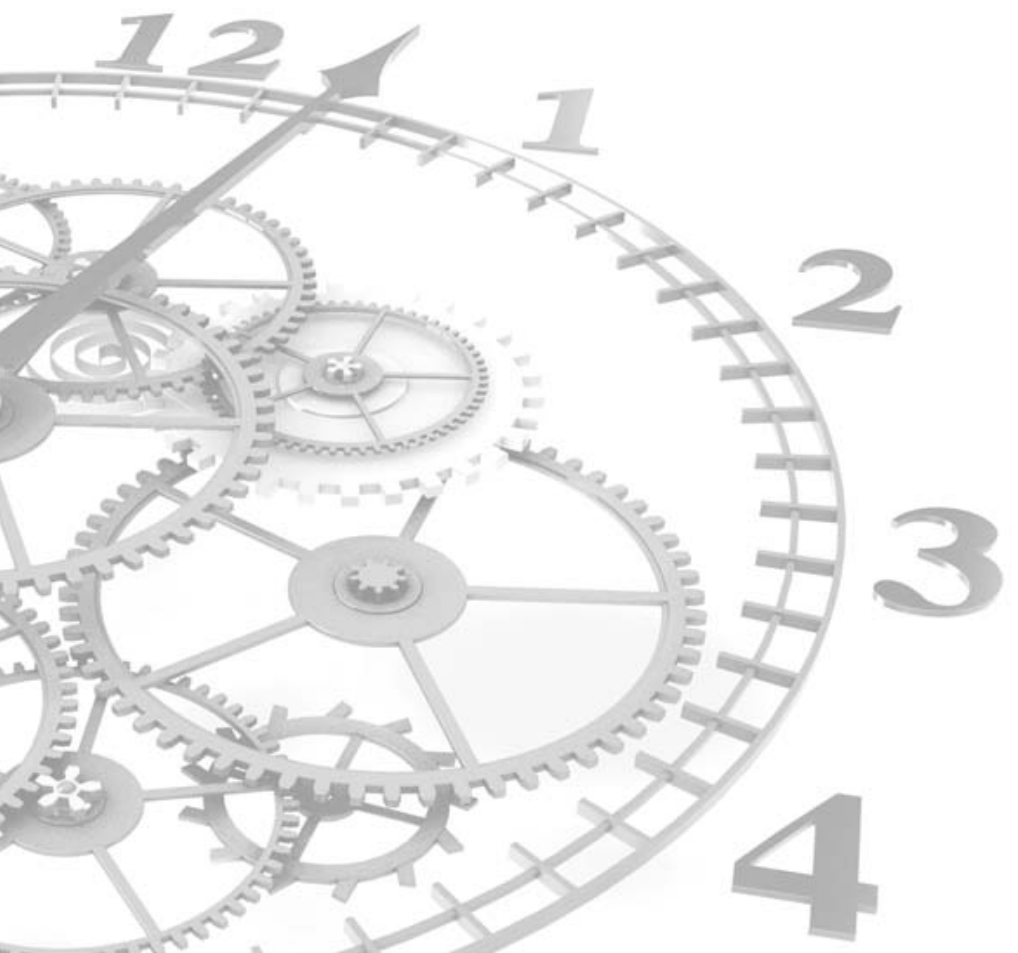

Van Bergen, S., Merckelbach, H., Horselenberg, R., Jelicic, M., \& Zuidberg, B. (2011). Did I do that? Memory distrust promotes internalised false confessions. Manuscript submitted for publication. 


\begin{abstract}
We examined the link between memory distrust and false confessions. Using the computer crash paradigm (Kassin \& Kiechel, 1996), undergraduates $(N=$ 80) were falsely accused of having caused a computer crash. Their memory distrust was manipulated by providing them with negative bogus feedback on a practice trial and/or giving them negative feedback as part of the Gudjonsson Suggestibility Scale prior to the computer test. Negative feedback given prior to the computer crash resulted in higher rates of internalised false confessions compared to not receiving any feedback (69\% vs. 22\%, respectively).
\end{abstract}

\title{
Introduction
}

According to many police officers, the main goal of a police interrogation is to obtain a confession as this increases the chance of a successful conviction. Conti (1999) estimates that approximately $80 \%$ of the criminal cases are solved by a confession. Although the prevalence of false confessions is unknown, numerous legal cases suggest that they occur more often than is usually assumed by law professionals (Costanzo \& Leo, 2007; Gudjonsson, 2003; Kassin et al., 2010). Thus, statistics gathered about DNA exoneration cases show that false confessions are an important antecedent of proven wrongful convictions, occurring in more than 15\% of these cases (Saks $\&$ Koehler, 2005). Although such cases are often portrayed in the media, most police officers still believe that people do not confess to crimes they did not commit (Henkel \& Coffman, 2004; Kassin, Meissner, \& Norwick, 2005).

Several studies have examined the phenomenon of false confessions in the laboratory. Most of them used the computer crash paradigm (e.g., Horselenberg et al., 2003; Horselenberg et al., 2006; Kassin \& Kiechel, 1996). In this paradigm, a participant is instructed to retype words or characters as fast as possible and is warned not to touch the Alt-key because this may cause the computer to crash. However, approximately after 1 min the computer crashes and the participant is accused of having touched the Alt-key. After the participant has been asked to sign a confession, the experimenter leaves the room and some time later a confederate enters. The confederate's task is to find out whether the participant really believes that he/she had touched the Alt-key (i.e., internalised the confession) or that the participant just confessed to be relieved from the pressure exerted by the experimenter while knowing that he/she did not touch the Alt-key.

Kassin and Wrightsman (1985) proposed a taxonomy of different types of false confessions: voluntary, coerced-compliant, and coerced-internalised 
false confessions. Gudjonsson (2003) changed the terms 'coerced' into 'pressured' and extended it with a classification of the sources of pressure, in a refinement of the original framework. The current study focuses on what Gudjonsson termed pressured-compliant false confessions and pressuredinternalised false confessions. Pressured-compliant false confessions occur when suspects want to escape from an aversive interrogation or when they want to obtain a promised reward (Gudjonsson, 2003). In such cases, a confession is merely an act of compliance. Pressured-internalised false confessions, on the other hand, refer to cases in which innocent suspects come to believe that they were involved in criminal acts (Kassin $\delta$ Gudjonsson, 2004). Often, they also develop false memories for the details of these acts (Kassin, 2005). Most cases of pressured-internalised false confessions have the following elements in common: a vulnerable suspect who is exposed to transient factors associated with the crime, interrogation, or custody (e.g., stress, fatigue, intoxication), who has poor memory and who is confronted with false evidence, resulting in a tentative admission of guilt that is finally converted into a fully detailed confession (Kassin, 2007).

A factor that is believed to contribute to pressured-internalised false confessions and that bears relevance to two of these components (i.e., vulnerable suspect and poor memory) is memory distrust (Gudjonsson et al., 1999; Kassin \& Gudjonsson, 2004). Memory distrust is defined as "a condition where people develop profound distrust of their memory recollections, as a result of which they are particularly susceptible to relying on external cues and suggestions" (Gudjonsson, 2003, p. 196). People suffering from memory distrust, therefore, easily mistake false memories for authentic memories. Two forms of memory distrust can be distinguished: trait and state memory distrust (Van Bergen et al., 2009). Trait memory distrust can be seen as a personality characteristic. People scoring high on this trait regularly have habitual doubts about their own memory capabilities. State memory distrust, on the other hand, is temporary and is mainly described in forensic case vignettes and is evoked by interrogative pressure.

In laboratory studies, state memory distrust can be manipulated, amongst others, by providing false feedback. An example of this can be found in the Gudjonsson Suggestibility Scale (GSS; Gudjonsson, 1997). The GSS can be used either as a practical tool to identify individuals' susceptibility to suggestive influences or as a research instrument for obtaining a clearer understanding of the nature and mechanism of interrogative suggestibility. The GSS also measures the tendency of people to shift their answers after receiving negative feedback. The more people start to doubt their recollections, the more often they will shift their answers. According to Gudjonsson (2003), the Shift score can be seen as an index of state memory distrust. 
Although memory distrust is often mentioned anecdotally as an important factor in false confessions cases, few studies have systematically looked at this factor. One of the few studies in this area examined the relationship between memory distrust, false confessions, and interrogation techniques (Van Bergen et al., 2008). Participants were falsely accused of exam fraud and were subsequently confronted with five different interrogation techniques: providing false technical evidence, providing false eyewitness evidence, minimisation (i.e., trivialising the crime), maximisation (i.e., dramatising the consequences of the crime), and suggesting memory problems. Not surprisingly, the latter technique resulted in the strongest tendency to distrust one's own memory. Importantly, memory distrust was related to false confessions. Note, however, that this study relied on a correlational design, which precludes any claims as to the causal link between memory distrust and false confessions.

Using the computer crash paradigm (Kassin \& Kiechel, 1996), the present study addressed this causal link. Memory distrust was manipulated by giving negative bogus feedback on a practice trial and/or by administering the GSS (Gudjonsson, 1997). Although these manipulations differed in wording, they both contained comments about poor memory performance and hence might be expected to promote state memory distrust. We expected that relative to the control condition (in which no feedback was given), higher levels of memory distrust in the negative feedback groups would elicit more internalised false confessions in these groups.

\section{Method}

\section{Participants}

In total, 80 undergraduate students (67 women; $M=19.6 ; S D=1.4$ ) participated. Participants were assigned to one of four conditions. In condition 1 , participants received negative bogus feedback on the practice trial and were given the GSS before the computer task. In condition 2, participants were given negative feedback on their practice trial and the GSS was administered after the computer task. In condition 3, the GSS was administered before the computer task, but no feedback was given on the practice trial. Finally, in the control group (condition 4), no comments were made about the practice trial and the GSS was administered after the computer crash. The study was approved by the standing ethical committee of the Faculty of Psychology and Neuroscience, Maastricht University. 


\section{Materials}

Computer task

A Dell PC was used running a Delphi computer programme in Windows. Words appeared on a 19-inch screen in black against a grey background. After retyping the words, participants had to press 'enter' resulting in the appearance of the next word. During the practice trial, 15 words were presented to make the participants accustomed to the test. After the practice trial, participants were asked whether they remembered making any mistakes followed by false feedback. During the test trial, the computer was programmed to crash after the $31^{\text {st }}$ word (i.e., after approximately $1 \mathrm{~min}$ ). A screen appeared that indicated that the computer had crashed and that the person should contact the administrator. If participants unintentionally hit the Alt-key, a different screen appeared. In fact, none of the participants did so.

\section{Manipulation check}

To check whether people developed memory distrust, a scale consisting of 10 items was administered, with 9 bogus items pertaining to mood, memory and concentration and 1 critical item (i.e., 'I distrust my memory'). Participants had to answer items on a $100 \mathrm{~mm}$ visual analogue scale (anchors: $0=$ 'not at all'; $100=$ 'extremely'). The scale was administered twice: before the practice trial and after the computer crash.

\section{GSS}

The GSS (Gudjonsson, 1984, 1997) was administered to elicit memory distrust as it also involves negative bogus feedback. Briefly, the GSS consists of a story about a robbery that is read aloud to the participants and that is followed by 20 questions (consisting of 15 suggestive questions and 5 memory questions). After having answered all questions, negative feedback is administered implying that the participant made several mistakes. Questions are then repeated.

\section{Procedure and Instruction}

Participants arrived at the laboratory under the impression that they would be subjected to a computer test examining the influence of language on reaction times. After giving informed consent, they had to complete some filler questionnaires. Next, they were told that they had to re-type words that were presented on the screen as fast as possible. They were also instructed not to hit the Alt-key, because this would cause the computer to crash. First, they had a practice trial. After the practice trial, half of the participants received negative feedback, while the other half received no feedback. Partici- 
pants in the negative feedback conditions (condition 1 and 2) were asked if they could remember making any mistakes during the practice trial. Subsequently, they were shown a false print of the practice words containing several mistakes. In addition, the experimenter commented that their recollections apparently were not as accurate as they had thought. After this feedback, the test trial started. Again, participants had to retype words that were presented on the computer screen. To make the computer crash plausible, the computer was programmed to crash during typing the word 'success'. This happened immediately after typing the second ' $c$ ', a letter close to the Alt-key. The experimenter then accused the participants of having touched the Alt-key and asked them to sign a confession, stating that they were responsible for the computer crash. After the confession was signed (or not), the experimenter left the room supposedly to consult his supervisor on how to proceed. After a few minutes, a confederate entered the room with the excuse that he had to work on that specific computer. After the confederate discovered that the computer had crashed, he asked the participant what had happened. The confederate's task was to find out whether the confession had been externalised (i.e., pressured-compliant false confession) or internalised (i.e., pressured-internalised false confession). After the confederate had left the room, the experimenter returned. The GSS was administered either before (condition 1 and 3) or after (condition 2 and 4) the computer task. At the end of the experiment, all participants were debriefed.

\section{Results}

One participant (from condition 1) was excluded from further analysis, because he was familiar with the computer crash paradigm.

\section{Manipulation Check}

As a manipulation check, the differences between the pre- and post-test scores on the memory distrust item were evaluated with $t$-tests. As can be seen in Table 6.1, memory distrust increased significantly in conditions 1 and 2 (both $p s<.05)$. In condition 3 , this increase was borderline significant $(p=$ $.07)$, whereas in the control condition it failed to reach significance $(p=.71)$. The four conditions did not differ with respect to pre-test scores $[F(3,75)=$ $.20, p=.90]$. 
Table 6.1

Mean Pre-Test and Post-Test Scores on the Memory Distrust Item (Standard Deviations are given in Parentheses), including $t$ and Cohen's $d$ Values

\begin{tabular}{|l|c|c|c|c|c|}
\hline Condition & $n$ & M pre-test & M post-test & $t$ & $d$ \\
\hline 1. Negative feedback \& GSS & 19 & $27.7(16.1)$ & $34.1(15.4)$ & $2.51^{*}$ & .40 \\
\hline 2. Negative feedback only & 20 & $30.8(23.2)$ & $41.0(22.3)$ & $3.79 *$ & .45 \\
\hline 3. GSS only & 20 & $29.9(19.7)$ & $36.8(15.8)$ & $1.91^{*}$ & .38 \\
\hline 4. Control & 20 & $32.5(19.0)$ & $33.9(15.4)$ & .38 & .08 \\
\hline
\end{tabular}

${ }^{*} p<.05$ (one-tailed).

\section{False Confessions}

In total, 41 of the 79 participants (52\%) falsely confessed. The 41 confessions consisted of $17(41.5 \%)$ compliant and $24(58.5 \%)$ internalised false confessions. The four conditions did not differ with respect to overall confession rate $\left[\chi^{2}(3, N=79)=2.56, p=.46\right]$. Apparently, negative feedback (induced by bogus feedback and/or by the GSS) did not contribute to the total number of false confessions. However, the conditions did differ with respect to false confession type $\left[\chi^{2}(3, N=41)=8.89, p=.03\right.$, Cramer's $\left.V=.49\right]$, with conditions 1, 2, 3, and 4 involving 4, 4, 2, and 7 compliant false confessions and 4, 7,11 , and 2 internalised false confessions, respectively.

Follow-up comparisons indicated that it was not the presence or absence of negative bogus feedback about trial performance (conditions 1 \& 2 vs. conditions $3 \& 4$ ) that was crucial for the group differences in false confession type $\left[\chi^{2}(1, N=41=.01, p=.94]\right.$. Neither was the pre-test administration of the GSS versus post-test administration (conditions $1 \& 3$ vs. conditions $2 \& 4)$ critical $\left[\chi^{2}(1, N=41)=2.95, p=.09\right] .{ }^{10}$ Rather, it was the presence of any type of negative evaluation (conditions 1, 2, \& 3 vs. condition 4 ), that increased the proportion of internalised false confessions relative to the control condition $\left[\chi^{2}(1, N=41)=6.27, p=.01\right.$, Cramer's $\left.V=.39\right]$. This is shown in Figure 6.1.

\footnotetext{
${ }^{10}$ Logistic regression analyses revealed that none of the GSS parameters (i.e., Yield1, Yield2, Shift, and GSS total score) significantly predicted either false confession rate or type of false confession.
} 


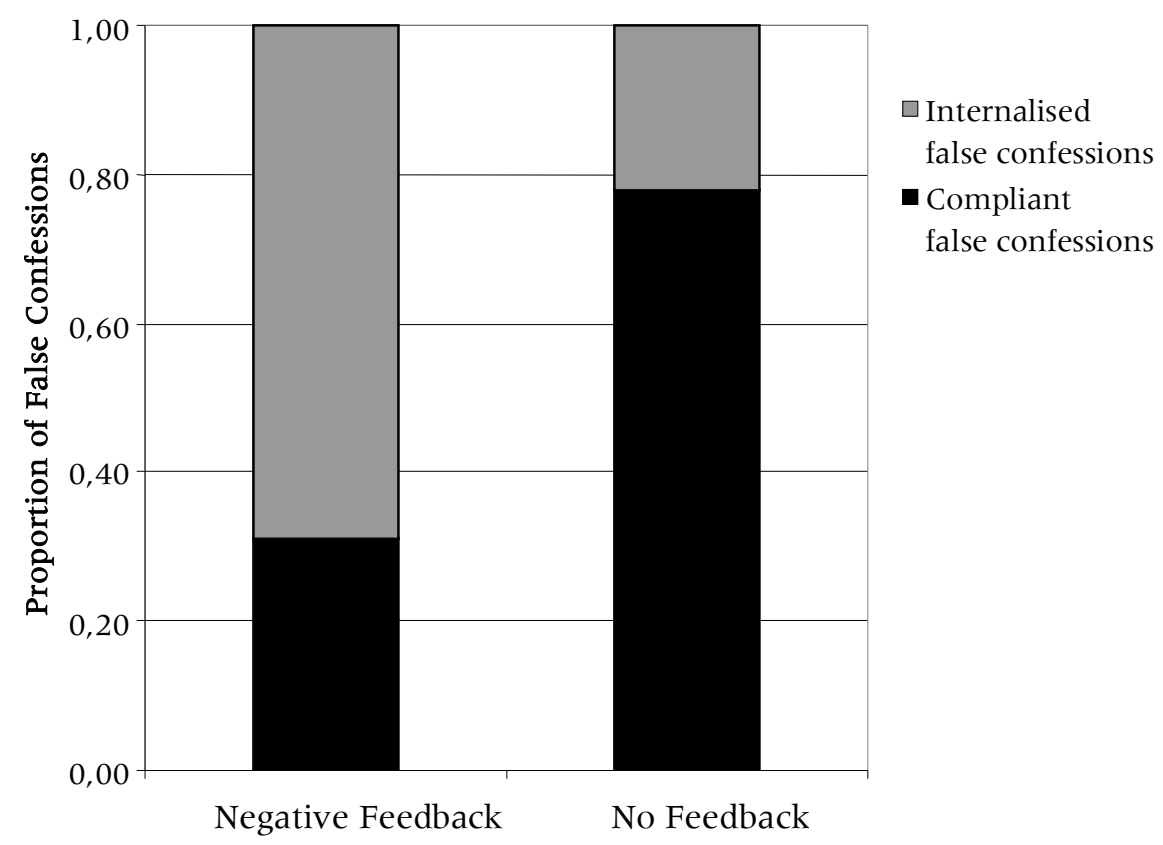

Figure 6.1. Proportion of compliant and internalised false confessions in the negative feedback conditions (1,2, and 3) and the control condition (4).

\section{Discussion}

The results of the present study can be summarised as follows. First, half of our participants $(52 \%)$ were willing to falsely confess to have caused a computer crash and of these, $58.5 \%$ internalised their false confessions. Second, at first glance, participants who received negative evaluations either in the form of negative feedback on their practice trial performance, the GSS, or both, did not confess more often than participants who did not receive such evaluations. However, when looking specifically at the type of false confessions, we found that any negative feedback prior to the computer crash led to an increase of internalised false confessions.

The first finding is somewhat atypical in that our overall false confession rate is lower than that reported in earlier studies. Thus, in previous studies, false confession rates varied from $69 \%$ to $82 \%$ (Horselenberg et al., 2003; Kassin 8 Kiechel, 1996). Perhaps, our students had more knowledge about computers and were more suspicious when dealing with crashed computers in psychological experiments. The rate of internalised false confessions, on the other hand, was higher than that reported in previous studies (i.e., be- 
tween $28 \%$ and $42 \%$ ). There are good reasons to assume that this heightened frequency has to do with our memory distrust manipulation. It seems that negative feedback makes participants seriously doubt their recollections and renders them more vulnerable to internalise a false confession. Obviously, the levels of memory distrust in police interrogations can easily exceed those elicited in our study. We therefore suspect that the false confession effects of false feedback that we found are an underestimation of the effects in real-life situations. Combined with interrogative pressure, anxiety, and sleep deprivation, memory distrust may lead to even higher rates of false confessions. After all, false confessions seem to be more typical for serious crimes such as murder (Drizin \& Leo, 2004).

Our results show that participants exposed to negative feedback do not confess more often than people who received no feedback. However, negative feedback per se promotes pressured-internalised false confessions. This is what one would expect on theoretical grounds (i.e., that memory distrust fosters acceptance of misleading information; Gudjonsson et al., 1999) and it is in line with case studies and empirical research in this domain (Gudjonsson, 2003; Gudjonsson \& MacKeith, 1982; Van Bergen et al., 2008).

The present study has limitations that deserve some comment. First, one might of course question the ecological validity of the paradigm that we used. The computer crash paradigm has been criticised for not being ecologically valid, as it does not capture certain key elements of real-world interrogations and confessions (Inbau et al., 2001). On the other hand, it seems hardly impossible to design a false confession paradigm that does not go beyond the ethical standards. Also, the memory distrust levels induced by negative feedback are lower than levels experienced in interrogation settings. In those settings, giving negative feedback is an often used strategy while interviewing suspects, for example, by calling the suspect a liar (Kassin, 2005) or by repeating questions (Garven, Wood, Malpass, \& Shaw, 1998). Still, that false confessions and memory distrust can be relatively easily induced in students (i.e., people who possess above average intelligence and are therefore rather confident in their memory) suggests that in real-life situations effects of memory distrust might be much more dramatic.

In future research, a more ecologically valid false confession paradigm should be considered. An example within the field of memory distrust may be to falsely accuse people of being late for a meeting. It might also be interesting to investigate the relationship between memory distrust and false confessions in other than student samples, such as community samples or patients who are known for being less confident in their own memory (e.g., people suffering from depression or ADHD).

False confessions are not uncommon in the legal system and when they occur, they might have dramatic consequences (Davis \& Loftus, 2006). Such 
consequences might be especially likely when innocent suspects do not retract their false confessions because they have come to believe them. As a result, research exploring the antecedents of such internalised false confessions is highly relevant. The present findings show that memory distrust is one such antecedent. Therefore, interrogation officers should be reluctant in communicating to suspects that their memory is suboptimal. 


\section{GENERAL DISCUSSION}

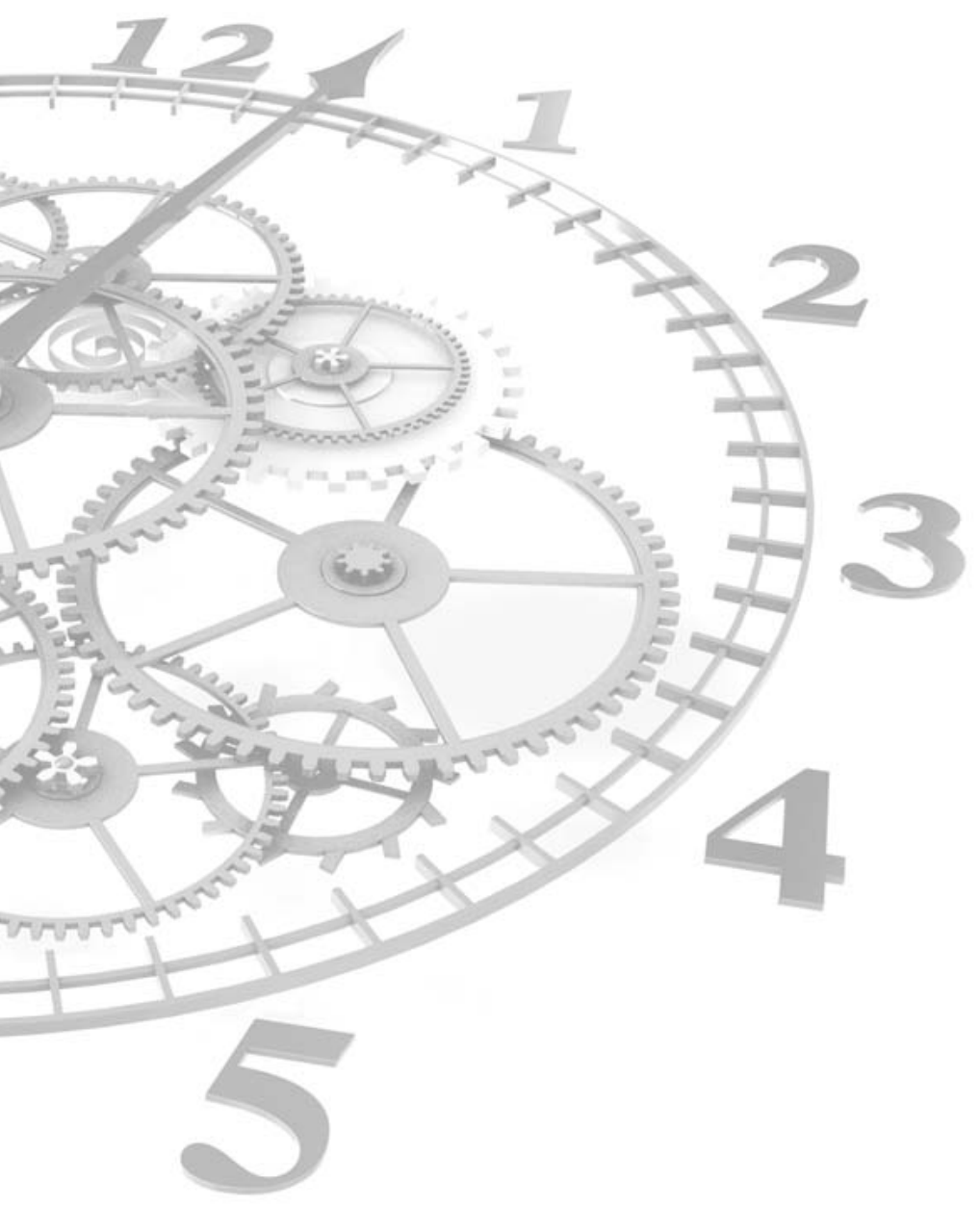




\section{Introduction}

This dissertation focuses on memory distrust, which is defined as "a condition where people develop a profound distrust of their memory recollections, as a result of which they are particularly susceptible to relying on external cues and suggestions" (Gudjonsson, 2003, p. 196). Memory distrust seems to manifest itself both within clinical and forensic settings and may have farreaching consequences. This was already noticed by Gudjonsson and colleagues (1999) who claimed that "a memory distrust syndrome makes some people susceptible to developing a false memory or confabulation" (p. 455). In the legal domain, the memory distrust syndrome has only been described in case studies. No experimental research has examined this concept and its consequences for the forensic field thoroughly. The present dissertation is a first attempt to develop a more systematic corpus of knowledge on memory distrust.

Memory distrust can be divided into two types: trait memory distrust and state memory distrust. Both types may become relevant at different times during the interrogation process. Trait memory distrust is already present in a person before he/she enters the interrogation room. State memory distrust, on the other hand, may arise during the interrogation, for example, as a result of psychological manipulations by police officers. One could argue that a combination of both trait memory distrust and interrogative pressure (leading to state memory distrust) may increase the psychological vulnerability of the defendant tremendously. ${ }^{11}$ In some cases, this may result in false confessions. It should be noted that no empirical evidence has yet confirmed the assumptions that are pointed out in this paragraph.

This thesis is divided into two parts; the first part addresses studies examining trait memory distrust (Chapters 2, 3, and 4), whereas the second part looks into state memory distrust (Chapters 5 and 6). In this concluding chapter the main findings of the studies presented in this thesis will be discussed. Also, limitations and suggestions for future research as well as practical implications will be formulated.

\footnotetext{
${ }^{11}$ Note that each type of memory distrust individually may already increase a person's vulnerability.
} 


\section{Summary of Empirical Findings}

\section{Measuring Trait Memory Distrust}

Trait memory distrust refers to fundamental and habitual doubts that individuals have about their own memory functioning. In a legal setting, these doubts may have a large impact on the statements of suspects or eyewitnesses. Therefore, it is useful to develop a test that quantifies the degree of memory distrust. Although there are many tests that assess objective memory performance (e.g., AVLT; Rey, 1964), the number of instruments that focus specifically on subjective memory performance is limited. And most of the existing questionnaires are not useful for measuring trait memory distrust, for example, because they focus merely on prospective aspects of memory (e.g., PRMQ; Smith et al., 2000), or because they are not concise enough (e.g., MIA; Dixon \& Hultsch, 1983).

This does not apply to the adapted Dutch version of the Squire Subjective Memory Questionnaire (Van Bergen, 2008; Van Bergen et al., 2010a). The validation study described in Chapter 2 shows that the SSMQ is a psychometrically sound instrument that can be helpful in assessing subjective memory evaluation, both in the clinical and the forensic domain. People who often doubt their memory will be most likely to evaluate their memory in a negative way. Therefore, a low score on the SSMQ can be seen as an indication of trait memory distrust. Because this one-dimensional questionnaire is shown to be reliable and valid, it can be used to identify vulnerable suspects and/or eyewitnesses in an early stage. ${ }^{12}$ The statements of these individuals should be interpreted cautiously and the level of interrogative pressure should be adjusted to accord with the degree of memory distrust. Ideally, this will diminish the frequency of false confessions or false statements.

\section{Related Concepts of Memory Distrust}

The various chapters of this dissertation examined several concepts that were expected to relate to memory distrust (as measured by the SSMQ) based on forensic cases and psychogeriatric studies (Commissaris et al., 1998; Gudjonsson, 2003; Gudjonsson et al., 1999; Merckelbach \& Muris, 2008). Although some relationships are not as straightforward as anticipated, most

\footnotetext{
${ }^{12}$ Note that this vulnerability only pertains to poor memory, and not to other vulnerabilities often mentioned in the literature, such as mental disorders, abnormal mental states, poor intellectual functioning, and personality disorders (Gudjonsson, 2010).
} 
findings are robust. First, trait memory distrust correlates positively with cognitive failures (i.e., everyday lapses in memory, attention, and action; Broadbent et al., 1982). That is, the more one suffers from memory distrust, the more cognitive failures one reports. Second, age and memory distrust are also closely related, with older individuals exhibiting more memory distrust.

Other variables such as objective memory performance, depression, and compliance correlate with memory distrust in the expected directions. However, these correlations do not always reach significance. As for actual memory performance, Chapter 2 showed that people who are confident in their memory also perform better on a memory task. Furthermore, it was shown that depression and compliance are both negatively linked to trait memory distrust. In other words, individuals who evaluate their own memory negatively are also more likely to score high on depression and are more compliant than persons scoring high (i.e., positive) on the SSMQ. Despite the fact that these links were not significant in all subsamples described in Chapter 2, the overall pattern changed when the relevant subsamples were collapsed. After combining these samples, subjective memory evaluation correlated significantly with objective memory $(n=182 ; r=.31 ; p<.001),{ }^{13}$ depression $(n=492 ; r=-.27, p<.001),{ }^{14}$ and compliance $(n=214 ; r=-.19, p=.006) .{ }^{15}$ In sum, trait memory distrust as measured by the SSMQ goes along with an older age, more cognitive failures, poor objective memory performance, more depression, and more compliance.

Meanwhile, the study presented in Chapter 3 failed to show that memory distrust (as measured with the SSMQ) relates to higher levels of suggestibility and false memories. This is striking because case studies suggest that these three concepts are closely related (Gudjonsson, 2003). Our negative result might have to do with the fact that the type of memory distrust that we measured in Chapter 3 was trait-like by nature, whereas the case studies describe state memory distrust. Also, the false memory paradigm that we used, the DRM task, might not have been the most appropriate test to study false memories as such. Although the debate whether the DRM illusion can be generalised to autobiographic memories is still ongoing (Freyd $\delta$ Gleaves, 1996; Otgaar \& Candel, in press; Roediger \& McDermott, 1995; Roediger \& McDermott, 1996), a recent literature review (Gallo, 2010) provides substantial empirical evidence to assume that the DRM illusion is re-

\footnotetext{
13 When we collapsed data across samples and excluded outliers, the correlation remained significant $(n=199 ; r=.29, p<.001)$.

${ }^{14}$ Idem, $n=510 ; r=-.24, p<.001$.

${ }^{15}$ Idem, $n=214 ; r=-.19, p=.006$. Since there were no outliers, both in the separate samples and in the collapsed samples, the total number of participants corresponds to the sum of the separate samples.
} 
lated to autobiographical memory distortions in settings outside the lab. Still, with regard to Chapter 3, a suggestion-induced paradigm might have been a better option than the DRM paradigm to examine the relationship between memory distrust and false memories, since it resembles real interrogation situations more closely.

\section{Misinformation}

Chapter 4 elaborates on the issue of how memory distortions and suggestibility can best be measured. This study was undertaken to overcome the limitations of the study described in Chapter 3. This time, a more realistic environment was created to test memory distrust in the way that it emerges in the justice system. To achieve this, we adopted some procedures that are commonly employed by the police, such as taking down the testimony (Malsch, Haket, \& Nijboer, 2008). We also used another paradigm to test false memories, namely the misinformation paradigm (Loftus, 2005; Loftus \& Palmer, 1974). In our experiment, we added information to the testimony of a witness who had seen video footage of a simulated robbery.

The findings of this study showed that individuals who suffer from trait memory distrust are more prone to accept misinformation than persons who are very confident in their memory. In other words, people suffering from memory distrust are more suggestible and therefore more likely to create false memories than those low on memory distrust. This contradicts the findings of Chapter 3 in which we did not find a significant relationship between memory distrust, suggestibility, and false memories. We argue that the findings in Chapter 4 carry more weight than those in Chapter 3 as these were obtained with a more ecologically valid paradigm.

Surprisingly, this study also showed that individuals who are very confident in their memory more often reject accurate information of their testimony. In other words, being very confident in your memory is no safeguard for making mistakes. However, when the effect size of this result is taken into account, it should be acknowledged that this effect is rather trivial. Furthermore, this finding is easy to explain by the fact that people suffering from memory distrust were probably less likely to express their doubts about the misinformation and the accurate information, whereas memory confident persons have a rather critical way of dealing with both outcome variables.

\section{Interrogation Techniques}

The second part of this thesis addressed state memory distrust, which is the type of memory distrust that is predominantly reported in forensic case vi- 
gnettes. Chapter 5 examined whether memory distrust could be elicited by interrogation techniques that are hypothesised to cause false confessions. Because there are numerous interrogation techniques, we selected those that were most likely to evoke memory distrust (i.e., false technical evidence, false eyewitness evidence, maximising, minimising, and suggesting memory problems). Furthermore, we were interested in the relationship between memory distrust and the tendency to falsely confess. In this experiment, undergraduate students were accused of exam fraud. After the accusation, they had to imagine several situations and had to indicate their tendency to distrust their memory and their tendency to falsely confess. These situations consisted of descriptions of the above mentioned interrogation techniques.

This study confirmed that state memory distrust correlates positively with the tendency to falsely confess. However, the interrogation techniques did not have a uniform effect on both concepts (i.e., memory distrust and false confessions). More specifically, suggesting memory problems had the largest impact on memory distrust, whereas false technical evidence made people most willingly to falsely confess. Also, this study showed that memory distrust is not always a static phenomenon; individuals fluctuate in the extent to which they are inclined to distrust their memory. This is another illustration of the existence of two different types of memory distrust (i.e., trait and state memory distrust). Because this study relied on a thought experiment, no conclusions could be drawn about the causal relationship between memory distrust and false confessions. However, it is plausible to assume that memory distrust precedes false confessions rather than vice versa.

\section{False Confessions}

The study described in Chapter 6 addressed the issue of causality. Using the computer crash paradigm (Kassin \& Kiechel, 1996), we accused undergraduate students of hitting a computer key which they were not allowed to touch. A group of participants had been manipulated into a state of memory distrust. In this way it was possible to examine the effect of memory distrust on false confession rates. The findings can be summarised as follows. First of all, we were successful in evoking memory distrust by giving participants negative bogus feedback. Second, more than half of the participants $(52 \%)$ falsely confessed to being responsible for the computer to crash, and of these, $58.5 \%$ internalised their confession. Third, the overall confession rate was not influenced by lowered memory confidence. However, when taking the type of false confession into account, findings show that participants with elevated state memory distrust (induced by any type of negative feed- 
back prior to the computer test) internalised their false confessions more often than participants who had not received negative feedback. This study, therefore, shows that memory distrust may be an antecedent of internalised false confessions.

\section{New Classification of False Confessions}

Applying the findings from Chapter 6 to the modified taxonomy of false confessions proposed by Gudjonsson (2003) suggests that this refinement of the original model of Kassin and Wrightsman (1985) is not optimal. While it is useful to classify the source of pressure and change the term coerced into pressured, as Gudjonsson (2003) did, the specific classification of sources might be reformulated so as to be more precise. Therefore, the following taxonomy is proposed.

\section{Table 7.1}

New Taxonomy for Classifying False Confessions

\begin{tabular}{l|l}
\hline Type of false confession & Source of pressure \\
\hline 1. Voluntary & Internal \\
\hline 2. Pressured-compliant & Internal / Custodial / Non-custodial \\
\hline 3. Pressured-internalised & Internal / Custodial / Non-custodial
\end{tabular}

Compared to the scheme proposed by Gudjonsson (2003; see also Table 1.1 of Chapter 1), this taxonomy elaborates on the sources of the pressured types of false confessions. We agree with Gudjonsson that voluntary false confessions only result from internal pressure. However, in light of the findings presented in Chapter 6, one might conclude that both pressuredinternalised and pressured-compliant false confessions may also result from internal pressure. Although Gudjonsson literally writes that "even when the confession results from external pressure there may also be an element of internal pressure to confess falsely" (Gudjonsson, 2003, p. 211), he failed to consider internal pressure into the pressured types of false confessions in his modified taxonomy. The findings of Chapter 6 , however, show that memory distrust promotes the development of internalised false confessions. Often, memory distrust will be evoked by custodial or non-custodial pressure (e.g., police interrogations), but it is also possible that it is present in a person without the existence of external circumstances. In any case, memory distrust is an internal process in which a person has doubts about his/her own recollections. As a result, s/he experiences an internal struggle and tries to 
resolve the tension s/he feels. This causes internal pressure. The importance of internal pressure should therefore not be dismissed and should be included in the modified framework.

\section{Conceptual Critique}

As stated earlier, Gudjonsson defines the memory distrust syndrome as "a condition where people develop a profound distrust of their memory recollections, as a result of which they are particularly susceptible to relying on external cues and suggestions" (Gudjonsson, 2003, p. 196). This definition is problematic for several reasons. To begin with, it describes a phenomenon in terms of its outcome. From a scientific point of view this is questionable, because it invites circular reasoning and hypotheses that run the risk of becoming difficult to falsify. Consider the analogy with a disease (e.g., cancer) that includes the outcome (e.g., death) in its definition. Whenever death does not occur, one cannot argue anymore that the patient has cancer. In other words, based on the definition one has to argue that it was a different type of disease. Thus, with this in mind, it would be wiser to define memory distrust only by its symptoms. Specifically, this would imply that the subordinate clause ("as a result ... cues and suggestions") should be left out.

The second reason why the definition is problematic is that there is no a priori reason to assume that memory distrust invariably promotes the acceptance of misinformation. For example, Hekkanen and McEvoy (2002) argued that memory distrust might make people reluctant to accept any type of information. By this view, memory distrust makes individuals hypercritical, the precise opposite of what Gudjonsson's definition implies. Since the definition of memory distrust is solely based on forensic case studies, it would be wise to extensively examine whether individuals with memory distrust are more prone to accept misinformation or whether they adopt a more critical attitude. The study described in Chapter 4 was the first one to examine this issue and confirmed Gudjonsson's line of reasoning. Note however, that the data described in Chapter 3 of this dissertation provide an empirical demonstration of memory distrust without raised levels of suggestibility. Apparently, the association between memory distrust and suggestibility and/or acceptance of misinformation is not clear-cut. More studies should be undertaken to examine this relationship. This could lead to a reformulation of the definition of memory distrust as proposed by Gudjonsson.

There is another conceptual issue that warrants comment. Gudjonsson presented memory distrust as a free standing concept, but the results of the studies in Chapters 2 and 3 illustrate that memory distrust and cognitive failures overlap to a considerable degree. This raises the question whether 
there might be an overarching factor or variable that might encompass related concepts such as memory distrust, depression, cognitive failures, etc. Interestingly, it was Gudjonsson himself who in older articles stressed the significance of low self-esteem. Gudjonsson and Lister (1984) argued that interrogators who attempt to undermine suspects' or witnesses' self-esteem or self-confidence may make them particularly prone to misleading suggestions. Likewise, Singh and Gudjonsson (1984) contended that self-esteem interacts with the unfamiliarity of the interrogation context such that suspects or eyewitnesses low in self-esteem become more vulnerable to misinformation. Gudjonsson and Sigurdsson (2003, p. 122) wrote that "Persons with low self-esteem are vulnerable to giving in to pressure from others, because of their eagerness to please and the accompanying reluctance to engage in confrontation with people." The issue is important because one could argue that as long as memory distrust does not co-occur with low selfesteem, as might be the case in what we term state memory distrust, it does not result in heightened suggestibility or compliance.

\section{Methodological Remarks}

In this section, a general overview is presented of the methodological limitations that were encountered during the studies described in the current dissertation. One of the main problems was figuring out whether participants really experienced memory distrust. In the studies that examined trait memory distrust, we could not test this independently, and therefore had to rely on self-reports. We also had to assume that persons who evaluate their memory as poor base this judgement on their habitual memory doubts. It might well be that some of these individuals only suffered from a specific type of memory distrust (e.g., forgetting names or faces), or based their evaluation on feedback from others. This made it difficult to create distinctive homogeneous groups and therefore less likely to find striking results when comparing two memory groups (i.e., memory confidence and memory distrust, respectively) on an outcome variable, such as suggestibility or false memories.

In the studies which examined state memory distrust, the main problem was to develop a successful manipulation and a realistic design. One can only conclude that a manipulation has been successful with a valid manipulation check. This is complicated by the fact that most studies do not reveal the real purpose at the beginning of the experiment. As a result, the manipulation check cannot be made too explicit. Most of the times, the manipulation check consisted of a memory evaluation that participants gave twice (i.e., before and after the manipulation). The difference between both 
measurements and between groups indicated whether the manipulation had been successful. This could lead to the following potential problem, namely that the manipulation did work but that this was not captured correctly by the specific question, leading to a wrongful conclusion that the manipulation failed, while in fact the check was not reliable.

Apart from the manipulation, the overall design of the studies had to be realistic and at the same time not too coercive, because this would raise ethical concerns. In this way, several of the original plans were rejected by the standing ethical committee of our Faculty because these experiments accepted the risk of putting intolerable pressure on participants. The downscaled designs we used had negative consequences for generalising the obtained results to the police practice. Obviously, the levels of memory distrust (and other types of stress-induction) in real police interrogations exceed those elicited in our studies. We anticipate that the results found in our lab studies can therefore be seen as an underestimation of the effects in real-life situations.

Another problem was the recruitment of participants. Although the first searches for community samples were fruitful, later efforts met with great difficulty to find new people who were interested in participating. This substantial decrease of community samples willing to volunteer in our research and the high costs that testing community samples requires, made it impossible to conduct our research solely with persons from the community. Therefore, it became inevitable to ask undergraduate students to participate in our studies. It could be argued that this compromised the ecological validity of our experiments, because a more or less homogeneous student group is not representative for individuals who suffer from trait memory distrust. However, there is evidence showing that undergraduate students behave in the same way as prison inmates and community samples with regard to false confessions (Horselenberg et al., 2007). To solve this potential problem as much as possible, we conducted the research on trait memory distrust with community samples, and the state memory distrust research with undergraduate students. As forensic case vignettes have already shown that even healthy, intelligent individuals are vulnerable to develop state memory distrust (see case vignette 2; Gudjonsson \& Sigurdsson, 2010), we anticipated that the approach taken in this dissertation would be justified. Moreover, one could argue that when memory distrust can be demonstrated among students (i.e., highly intelligent persons), this implies that the effects obtained would be even larger in the general population, and especially among vulnerable people, such as juveniles, mentally ill patients, and individuals suffering from developmental disorders (e.g., ADHD; Gudjonsson et al., 2007). 
A final issue that should be noted in this section is the difficulty of making the distinction between trait memory distrust and state memory distrust. In our studies, we aimed at examining these two types of memory distrust separately. As we did not put any stress on the participants who were involved in the trait memory distrust research (Chapters 2, 3, and 4), we assumed that the findings of these studies reflect trait memory distrust. The same applies to the studies that involved state memory distrust (Chapters 5 and 6). In these studies we chose to rely on undergraduate students. These participants are intelligent and, as a rule, do not suffer from trait memory distrust (see relatively high mean SSMQ total scores). However, we cannot entirely rule out that there were instances in which both types of memory distrust were present in some participants. An example of this is described in Chapter 3, when persons scoring high on trait memory distrust underwent the GSS and the negative feedback it implied. The presence of both types of memory distrust is undesirable for experimental research in which you want to control all factors as much as possible. However, it should not have any negative consequences for generalising the findings to real-life situations, because in practice it is also likely that suspects suffer from both types of memory distrust. For example, a suspect who enters the interrogation room may already have serious doubts about his recollections (i.e., trait memory distrust), and will later be confronted with interrogation techniques eliciting state memory distrust.

\section{Directions for Future Research}

\section{Repeated Questioning}

Over the last few years, memory distrust has been extensively researched in the field of the Obsessive-Compulsive Disorder (OCD; Boschen $\&$ Vuksanovic, 2007; Coles, Radomsky, $\delta$ Horng, 2006; Dek, Van den Hout, Giele, $\delta$ Engelhard, 2010; Harkin $\delta$ Kessler, 2009; Radomsky $\&$ Alcolado, 2010; Radomsky, Gilchrist, $\&$ Dussault, 2006; Van den Hout $\delta$ Kindt, 2003a, 2003b, 2004; Van den Hout, Engelhard, De Boer, Du Bois, \& Dek, 2008). These studies focus on one of the two main characteristics of OCD, namely compulsive behaviour, and more specifically, repeated checking. Overall, the studies in this domain employed the following design. Individuals are asked to turn on thee out of six gas stoves/lamps, ${ }^{16}$ to turn them off, and to check whether they have correctly turned them off. Subsequently, a pre-test is

\footnotetext{
${ }^{16}$ This happens either during a computer animation or in reality.
} 
used to assess their accuracy and metamemory beliefs (i.e., liveliness, details, and memory confidence). Then, they are instructed to repeatedly check either relevant or irrelevant controls (i.e., experimental vs. control group, respectively). The relevant controls are the same objects as participants used initially, while the irrelevant controls are different objects than the original ones (e.g., lamps instead of gas stoves, and vice versa). Finally, they are all given a post-test which corresponds with the pre-test. Findings show that both groups are equally accurate in remembering which gas stoves/lamps they had turned on. However, the experimental group shows a decrease on all three aspects of metamemory: liveliness, details, and memory confidence. In other words, compared to the control group, the experimental participants report less lively and less detailed memories and less memory confidence on the post-test (Van den Hout, 2010). In sum, repeated checking not only originates from, but also causes, memory distrust. This robust effect has been demonstrated in samples of both patients and healthy individuals.

The experimental paradigms that are used in these studies may be applicable to the forensic field as well. During police interrogations, questions are often repeated and answered. This resembles the repetitive procedure that is described in the OCD literature. By repeating the questions, an interrogator implicitly gives the impression that the suspect or witness is mistaken and that their memories are incorrect. ${ }^{17}$ This is an ideal breeding ground for memory distrust (Van Bergen, 2009a). Therefore, the OCD literature might provide us with a new, ecologically valid paradigm to investigate (legal) memory distrust in the lab.

So far, two pilot studies have been conducted in our lab with this paradigm. We examined the influence of repeated questioning on memory distrust in an interrogative setting. At first sight, it might seem simple to translate the OCD procedure to the forensic field. However, we discovered that the practical implementation is rather complex. For example, repeating the same question many times is not very realistic over a short time period, especially when the participants are not informed about the real purpose of the experiment.

In our first pilot study, we examined whether repeated questioning induced memory distrust. In this experiment, 44 undergraduate students participated. They had to choose one of two envelopes and were told that they had to act according to an 'innocent' or a 'guilty' scenario. Next, they had to go to a lab that was decorated as a bar. In this lab, a male dummy was situated on the ground. The envelopes were manipulated in a way that all par-

\footnotetext{
${ }^{17}$ Besides this, suspects are often also explicitly accused of lying (Inbau et al., 2001; Kassin et al., 2010).
} 
ticipants received the innocent scenario (i.e., they had to check the dummy's wallet, but they were not allowed to steal it). However, they were under the impression that they also could have received the guilty scenario instruction (i.e., that they had to steal the dummy's wallet). In this way, it would be logical that they would be interrogated about, and possibly be accused of, stealing the wallet. During a subsequent interrogation, both relevant and irrelevant questions were asked. The relevant questions consisted of details of the bar and the wallet. Half of the participants had to answer the relevant questions four times ${ }^{18}$ altogether (i.e., experimental condition, $n=22$ ), while the other half had to answer them only once and received many irrelevant questions (i.e., control condition, $n=22$ ).

The main outcome measure of this study was the way the participants evaluated their memory on the post-test (compared to the pre-test). Findings indicated that there were no differences between the two groups in the way they evaluated their memory $[t(42)=.80, p=.43]$. One explanation for this may be that the number of repetitions was not sufficient. Coles and coauthors (2006) have claimed that more repetitions lead to a larger effect. A significant increase is reached after more than five repetitions. But other research has shown that memory distrust can already be evoked after two and five repetitions (Van den Hout, 2010). Furthermore, we also assessed whether persons who changed their answers, judged their memory as worse on the post-test. It appeared that shifting answers and memory evaluation correlated borderline significantly $(r=-.39, p=.08)$. More specifically, the more participants changed their answers, the poorer they judged their memory on the post-test (compared to the pre-test).

The second pilot study also examined the effect of repeated interrogations on memory confidence (Kraasch, 2009). Undergraduate students $(N=$ 50) received the same instruction as was given in the first pilot study. This time, the interrogation part was set up differently. When the participants returned to the test room, they were asked to give a full written report about the situation they had encountered in the bar lab. Following this, the experimental group $(n=25)$ was instructed to verbally recall the situation for another five times. Note that, compared to the first pilot study, the number of repetitions was increased (i.e., six recall trials in the experimental group instead of four). They were given five cues to help them remember (i.e., entry, bar, dummy, envelope, leaving). The control group $(n=25)$ had to repeatedly recall an irrelevant event (i.e., their journey from home to the lab). Subsequently, all participants were given a cued recall task consisting of

\footnotetext{
${ }^{18}$ To keep the design as realistic as possible, the 10 relevant questions that were repeated four times, were alternated with an equal number of irrelevant questions (i.e., 40) and were paraphrased each time so that the real purpose of the experiment would not become too obvious.
} 
30 items. They also gave confidence estimates for each question on a 7-point Likert scale (anchors: 1 = 'totally not confident'; 7 = 'totally confident').

The results indicated that repetition lead to confidence inflation, rather than deflation $[t(48)=1.99, p=.05]$. In other words, the experimental group $(M=5.67, S D=.71)$ was more confident than the control group $(M=$ $5.21, S D=.90)$. Note that this difference, in absolute terms, consists of less than .5 on a 7-point Likert scale. Furthermore, no group differences were found on the objective memory parameters (i.e., cued recall and recognition). However, findings reflect an intact confidence-accuracy relationship. Specifically, more correct cued recall co-varied with more confidence in both the experimental and control group $(r=.39, p=.05$, and $r=.62, p=.001$, respectively).

These two pilot studies show that memory distrust is apparently more difficult (or even impossible) to trigger when using (repetitions of) questions instead of actions (which were used in the OCD-studies). An explanation of our null results may be that the number of repetitions was too small to obtain a confidence deflating effect. However, increasing the number of repetitions more than six times would seriously undermine the credibility of the lab experiment, and therefore the outcomes. In real life, on the other hand, it is quite realistic that suspects are repeatedly asked the same questions, over the course of several interrogation sessions. Most of the time, this occurs if the suspect's answers do not correspond to the expectations of the interrogators. People often report getting hesitant when they are asked the same question again and change their answers. Evidence for this has been found for suspects and witnesses (both children and adults) who are questioned during lengthy interrogations (Garven et al., 1998; Krähenbühl, Blades, \& Eiser, 2009; Odinot, Wolters, \& Van Giezen, 2008). In other words, these repetitions induce confidence deflation, or memory distrust. However, under some conditions, repeated questioning can also lead to perseverance and thus confidence inflation (Odinot \& Wolters, 2006; Odinot, Wolters, \& Lavender, 2009; Shaw \& McClure, 1996).

Another scenario would be that police officers continue to repeat questions because the suspect or witness is very hesitant and self-doubting. ${ }^{19}$ Here, repeated questioning does not cause memory distrust, but results from memory distrust. Also, it is quite likely that a combination of factors contributes to the elicitation of memory distrust. Consider, for example, stress, sleep deprivation, and personality factors (e.g., low self-esteem) that affect related concepts such as suggestibility (Gudjonsson, 2003). If this broad range of factors is taken into account, it is not so remarkable that both pilot studies

${ }^{19}$ Here, we are dealing with trait instead of state memory distrust. 
resulted in null findings. It would, however, still be interesting to pursue this line of research to see if we can find experimental evidence for evoking memory distrust through repeated questioning.

Other interesting issues to explore are whether it is the mere repetition of questions, the repeated retrieval of information from memory, or repeatedly answering questions, that leads to memory distrust. It might be that the first option per se does not undermine memory distrust, but the other two do. In sum, there is still much to be researched in this field. This is all the more true as most of the research on repeated questioning has been performed with children and only few studies have examined its consequences among adults.

Another approach to examine the influence of repetition is the following. In police practice, suspects and witnesses are often encouraged to imagine what could have happened at a crime scene. In such situations, repetition of events also comes into play. Studies have already shown that imagining an event can be very powerful and sometimes may even lead to false confessions (Horselenberg, De Zutter, \& Van Bergen, 2010). This may provide us with an interesting and ecologically valid version of the repeated questioning paradigm. In such a paradigm, participants are instructed to imagine about a scenario of what could have happened. As a result they might start to distrust their memory. ${ }^{20}$ Memory distrust makes them more vulnerable to making source monitoring errors, which could eventually lead to false statements or confessions. This line of research is still in its infancy, but might be a fascinating field to explore in the future.

\section{Amnesia}

Chapter 1 stated two conditions under which the memory distrust syndrome may occur (Gudjonsson, 2003). This thesis, however, has not focused on situations in which individuals have no clear memory of a specific event due to head injury or substance abuse (e.g., excessive alcohol use; Van Oorsouw, Merckelbach, Ravelli, Nijman, \& Pompen, 2004). This type of memory loss is called organic amnesia (Kopelman, 2002). Organic amnesia may be permanent, in case of structural brain damage, but can also be transient by nature, in case of substance abuse, or mild traumatic head injury. Amnesic individuals may be a very interesting new group to study in future memory distrust research.

\footnotetext{
${ }^{20}$ OCD research has already provided evidence that mental checking, comparable to imagination, leads to memory distrust (Radomsky \& Alcolado, 2010).
} 


\section{Practical Implications}

\section{Forensic Practice}

Although vulnerable suspects and eyewitnesses are often described in the forensic literature, it remains unclear why these individuals give a false confession or a false statement (Gudjonsson, 2010). Based on this dissertation, it may be assumed that memory distrust may be (part of) the answer to this question. Legal psychologists who advise the police on how to interrogate suspects and eyewitness should be aware of the influence of memory distrust. In this way, experts can identify memory distrust early in the interrogation process, which warrants the fairness of the investigation.

Many cases are known in which vulnerable persons suffering from memory distrust are convicted for crimes they did not commit (e.g., Gudjonsson et al., 1999; Gudjonsson \& Sigurdsson, 2010). Also in these cases, expert witnesses can make a difference by giving psychological evidence (e.g., during an appeal). The focus of these psychological evaluations should be on the strengths and weaknesses (i.e., vulnerabilities) of the witness/suspect, which may have bearing on the reliability of the evidence (Gudjonsson, 2006). Sometimes these evaluations may provide a legal basis for exoneration.

The term memory distrust syndrome actually stems from these types of psychological evaluations. Psychologists are often tempted to easily term a new phenomenon a syndrome. Examples are the false memory syndrome (Freyd \& Taub, 1999) and the amnesic syndrome (Kopelman, 2002). One could argue though, that the memory distrust syndrome is not truly a syndrome. A syndrome implies a fixed constellation of symptoms and a clear aetiology which often has a medical connotation. This is, however, not applicable to all the forensic cases that have described suspects suffering from memory distrust. In most of these cases, memory distrust is a situational phenomenon rather than a syndrome. Therefore, one should be careful with using terms such as 'syndrome', as it may give the impression that it is a rare phenomenon from which normal healthy individuals will not suffer. It goes without saying, that this is obviously not the case for memory distrust.

\section{Clinical Practice}

Although this dissertation mainly focuses on the legal field, some of the findings can easily be translated to clinical practice. First of all, the SSMQ may prove to be useful in clinical practice. It may provide psychologists in the field with an instrument that assesses the subjective beliefs that individuals have about their own memory functioning. It may also give clinicians insight 
in whether people's own beliefs differ from reality. For example, some older persons may believe that they have poor memory, while in reality their memory functions well. The results of the questionnaire may give practitioners an entry to address the unrealistic beliefs their patients have.

Furthermore, the results of Chapters 4 and 6 imply that psychotherapists should be careful when treating patients with psychological problems who do not feel very confident in their memory. These patients will be vulnerable to incorporate suggestions from others (e.g., the therapist) into their own story. In some cases, this may lead to source monitoring errors, in which the patients mistake these suggestions for authentic memories. Another lesson that can be drawn from this thesis is that therapists should be cautious with any negative feedback that they provide, since it may induce memory distrust. The phenomena documented in Chapters 4 and 6 may have farreaching consequences. For example, patients may come to believe that they experienced a trauma (e.g., kidnapping, sexual abuse, murder) in their childhood, while in reality they have not. In some of these cases, this may result in false accusations of innocent individuals (Loftus \& Davis, 2006).

\section{Closing Remarks}

This dissertation is a first experimental attempt to examine memory distrust in the legal arena. It provides an overview of related concepts of memory distrust, its consequences and possible ways to test it. Furthermore, it also stresses the difficulties that emerge in the lab when examining phenomena that have only been described in case studies. Despite these limitations, it has provided us with some guidelines on how to address individuals with memory distrust in a legal situation. First, it is useful to get an impression of a person's memory doubts at the start of an interrogation. The SSMQ is a simple and efficient instrument to assess memory distrust. Second, police officers should be cautious when using interrogative pressure and negative feedback since this may elicit memory distrust, which in some cases may have serious consequences, such as internalised false confessions. Third, persons who are suffering from memory distrust may be prone to confuse misinformation for authentic information. Therefore, police interrogators should refrain from providing suspects with information that is false or unknown to the suspect, and that later can be misinterpreted as guilty knowledge by police officers. When these guidelines are considered in the future, it will be less likely that innocent individuals such as Andrew Evans (case vignette 1, p. 8) and Mr A (case vignette 2, p. 9) will falsely confess and ultimately will be convicted. 



\section{REFERENCES}

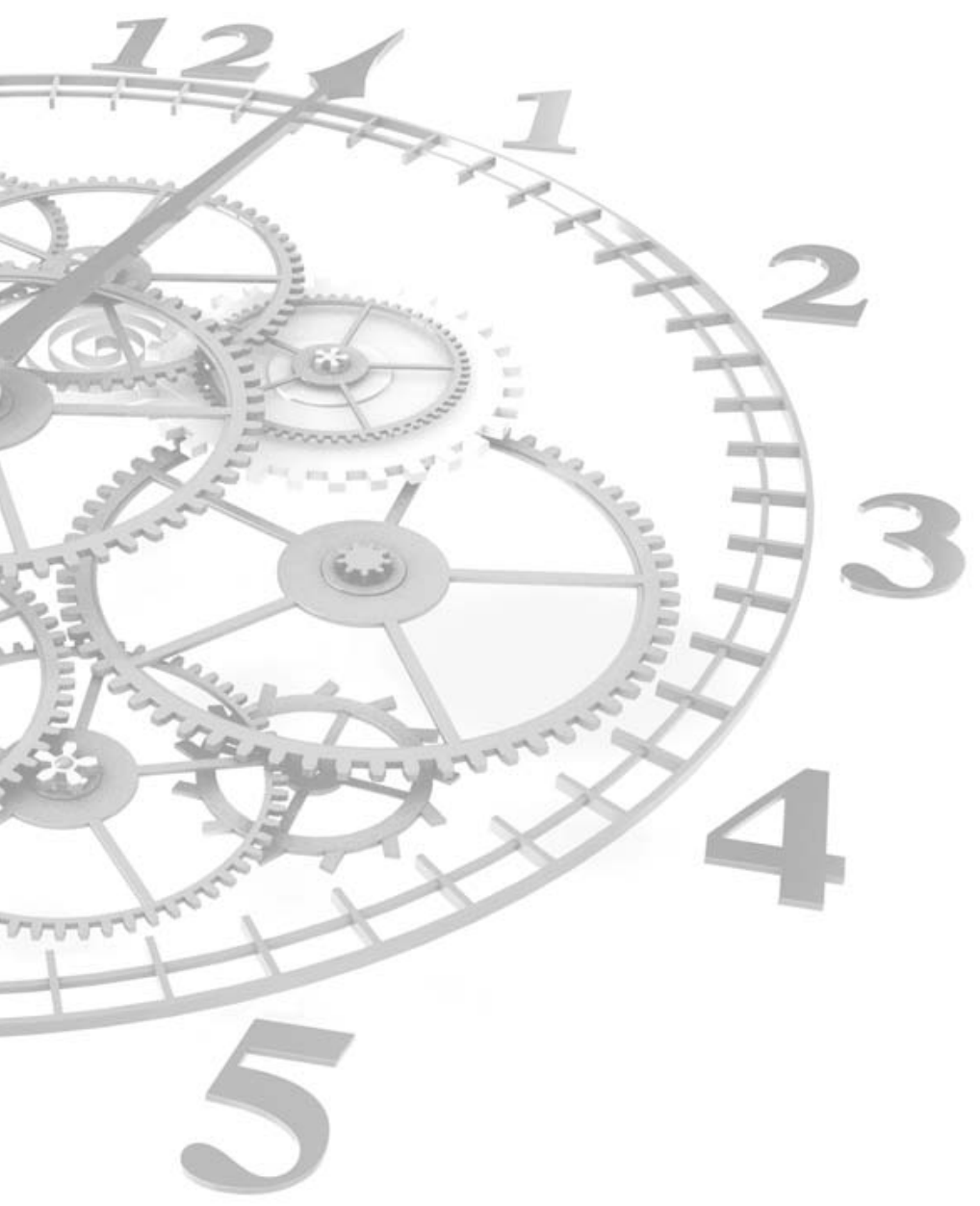


Baldwin, J. (1993). Police interview techniques: Establishing truth or proof? British Journal of Criminology, 33, 325-352.

Beck, A. T., \& Steer, R. A. (1996). Manual for the Beck Depression Inventory-II. San Antonio, TX: Psychological Corporation.

Bernstein, D. M., Laney, C., Morris, E. K., \& Loftus, E. F. (2005). False memories about food can lead to food avoidance. Social Cognition, 23, $11-34$.

Blaauw, J. A., \& Blaauw, J. (2009). De Puttense moordzaak: De volledige geschiedenis van Nederlands grootste rechterlijke dwaling [The Putten murder case: The full history of the largest Dutch miscarriage of justice] (5e ed.). Baarn: Fontein.

Boschen, M. J., \& Vuksanovic, D. (2007). Deteriorating memory confidence, responsibility perceptions and repeated checking: Comparisons in OCD and control samples. Behaviour Research and Therapy, 45, 2098-2109.

Brewer, N. (2006). Uses and abuses of eyewitness identification confidence. Legal and Criminological Psychology, 11, 3-23.

Brewin, C. R., \& Stokou, L. (2002). Validating reports of poor childhood memory. Applied Cognitive Psychology, 16, 509-514.

Bright, P., Jaldow, E., \& Kopelman, M. D. (2002). The National Adult Reading Test as a measure of premorbid intelligence: A comparison with estimates derived from demographic variables. Journal of the International Neuropsychological Society, 8, 847-854.

Broadbent, D. E., Cooper, P. F., Fitzgerald, P., \& Parkes, K. R. (1982). The Cognitive Failures Questionnaire (CFQ) and its correlates. British Journal of Clinical Psychology, 21, 1-16.

Bruck, M., \& Ceci, S. J. (1999). The suggestibility of children's memory. Annual Review of Psychology, 50, 419-439.

Christianson, S. A., Engelberg, E., \& Gustafson, A. (2007). Recognition of previous eyewitness testimony from an altered interrogation protocol: Potential effects of distortions. Psychology, Crime $\mathcal{E}$ Law, 13, 583-589.

Coles, M. E., Radomsky, A. S., \& Horng, B. (2006). Exploring the boundaries of memory distrust from repeated checking: Increasing external validity and examining thresholds. Behaviour Research and Therapy, 44, 9951006.

Commissaris, C., Ponds, R., \& Jolles, J. (1998). Subjective forgetfulness in a normal Dutch population: Possibilities for health education and other interventions. Patient Education and Counseling, 34, 25-32.

Conti, R. P. (1999). The psychology of false confessions. The Journal of Credibility Assessment and Witness Psychology, 2, 14-36. 
Costanzo, M., \& Leo, R. A. (2007). Research and expert testimony on interrogations and confessions. In M. Costanzo, D. Krauss \& K. Pezdek (Eds.), Expert psychological testimony for the courts (pp. 69-98). Mahwah, NJ: Lawrence Erlbaum Associates Publishers.

Crawford, J. R., Smith, G., Maylor, E. A., Della Sala, S., \& Logie, R. H. (2003). The Prospective and Retrospective Memory Questionnaire (PRMQ): Normative data and latent structure in a large non-clinical sample. Memory, 11, 261-275.

Crombag, H., Merckelbach, H., \& Elffers, H. (2000). Other people's memory. Psychology, Crime \& Law, 6, 251-265.

Davis, D., \& Loftus, E. F. (2006). Psychologists in the forensic world. In S. I. Donaldson, D. E. Berger \& K. Pezdek (Eds.), Applied psychology: New frontiers and rewarding careers (pp. 171-200). Mahwah, NJ: Lawrence Erlbaum Associates Publishers.

Deelman, B. G., Brouwer, W. H., Van Zomeren, A. H., \& Saan, R. J. (1980). Functiestoornissen na trauma capitis [Cognitive dysfunctions following trauma capitis]. In A. Jennekens-Schinkel, J. J. Diamant, H. F. A. Diesfeldt \& R. Haaxma (Eds.), Neuropsychologie in Nederland (pp. 253-281). Deventer: Van Loghum Slaterus.

Dek, E. C. P., Van den Hout, M. A., Giele, C. L., \& Engelhard, I. M. (2010). Repeated checking causes distrust in memory but not in attention and perception. Behaviour Research and Therapy, 48, 580-587.

Devilly, G. J., Varker, T., Hansen, K., \& Gist, R. (2007). An analogue study of the effects of psychological debriefing on eyewitness memory. Behaviour Research and Therapy, 45, 1245-1254.

Dixon, R. A., \& Hultsch, D. F. (1983). Structure and development of metamemory in adulthood. Journal of Gerontology, 38, 682-688.

Doyle, J. M. (2005). True witness: Cops, court, science, and the battle against misidentification. New York: Palgrave Macmillan.

Drizin, S. A., \& Leo, R. A. (2004). The problem of false confessions in the post-DNA world. North Carolina Law Review, 82, 891-1007.

Duijf, L. (2005). De invloed van verhoorinterventies op de bereidheid tot het afleggen van een bekentenis [The influence of interrogation techniques on the tendency to falsely confess]. Unpublished master's thesis, Maastricht University, Maastricht, The Netherlands.

Franssens, D., \& Peters, G.-J. Y. (2004). No false memories without amnesia? Unpublished bachelor's thesis, Maastricht University, Maastricht, The Netherlands.

Freyd, J. J., \& Gleaves, D. H. (1996). “Remembering" words not presented in lists: Relevance to the current recovered/false memory controversy. Journal of Experimental Psychology: Learning, Memory, and Cognition, 22, 811-813. 
Freyd, P., \& Taub, S. (1999). About the False Memory Syndrome Foundation. In S. Taub (Ed.), Recovered memories of child sexual abuse: Psychological, social, and legal perspectives on a contemporary mental health controversy (pp. 17-39). Springfield, IL: Charles C. Thomas Publisher.

Gabbert, F., Memon, A., Allan, K., \& Wright, D. B. (2004). Say it to my face: Examining the effects of socially encountered misinformation. Legal and Criminological Psychology, 9, 215-227.

Gallo, D. A. (2010). False memories and fantastic beliefs: 15 years of the DRM illusion. Memory \& Cognition, 38, 833-848.

Garry, M., Manning, C. G., Loftus, E. F., \& Sherman, S. J. (1996). Imagination inflation: Imagining a childhood event inflates confidence that it occurred. Psychonomic Bulletin and Review, 3, 208-214.

Garry, M., \& Polaschek, D. L. L. (2000). Imagination and memory. Current Directions in Psychological Science, 9, 6-10.

Garven, S., Wood, J. M., Malpass, R. S., \& Shaw, J. S., III. (1998). More than suggestion: The effect of interviewing techniques from the McMartin Preschool case. Journal of Applied Psychology, 83, 347-359.

Geraerts, E., Smeets, E., Jelicic, M., Van Heerden, J., \& Merckelbach, H. (2005). Fantasy proneness, but not self-reported trauma is related to DRM performance of women reporting recovered memories of childhood sexual abuse. Consciousness and Cognition, 14, 602-612.

Gudjonsson, G. H. (1984). A new scale of interrogative suggestibility. Personality and Individual Differences, 5, 303-314.

Gudjonsson, G. H. (1989). Compliance in an interrogative situation: A new scale. Personality and Individual Differences, 10, 535-540.

Gudjonsson, G. H. (1997). The Gudjonsson Suggestibility Scales manual. Hove: Psychology Press.

Gudjonsson, G. H. (2001). False confession. The Psychologist, 14, 588-591.

Gudjonsson, G. H. (2003). The psychology of interrogations and confessions: $A$ handbook. New York: Wiley.

Gudjonsson, G. H. (2006). The psychological vulnerabilities of witnesses and the risk of false accusations and false confessions. In A. HeatonArmstrong, E. Shepherd, G. H. Gudjonsson \& D. Wolchover (Eds.), Witness testimony: Psychological, investigative and evidential perspectives (pp. 61-75). Oxford: Oxford University Press.

Gudjonsson, G. H. (2010). Psychological vulnerabilities during police interviews: Why are they important? Legal and Criminological Psychology, $15,161-175$.

Gudjonsson, G. H., Hannesdottir, K., Petursson, H., \& Bjornsson, G. (2002). The effects of alcohol withdrawal on mental state, interrogative suggestibility and compliance: An experimental study. Journal of Forensic Psychiatry, 13, 53-67. 
Gudjonsson, G. H., Kopelman, M. D., \& MacKeith, J. A. C. (1999). Unreliable admissions to homicide: A case of misdiagnosis of amnesia and misuse of abreaction technique. British Journal of Psychiatry, 174, 455-459.

Gudjonsson, G. H., \& Lister, S. (1984). Interrogative suggestibility and its relationship with self-esteem and control. Journal of the Forensic Science Society, 24, 99-110.

Gudjonsson, G. H., \& MacKeith, J. A. C. (1982). False confessions: Psychological effects of interrogation. A discussion paper. In A. Trankell (Ed.), Reconstructing the past: The role of psychologists in criminal trials (pp. 253-269). Deventer: Kluwer.

Gudjonsson, G. H., \& Sigurdsson, J. F. (2003). The relationship of compliance with coping strategies and self-esteem. European Journal of Psychological Assessment, 19, 117-123.

Gudjonsson, G. H., \& Sigurdsson, J. F. (2010). False confessions in the Nordic countries: Background and current landscape. In P. A. Granhag (Ed.), Forensic psychology in context: Nordic and international approaches (pp. 94-116). Devon: Willan Publishing.

Gudjonsson, G. H., Young, S., \& Bramham, J. (2007). Interrogative suggestibility in adults diagnosed with Attention-Deficit Hyperactivity Disorder (ADHD). Personality and Individual Differences, 43, 737-745.

Harkin, B., \& Kessler, K. (2009). How checking breeds doubt: Reduced performance in a simple working memory task. Behaviour Research and Therapy, 47, 504-512.

Hartwig, M., Granhag, P. A., \& Vrij, A. (2005). Police interrogation from a social psychology perspective. Policing and Society, 15, 379-399.

Hekkanen, S. T., \& McEvoy, C. (2002). False memories and sourcemonitoring problems: Criterion differences. Applied Cognitive Psychology, 16, 73-85.

Henkel, L. A., \& Coffman, K. J. (2004). Memory distortions in coerced false confessions: A source monitoring framework analysis. Applied Cognitive Psychology, 18, 567-588.

Horselenberg, R., De Zutter, A., \& Van Bergen, S. (2010, June). Imagine you made the computer crash. Paper presented at the 20th Conference of the European Association of Psychology and Law, Göteborg, Sweden.

Horselenberg, R., Merckelbach, H., \& Josephs, S. (2003). Individual differences and false confessions: A conceptual replication of Kassin and Kiechel (1996). Psychology, Crime \& Law, 9, 1-8.

Horselenberg, R., Merckelbach, H., Smeets, T., Franssens, D., Peters, G.-J. Y., $\delta$ Zeles, G. (2006). False confessions in the lab: Do plausibility and consequences matter? Psychology, Crime \& Law, 12, 61-75. 
Horselenberg, R., Smeets, T., \& Zonnenberg, A. (2007, July). The alt-key in prison. Paper presented at the 3rd International Congress of Psychology and Law, Adelaide, Australia.

Huffman, M. L., Crossman, A. M., \& Ceci, S. J. (1997). “Are false memories permanent?": An investigation of the long-term effects of source misattributions. Consciousness and Cognition, 6, 482-490.

Inbau, F. E., Reid, J. E., Buckley, J. P., \& Jayne, B. C. (2001). Criminal interrogation and confessions (4th ed.). Gaithersburg, MD: Aspen.

Israëls, H., \& Horselenberg, R. (2010). Valse bekentenissen [False confessions]. In P. J. van Koppen, H. Merckelbach, M. Jelicic \& J. W. de Keijser (Eds.), Reizen met mijn rechter: Psychologie van het Recht (pp. 765783). Deventer: Kluwer.

Itsukushima, Y., Nishi, M., Maruyama, M., \& Takahashi, M. (2006). The effect of presentation medium of post-event information: Impact of cowitness information. Applied Cognitive Psychology, 20, 575-585.

Johnson, M. K., Hashtroudi, S., \& Lindsay, D. S. (1993). Source monitoring. Psychological Bulletin, 114, 3-28.

Johnson, M. K., \& Raye, C. L. (1981). Reality monitoring. Psychological Review, 88, 67-85.

Kalska, H., Punamäki, R. L., Mäkinen-Pelli, T., \& Saarinen, M. (1999). Memory and metamemory functioning among depressed patients. $A p$ plied Neuropsychology, 6, 96-107.

Kassin, S. M. (2005). On the psychology of confessions: Does innocence put innocents at risk? American Psychologist, 60, 215-228.

Kassin, S. M. (2007). Internalized false confessions. In M. P. Toglia, J. D. Read, D. F. Ross \& R. C. L. Lindsay (Eds.), The handbook of eyewitness psychology, Volume 1: Memory for events (pp. 175-192). Mahwah, NJ: Lawrence Erlbaum Associates.

Kassin, S. M. (2008). The psychology of confessions. Annual Review of Law and Social Science, 4, 193-217.

Kassin, S. M., Drizin, S. A., Grisso, T., Gudjonsson, G. H., Leo, R. A., \& Redlich, A. D. (2010). Police-induced confessions: Risk factors and recommendations. Law and Human Behavior, 34, 3-38.

Kassin, S. M., \& Gudjonsson, G. H. (2004). The psychology of confessions: A review of the literature and issues. Psychological Science in the Public Interest, 5, 33-67.

Kassin, S. M., \& Kiechel, K. L. (1996). The social psychology of false confessions: Compliance, internalization, and confabulation. Psychological Science, 7, 125-128.

Kassin, S. M., \& McNall, K. (1991). Police interrogations and confessions: Communicating promises and threats by pragmatic implication. LaW and Human Behavior, 15, 233-251. 
Kassin, S. M., Meissner, C. A., \& Norwick, R. J. (2005). “I'd know a false confession if I saw one": A comparative study of college students and police investigators. Law and Human Behavior, 29, $211-227$.

Kassin, S. M., \& Neumann, K. (1997). On the power of confession evidence: An experimental test of the fundamental difference hypothesis. LaW and Human Behavior, 21, 469-484.

Kassin, S. M., \& Wrightsman, L. S. (1985). Confession evidence. In S. M. Kassin \& L. S. Wrightsman (Eds.), The psychology of evidence and trial procedure (pp. 67-94). Beverly Hills, CA: Sage.

Kopelman, M. D. (2002). Disorders of memory. Brain: A Journal of Neurology, 125, 2152-2190.

Kraasch, M. (2009). The effect of repeated interrogations on confidence and memory. Unpublished master's thesis, Maastricht University, Maastricht, The Netherlands.

Krähenbühl, S., Blades, M., \& Eiser, C. (2009). The effect of repeated questioning on children's accuracy and consistency in eyewitness testimony. Legal and Criminological Psychology, 14, 263-278.

Lee, K. (2004). Age, neuropsychological, and social cognitive measures as predictors of individual differences in susceptibility to the misinformation effect. Applied Cognitive Psychology, 18, 997-1019.

Leippe, M. R., Manion, A. P., \& Romanczyk, A. (1992). Eyewitness persuasion: How and how well do fact finders judge the accuracy of adults' and children's memory reports? Journal of Personality and Social Psychology, 63, 181-197.

Leo, R. A. (1996). Inside the interrogation room. Journal of Criminal Law and Criminology, 86, 266-303.

Leo, R. A. (2009). False confessions: Causes, consequences, and implications. Journal of the American Academy of Psychiatry and the Law, 37, 332343.

Liebman, J. I., McKinley Pace, M. J., Leonard, A. M., Sheesley, L. A., Gallant, C. L., Renkey, M. E., et al. (2002). Cognitive and psychosocial correlates of adults' eyewitness accuracy and suggestibility. Personality and Individual Differences, 33, 49-66.

Loftus, E. F. (1997). Creating childhood memories. Applied Cognitive Psychology, 11, 75-86.

Loftus, E. F. (2005). Planting misinformation in the human mind: A 30-year investigation of the malleability of memory. Learning and Memory, 12, 361-366.

Loftus, E. F., \& Davis, D. (2006). Recovered memories. Annual Review of Clinical Psychology, 2, 469-498. 
Loftus, E. F., \& Palmer, J. C. (1974). Reconstruction of automobile destruction: An example of the interaction between language and memory. Journal of Verbal Learning and Verbal Behavior, 13, 585-589.

Magnussen, S., Andersson, J., Cornoldi, C., De Beni, R., Endestad, T., Goodman, G. S., et al. (2006). What people believe about memory. Memory, 14, 595-613.

Malsch, M., Haket, V., \& Nijboer, H. (2008). De gevaren van het procesverbaal [The dangers of the filed report]. Nederlands Juristenblad, 41, 2578-2582.

McCann, J. T. (1998). A conceptual framework for identifying various types of confessions. Behavioral Sciences and the Law, 16, 441-453.

McCloskey, M., \& Zaragoza, M. (1985). Misleading postevent information and memory for events: Arguments and evidence against memory impairment hypotheses. Journal of Experimental Psychology: General, 114, $1-16$.

McNally, R. J., \& Kohlbeck, P. A. (1993). Reality monitoring in ObsessiveCompulsive Disorder. Behaviour Research and Therapy, 31, 249-253.

Merckelbach, H., \& Jelicic, M. (2005). Hoe een CIA-agent zijn geheugen hervond en andere waargebeurde verhalen [On how a CIA-agent recovered his memory and other true stories]. Amsterdam: Contact.

Merckelbach, H., \& Muris, P. (2008). Cognitive Failures Questionnaire. In T. Giesbrecht, C. de Ruiter \& M. Jelicic (Eds.), Forensisch psychodiagnostisch gereedschap: Malingering, psychopathie en andere persoonlijkheidstrekken (pp. 129-135). Amsterdam: Harcourt.

Merckelbach, H., Muris, P., Nijman, H., \& De Jong, P. J. (1996). Selfreported cognitive failures and neurotic symptomatology. Personality and Individual Differences, 20, 715-724.

Merckelbach, H., Muris, P., Wessel, I., \& Van Koppen, P. J. (1998). The Gudjonsson Suggestibility Scale (GSS): Further data on its reliability, validity, and metacognition correlates. Social Behavior and Personality, 26, 203210.

Merckelbach, H., \& Wessel, I. (2000). Memory for actions and dissociation in Obsessive-Compulsive Disorder. Journal of Nervous and Mental Disease, 188, 846-848.

Merckelbach, H., Wiers, R., Horselenberg, R., \& Wessel, I. (2001). Effects of retrieving childhood events on metamemory judgments depend on the questions you ask. British Journal of Clinical Psychology, 40, 215-220.

Morris, E. K., Laney, C., Bernstein, D. M., \& Loftus, E. F. (2006). Susceptibility to memory distortion: How do we decide it has occurred? American Journal of Psychology, 119, 255-274.

Nelson, H. E. (1982). National Adult Reading Test. Windsor: NFER-Nelson. 
Odinot, G., \& Wolters, G. (2006). Repeated recall, retention interval and the accuracy-confidence relation in eyewitness memory. Applied Cognitive Psychology, 20, 973-985.

Odinot, G., Wolters, G., \& Lavender, T. (2009). Repeated partial eyewitness questioning causes confidence inflation but not retrieval-induced forgetting. Applied Cognitive Psychology, 23, 90-97.

Odinot, G., Wolters, G., \& Van Giezen, A. (2008). Repeated suggestive questioning, accuracy, confidence and consistency in eyewitness event memory. In G. Odinot (Ed.), Eyewitness confidence: The relation between accuracy and confidence in episodic memory (pp. 37-55). Leiden: University of Leiden.

Ofshe, R. J., \& Leo, R. A. (1997). The social psychology of police interrogation: The theory and classification of true and false confessions. Studies in Law, Politics and Society, 16, 189-251.

Otgaar, H., \& Candel, I. (in press). Children's false memories: Different false memory paradigms reveal different results. Psychology, Crime $\&$ Law.

Otgaar, H., Candel, I., Merckelbach, H., \& Wade, K. A. (2009). Abducted by a UFO: Prevalence information affects young children's false memories for an implausible event. Applied Cognitive Psychology, 23, 115-125.

Pearse, J., \& Gudjonsson, G. H. (1999). Measuring influential police interviewing tactics: A factor analytic approach. Legal and Criminological Psychology, 4, 221-238.

Peters, M. J. V., Jelicic, M., Haas, N., \& Merckelbach, H. (2006). Mild executive dysfunctions in undergraduates are related to remembering words never presented. International Journal of Neuroscience, 116, 1065-1077.

Peterson, C., Semmel, A., Von Baeyer, C., Abramson, L. T., Metalsky, G. I., \& Seligman, M. E. P. (1982). The Attributional Style Questionnaire. Cognitive Therapy and Research, 6, 287-300.

Ponds, R. W. H. M., \& Jolles, J. (1996). Memory complaints in elderly people: The role of memory abilities, metamemory, depression, and personality. Educational Gerontology, 22, 341-357.

Ponds, R. W. H. M., Van Boxtel, M. P. J., \& Jolles, J. (2000). Age-related changes in subjective cognitive functioning. Educational Gerontology, 26, 67-81.

Radomsky, A. S., \& Alcolado, G. M. (2010). Don't even think about checking: Mental checking causes memory distrust. Journal of Behavior Therapy and Experimental Psychiatry, 41, 345-351.

Radomsky, A. S., Gilchrist, P. T., \& Dussault, D. (2006). Repeated checking really does cause memory distrust. Behaviour Research and Therapy, 44, 305-316. 
Radomsky, A. S., \& Rachman, S. (2004). The importance of importance in OCD memory research. Journal of Behavior Therapy and Experimental Psychiatry, 35, 137-151.

Rey, A. (1964). L'examen clinique en psychologie [The clinical examination in psychology]. Paris: Presses Universitaires de France.

Roediger, H. L., III, \& McDermott, K. B. (1995). Creating false memories: Remembering words not presented in lists. Journal of Experimental Psychology: Learning, Memory, and Cognition, 21, 803-814.

Roediger, H. L., III, \& McDermott, K. B. (1996). False perceptions of false memories. Journal of Experimental Psychology: Learning, Memory, and Cognition, 22, 814-816.

Russano, M. B., Meissner, C. A., Narchet, F. M., \& Kassin, S. M. (2005). Investigating true and false confessions within a novel experimental paradigm. Psychological Science, 16, 481-486.

Saks, M. J., \& Koehler, J. J. (2005). The coming paradigm shift in forensic identification science. Science, 309, 892-895.

Scheck, B., Neufeld, P., \& Dwyer, J. (2001). Actual innocence: When justice goes wrong and how to make it right. New York: Signet.

Schmand, B., Lindeboom, J., \& Van Harskamp, F. (1992). Nederlandse Leestest voor Volwassenen [Dutch Adult Reading Test]. Lisse: Swets \& Zeitlinger.

Schooler, J. W., \& Loftus, E. F. (1993). Multiple mechanisms mediate individual differences in eyewitness accuracy and suggestibility. In J. M. Puckett \& H. W. Reese (Eds.), Mechanisms of everyday cognition (pp. 177-203). Hillsdale, NJ: Lawrence Erlbaum Associates.

Scoboria, A., Mazzoni, G. A. L., \& Jarry, J. L. (2008). Suggesting childhood food illness results in reduced eating behavior. Acta Psychologica, 128, 304-309.

Scoboria, A., Mazzoni, G. A. L., Kirsch, I., \& Relyea, M. (2004). Plausibility and belief in autobiographical memory. Applied Cognitive Psychology, $18,791-807$.

Shaw, J. S., \& McClure, K. A. (1996). Repeated postevent questioning can lead to elevated levels of eyewitness confidence. LaW and Human Behavior, 20, 629-653.

Singh, K. K., \& Gudjonsson, G. H. (1984). Interrogative suggestibility, delayed memory and self-concept. Personality and Individual Differences, 5 , 203-209.

Smeets, T. (2008). Gudjonsson Suggestibility Scales en Gudjonsson Compliance Scale [Gudjonsson Suggestibility Scales and Gudjonsson Compliance Scale]. In T. Giesbrecht, C. de Ruiter \& M. Jelicic (Eds.), Forensisch psychodiagnostisch gereedschap: Malingering, psychopathie en andere persoonlijkheidstrekken (pp. 63-72). Amsterdam: Harcourt. 
Smeets, T., Candel, I., \& Merckelbach, H. (2004). Accuracy, completeness, and consistency of emotional memories. American Journal of Psychology, 117, 595-609.

Smeets, T., Merckelbach, H., Horselenberg, R., \& Jelicic, M. (2005). Trying to recollect past events: Confidence, beliefs, and memories. Clinical Psychology Review, 25, 917-934.

Smith, G., Della Sala, S. D., Logie, R. H., \& Maylor, E. A. (2000). Prospective and retrospective memory in normal ageing and dementia: A questionnaire study. Memory, 8, 311-321.

Sporer, S. L., Penrod, S. D., Read, D., \& Cutler, B. (1995). Choosing, confidence, and accuracy: A meta-analysis of the confidence-accuracy relation in eyewitness identification studies. Psychological Bulletin, 118, 315-327.

Squire, L. R., Wetzel, C. D., \& Slater, P. C. (1979). Memory complaint after electroconvulsive therapy: Assessment with a new self-rating instrument. Biological Psychiatry, 14, 791-801.

Stevens, J. (1992). Applied multivariate statistics for the social sciences (2nd ed.). Hillsdale: Lawrence Erlbaum Associates.

Sutherland, R., \& Hayne, H. (2001). The effect of postevent information on adults' eyewitness reports. Applied Cognitive Psychology, 15, 249-263.

The Innocence Project. (2010). Understand the causes: False confessions/admissions. Retrieved 4 October, 2010, from http://www.innocence project.org/understand/False-Confessions.php.

Tolin, D. F., Abramowitz, J. S., Brigidi, B. D., Amir, N., Street, G. P., \& Foa, E. B. (2001). Memory and memory confidence in Obsessive-Compulsive Disorder. Behaviour Research and Therapy, 39, 913-927.

Tomes, J. L., \& Katz, A. N. (1997). Habitual susceptibility to misinformation and individual differences in eyewitness memory. Applied Cognitive Psychology, 11, 233-251.

Tomes, J. L., \& Katz, A. N. (2000). Confidence-accuracy relations for real and suggested events. Memory, 8, 273-283.

Tousignant, J. P., Hall, D., \& Loftus, E. F. (1986). Discrepancy detection and vulnerability to misleading postevent information. Memory $\mathcal{E}$ Cognition, 14, 329-338.

Tversky, A., \& Kahneman, D. (1973). Availability: A heuristic for judging frequency and probability. Cognitive Psychology, 5, 677-695.

Van Bergen, S. (2008). Squire Subjective Memory Questionnaire. In T. Giesbrecht, C. de Ruiter \& M. Jelicic (Eds.), Forensisch psychodiagnostisch gereedschap: Malingering, psychopathie en andere persoonlijkheidstrekken (pp. 137-142). Amsterdam: Harcourt.

Van Bergen, S. (2009a). Geheugenwantrouwen in de praktijk [Memory distrust in practice]. Tijdschrift voor Neuropsychiatrie $\&$ Gedragsneurologie, 8, 59-63. 
Van Bergen, S. (2009b). Memory distrust: Risky business? In L. Strömwall \& P. A. Granhag (Eds.), Memory: Reliability and personality. Proceedings of the Second Joint Nordic PhD course in Legal and Investigative Psychology (pp. 57-67). Göteborg: Göteborg University.

Van Bergen, S., Brands, I., Jelicic, M., \& Merckelbach, H. (2010a). Assessing trait memory distrust: Psychometric properties of the Squire Subjective Memory Questionnaire. Legal and Criminological Psychology, 15, 373384.

Van Bergen, S., Horselenberg, R., Merckelbach, H., Jelicic, M., \& Beckers, R. (2010b). Memory distrust and acceptance of misinformation. Applied Cognitive Psychology, 24, 885-896.

Van Bergen, S., \& Jelicic, M. (2007). De rol van geheugenfeedback op imaginatie-inflatie [The role of memory feedback on imagination inflation]. Directieve Therapie, 27, 5-16.

Van Bergen, S., Jelicic, M., \& Merckelbach, H. (2008). Interrogation techniques and memory distrust. Psychology, Crime \& Law, 14, 435-449.

Van Bergen, S., Jelicic, M., \& Merckelbach, H. (2009). Are subjective memory problems related to suggestibility, compliance, false memories, and objective memory performance? American Journal of Psychology, 122, 249-257.

Van Bergen, S., Merckelbach, H., Horselenberg, R., Jelicic, M., \& Zuidberg, B. (2011). Did I do that? Memory distrust promotes internalised false confessions. Manuscript submitted for publication.

Van Bergen, S., Merckelbach, H., \& Jelicic, M. (2006). Je eigen geheugen wantrouwen: Een riskante zaak? [Memory distrust: Risky Business?]. De Psycholoog, 41, 664-669.

Van den Hout, M. (2010). Even checken [Just checking]. In A. Jansen, M. van den Hout \& H. Merckelbach (Eds.), Gek: Over angst, verslaving, depressie en andere ellende (pp. 44-59). Houten: Bohn Stafleu van Loghum.

Van den Hout, M., \& Kindt, M. (2003a). Phenomenological validity of an OCD-memory model and the remember/know distinction. Behaviour Research and Therapy, 41, 369-378.

Van den Hout, M., \& Kindt, M. (2003b). Repeated checking causes memory distrust. Behaviour Research and Therapy, 41, 301-316.

Van den Hout, M., \& Kindt, M. (2004). Obsessive-Compulsive Disorder and the paradoxical effects of perseverative behaviour on experienced uncertainty. Journal of Behavior Therapy and Experimental Psychiatry, 35, $165-181$.

Van den Hout, M. A., Engelhard, I. M., De Boer, C., Du Bois, A., \& Dek, E. (2008). Perseverative and compulsive-like staring causes uncertainty about perception. Behaviour Research and Therapy, 46, 1300-1304. 
Van Koppen, P. J. (2007). Nederlandse feiten in het strafrecht [Dutch facts in criminal law]. $M r, 3,84$.

Van Koppen, P. J. (2009). Finding false confessions. In R. Bull, T. Valentine \& T. Williamson (Eds.), Handbook of psychology of investigative interviewing: Current developments and future directions (pp. 53-68). Chichester: Wiley.

Van Koppen, P. J., \& Penrod, S. D. (2003). Adversarial or inquisitorial: Comparing systems. In P. J. van Koppen \& S. D. Penrod (Eds.), Adversarial versus inquisitorial justice: Psychological perspectives on criminal justice systems (pp. 2-20). New York: Plenum.

Van Oorsouw, K. (2004). Amnesie als paradoxaal effect van herinneren [Amnesia as paradoxical effect of remembering]. De Psycholoog, 39, 544549.

Van Oorsouw, K. (2006). I honestly can't remember: Dissociative amnesia as a metamemory phenomenon. Maastricht: Universitaire Pers.

Van Oorsouw, K., Merckelbach, H., Ravelli, D., Nijman, H., \& Pompen, I. (2004). Alcoholic blackout for criminally relevant behavior. Journal of the American Academy of Psychiatry and the Law, 32, 364-370.

Vrij, A. (1998). Interviewing suspects. In A. Memon, A. Vrij \& R. Bull (Eds.), Psychology and Law: Truthfulness, Accuracy and Credibility (pp. 124144). Maidenhead: McGraw-Hill.

Wade, K. A., Garry, M., Read, J. D., \& Lindsay, D. S. (2002). A picture is worth a thousand lies: Using false photographs to create false childhood memories. Psychonomic Bulletin and Review, 9, 597-603.

Wagenaar, W. A. (2010). Broddelwerk; Over geklungel in het strafrechtelijk onderzoek [Botch-job; Fiddling about in criminal law investigations]. Amsterdam: Prometheus/Bert Bakker.

Ward, R. A., \& Loftus, E. F. (1985). Eyewitness performance in different psychological types. Journal of General Psychology, 112, 191-200.

Winkielman, P., Schwarz, N., \& Belli, R. F. (1998). The role of ease of retrieval and attribution in memory judgments: Judging your memory as worse despite recalling more events. Psychological Science, 9, 124-126.

Winograd, E., Peluso, J. P., \& Glover, T. A. (1998). Individual differences in susceptibility to memory illusions. Applied Cognitive Psychology, 12, S5S27.

Wright, D. B., Loftus, E. F., \& Hall, M. (2001). Now you see it; now you don't: Inhibiting recall and recognition of scenes. Applied Cognitive Psychology, 15, 471-482. 

The current dissertation addresses the concept of memory distrust in the legal context. Memory distrust can be defined as "a condition where people develop a profound distrust of their memory recollections, as a result of which they are particularly susceptible to relying on external cues and suggestions" (Gudjonsson, 2003, p. 196). Memory distrust can be encountered both in clinical and forensic settings. Especially in the legal setting, it may have far-reaching consequences. The memory distrust syndrome has only been described in forensic case studies. The present dissertation is a first attempt to develop a more systematic corpus of knowledge about memory distrust in the legal domain.

Chapter 1 presents two case vignettes of false confessions in which memory distrust played an important role. This chapter gives an overview of false memory and false confession research in which the memory distrust syndrome was firstly described. It also addresses other areas in which memory distrust is a common phenomenon (i.e., psychogeriatrics and the Obsessive-Compulsive Disorder). The following research questions are formulated and will be elaborated in the following chapters: What is memory distrust? What are related concepts of memory distrust? How can memory distrust be measured best? Are individuals suffering from memory distrust susceptible to developing false memories and/or false confessions?

This dissertation is divided into two parts; the first part addresses studies that examine trait memory distrust (Chapters 2, 3, and 4). This type of memory distrust manifests itself in people who have habitual memory doubts. The second part looks into state memory distrust, a temporary state in which individuals develop doubts about their memory (Chapters 5 and 6).

Chapter 2 describes a validation study of the Dutch adapted version of the Squire Subjective Memory Questionnaire (SSMQ) that can be used to assess trait memory distrust. The SSMQ proves to be a psychometrically sound instrument. In the forensic setting, it can be used to identify vulnerable suspects in an early stage. As a result, the level of interrogative pressure can be adjusted to the suspect's level of memory distrust. Ideally, this will diminish the frequency of false confessions.

To increase our understanding of memory distrust, we examined several concepts that were expected to relate to trait memory distrust in Chapter 2 , 3 , and 4. It can be concluded that trait memory distrust goes along with more cognitive failures (i.e., everyday lapses in memory, attention, and action) and a higher age. Furthermore, it appears that persons who distrust their memory perform more poorly on objective memory measures than controls. And most of the time, they are also more depressed and more compliant than individuals who are confident in their memory.

Contrary to our expectations, Chapter 3 failed to find that memory distrust relates to higher levels of suggestibility and false memories. This null- 
result might have to do with the fact that the type of memory distrust that we measured in this chapter was trait-like by nature, whereas all case studies referring to this relationship emphasise state memory distrust. Also, the false memory paradigm that we used, the DRM task, might not have been the most appropriate test to study false memories as such.

The study described in Chapter 4 therefore used a suggestion-induced paradigm to elicit false memories. As the name of this paradigm implies, it involves suggestions. The findings of this study show that individuals who suffer from trait memory distrust are more prone to accept misinformation than persons who are very confident in their memory. In other words, people suffering from memory distrust are more suggestible and therefore are more likely to create false memories. This contradicts the findings of Chapter 3. We think that the findings in Chapter 4 carry more weight than those in the former chapter as they were obtained with a more ecologically valid paradigm.

So far, the studies in this dissertation focused solely on trait memory distrust. The two chapters that follow concentrate on state memory distrust. Chapter 5 examined whether memory distrust could be elicited by interrogation techniques that have the potential of causing false confessions. Also, the relationship between memory distrust and the tendency to falsely confess was explored. This study confirmed that state memory distrust correlates positively with the tendency to falsely confess. However, the interrogation techniques did not have a uniform effect on both concepts (i.e., memory distrust and false confessions). More specifically, suggesting memory problems had the largest impact on memory distrust, whereas false technical evidence made individuals most willing to falsely confess. Because this study relied on a thought experiment, no conclusions could be drawn about the causal relationship between memory distrust and false confessions.

Chapter 6 presents a study that aimed to clarify this issue of causality. Using the computer crash paradigm (Kassin \& Kiechel, 1996), we accused undergraduate students of hitting a computer key they were not allowed to touch. A part of the participants had been manipulated into a state of memory distrust. In this way, it was possible to examine the effect of memory distrust on false confessions. Findings show that state memory distrust could be evoked by giving participants negative bogus feedback. More than half of the participants $(52 \%)$ falsely confessed to having caused the computer to crash, and of these, $58.5 \%$ internalised their confession. Furthermore, the overall confession rate was not influenced by lowered memory confidence. But findings demonstrate that participants with elevated state memory distrust (induced by negative feedback prior to the computer test) internalised their false confessions more often than participants who had not received 
this negative feedback. This study, therefore, indicates that memory distrust may be an antecedent of internalised false confessions.

In Chapter 7, the main findings of the studies presented in this thesis are summarised and discussed. Also, it looks at limitations and suggestions for future research as well as practical implications. 


\section{SAMENVATTING}

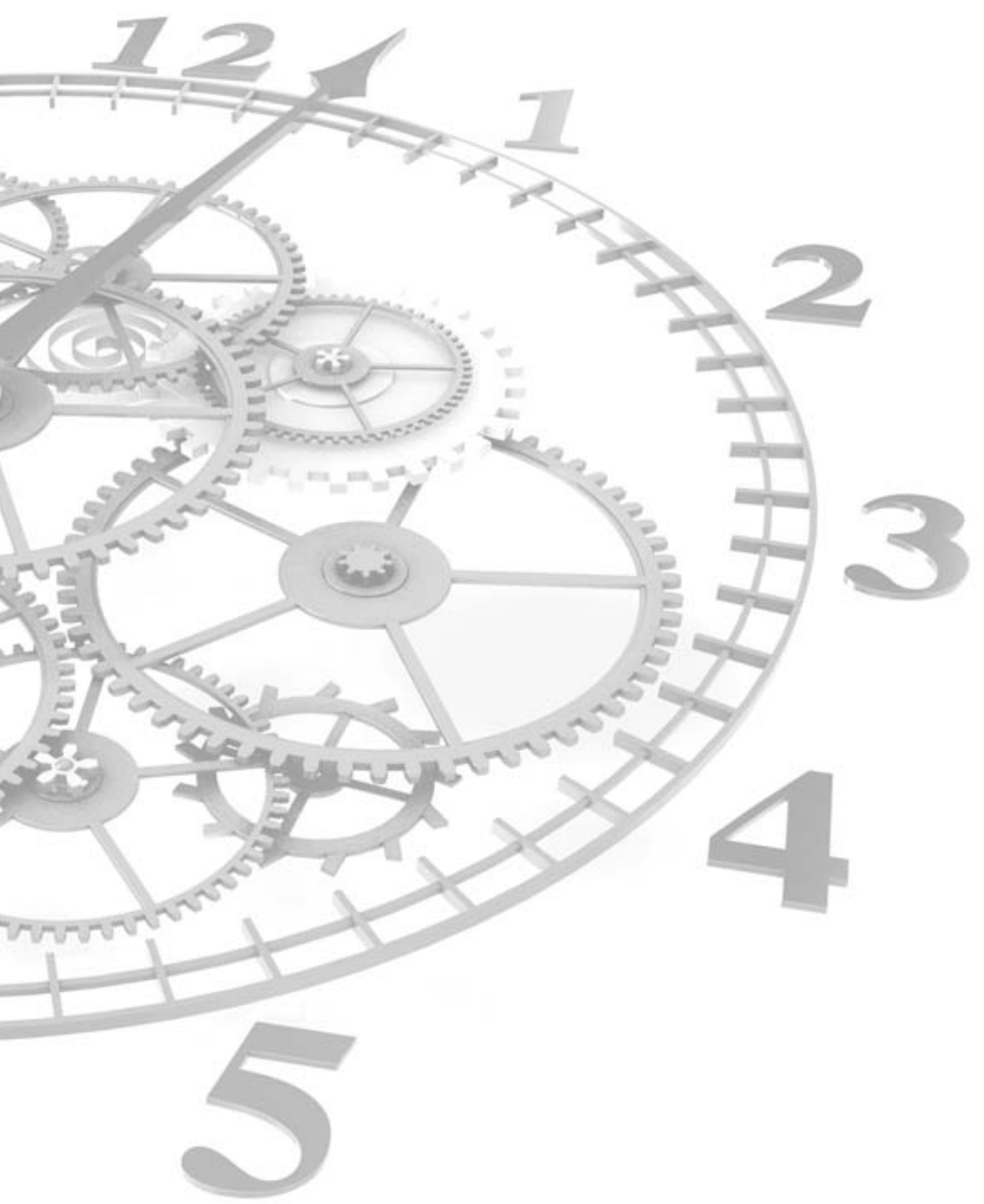


Dit proefschrift gaat over geheugenwantrouwen in de strafrechtelijke context. Geheugenwantrouwen kan worden gedefinieerd als een toestand waarin mensen een groot wantrouwen koesteren over hun herinneringen, waardoor ze extra vatbaar worden voor externe suggesties (Gudjonsson, 2003). Je kunt geheugenwantrouwen tegenkomen in zowel de klinische als forensische praktijk. Voornamelijk in de forensische praktijk kan geheugenwantrouwen verstrekkende gevolgen hebben. Tot dusverre is geheugenwantrouwen alleen beschreven aan de hand van casuïstiek. Dit proefschrift is een eerste poging om geheugenwantrouwen empirisch te onderzoeken. We hebben ons bij het uitvoeren van de studies vooral gericht op de strafrechtelijke context.

Hoofdstuk 1 begint met twee gevalsbeschrijvingen van valse bekentenissen waarbij geheugenwantrouwen een belangrijke rol heeft gespeeld. Dit hoofdstuk geeft een overzicht van onderzoek waarin geheugenwantrouwen in verband werd gebracht met pseudoherinneringen en valse bekentenissen. Het behandelt ook andere domeinen waarin geheugenwantrouwen een vaak voorkomend verschijnsel is, zoals onderzoek bij ouderen of bij patiënten met een obsessief-compulsieve stoornis. Tevens worden in dit hoofdstuk de onderzoeksvragen besproken die in de loop van dit proefschrift beantwoord worden, te weten: Wat is geheugenwantrouwen? Wat zijn de onderliggende mechanismen van geheugenwantrouwen? Hoe kun je geheugenwantrouwen het best meten? Zijn mensen die geheugenwantrouwen hebben vatbaarder voor het ontwikkelen van pseudoherinneringen of valse bekentenissen?

Dit proefschrift is opgedeeld in twee delen; het eerste deel bestaat uit studies naar geheugenwantrouwen als een soort persoonlijkheidstrek, genaamd 'trait memory distrust' (Hoofdstukken 2, 3 en 4). Deze variant van geheugenwantrouwen komt voor bij mensen die chronisch twijfelen aan hun geheugen. Het tweede deel richt zich op geheugenwantrouwen als een momentane toestand, te weten 'state memory distrust' (Hoofdstukken 5 en $6)$.

Hoofdstuk 2 beschrijft een valideringsstudie van de bewerkte Nederlandse versie van de Squire Subjective Memory Questionnaire (SSMQ). Deze vragenlijst kan gebruikt worden om geheugenwantrouwen als persoonlijkheidstrek te meten. De SSMQ is een valide en betrouwbaar instrument. In de forensische praktijk kan dit instrument gebruikt worden om kwetsbare verdachten in een vroeg stadium te identificeren. Op deze manier kan de druk tijdens het verhoor worden aangepast aan de mate van geheugenwantrouwen dat zich bij de verdachte manifesteert. In het beste geval zal dit het aantal valse bekentenissen verkleinen.

Om een beter zicht te krijgen op geheugenwantrouwen, is in de Hoofdstukken 2, 3 en 4 een aantal factoren onderzocht waarvan verwacht wordt 
dat ze gerelateerd zouden zijn aan geheugenwantrouwen. Uit deze hoofdstukken kan geconcludeerd worden dat geheugenwantrouwen samengaat met een hogere leeftijd en meer cognitieve fouten. Dit zijn kleine vergissingen in het geheugen, de aandacht, of de motoriek. Daarnaast lijken mensen die hun geheugen wantrouwen ook daadwerkelijk een slechter geheugen te hebben. Bovendien zijn ze vaak ook depressiever en meegaander dan individuen die zelfzeker zijn over hun geheugen.

Tegengesteld aan de verwachtingen blijkt uit Hoofdstuk 3 dat geheugenwantrouwen niet samenhangt met een hogere suggestibiliteit en pseudoherinneringen. Dit kan komen doordat het type geheugenwantrouwen dat in deze studie werd bekeken ('trait memory distrust') verschilt van het type dat vaak in gevalsbeschrijvingen centraal staat ('state memory distrust'). Een andere verklaring voor dit nulresultaat is dat het paradigma dat werd gebruikt om pseudoherinneringen uit te lokken, de DRM-taak, niet het meest geschikte paradigma is geweest.

De studie beschreven in Hoofdstuk 4 heeft daarom een ander paradigma gebruikt, waarbij suggesties worden gebruikt om pseudoherinneringen uit te lokken. Deze studie laat zien dat mensen die hun geheugen wantrouwen eerder foutieve informatie accepteren dan mensen die zeker zijn van hun geheugen. Mensen met geheugenwantrouwen zijn dus suggestiever en daardoor eerder geneigd pseudoherinneringen te ontwikkelen. Dit spreekt de resultaten van Hoofdstuk 3 tegen, maar de resultaten uit dit hoofdstuk wegen zwaarder aangezien hier gebruik is gemaakt van een paradigma met een hogere ecologische validiteit.

De studies die tot nu toe in dit proefschrift zijn beschreven, richtten zich allemaal op geheugenwantrouwen als persoonlijkheidstrek. De volgende twee hoofdstukken gaan over geheugenwantrouwen als een momentane toestand. De studie beschreven in Hoofdstuk 5 onderzocht of geheugenwantrouwen kan worden uitgelokt door verhoortechnieken die ook vaak valse bekentenissen teweegbrengen. Deze studie liet zien dat geheugenwantrouwen en de neiging tot vals bekennen met elkaar samenhangen. De verhoortechnieken hadden echter niet hetzelfde effect op geheugenwantrouwen en valse bekentenissen. Zo waren proefpersonen het meest geneigd hun geheugen te wantrouwen als er een suggestie was aangedragen van geheugenproblemen. Aan de andere kant zorgde vals technisch bewijs ervoor dat de meeste mensen ertoe neigden om een valse bekentenis af te leggen. Omdat deze studie een gedachte-experiment betrof, kunnen geen conclusies getrokken worden over causaliteit.

Het experiment uit Hoofdstuk 6 werd opgezet om een uitspraak te doen over causaliteit. Studenten werden beschuldigd aan de hand van het computer crash paradigma (Kassin \& Kiechel, 1996). Een deel van de proefpersonen werd door middel van valse negatieve feedback gemanipuleerd in een 
toestand van geheugenwantrouwen. Op deze manier was het mogelijk om de effecten van geheugenwantrouwen op valse bekentenissen te onderzoeken. De resultaten laten zien dat het geven van valse negatieve feedback geheugenwantrouwen uitlokt. Iets meer dan de helft van de proefpersonen $(52 \%)$ legde een valse bekentenis af en gaf dus toe dat zij verantwoordelijk waren voor het crashen van de computer. Van deze groep geloofde 58,5\% daadwerkelijk dat zij de computercrash zelf hadden veroorzaakt. Zij legden dus een geïnternaliseerde valse bekentenis af. Het aantal valse bekentenissen was niet hoger in de groep studenten die hun geheugen begonnen te wantrouwen, maar de proportie geïnternaliseerde valse bekentenissen was wel hoger in deze groep vergeleken met de groep die geen valse negatieve feedback kreeg. Deze studie demonstreert dat geheugenwantrouwen best een voorloper van geïnternaliseerde valse bekentenissen kan zijn.

In het afsluitende Hoofdstuk 7 worden de belangrijkste bevindingen samengevat en de eventuele beperkingen van de studies besproken. Ook wordt een aantal suggesties gedaan voor toekomstig onderzoek. Het hoofdstuk eindigt met de praktische implicaties van de bevindingen. 


\section{DANKWOORD}

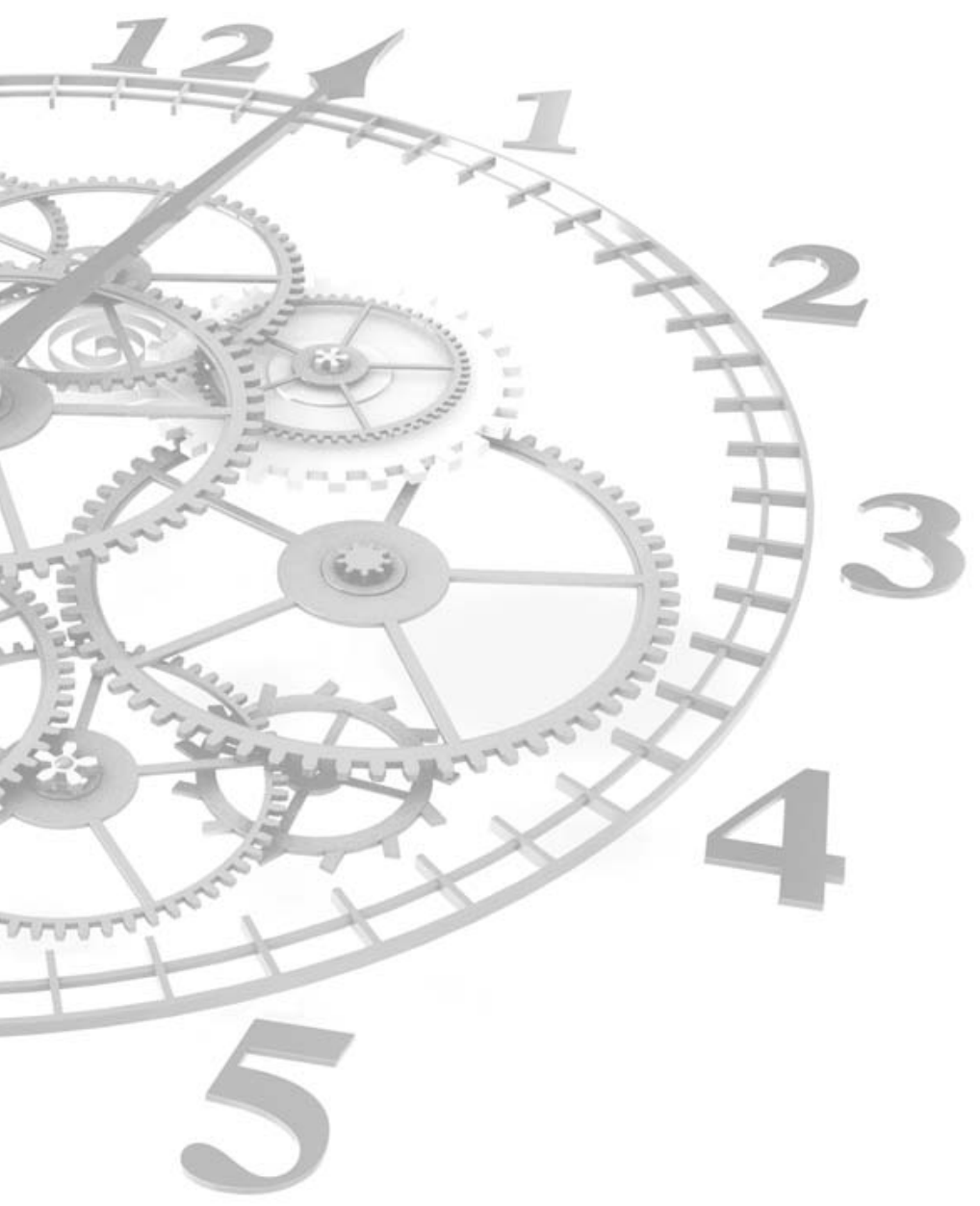


$\mathrm{Nu}$ is het dan zo ver, mijn boekje is af! Ik wil graag even stil staan bij de mensen die voor mij belangrijk zijn geweest in mijn aio-periode.

In eerste plaats wil ik mijn begeleiders bedanken. Harald, jij bent een promotor uit duizenden. In 2002 klopte ik bij jou aan voor keuzevakken in de rechtspsychologie en ik heb het veld sindsdien niet meer willen verlaten. Jij hebt mij heel erg veel geleerd tijdens mijn tijd als aio met name op schrijfgebied. Bovendien zijn je onderzoeksideeën en enthousiasme bewonderenswaardig. Marko, jij gaf mij genoeg vertrouwen om het project daadwerkelijk zelf uit te voeren en hebt mij daardoor gestimuleerd in mijn zelfstandigheid. Wanneer ik tegen dingen aanliep, kon ik altijd bij jou terecht. Dank daarvoor! De combinatie van jullie beiden als begeleiders zorgde voor een goede balans tijdens mijn project. Ik wil jullie ook heel erg bedanken voor jullie steunende houding tijdens mijn ziekteperiode. Ik ben ervan overtuigd dat dit positief heeft bijgedragen aan mijn herstel.

Onderzoek doen, doe je niet alleen. Ik ben daarom ook blij met de (oud-) collega's van mijn sectie: Alana, Anna, Beatrijs, Bruno, Conny, Corine, Dalena, David, Ewout, Glynis, Harald, Ingrid, Jill, Kim, Lieke, Linsey, Maarten, Maartje, Manuela, Marko, Melanie, Thomas, Timo en Tom. In het bijzonder wil ik me nog even richten op Lins en Jill. Dames, ik heb ontzettend genoten van al onze gezellige praatjes; bij jullie op de kamer vloog de tijd! Ook de collega's van de rechtenfaculteit verdienen het om hier genoemd te worden: André, Gwenny, Han, Hans, Liesbeth, Peter, Robert en Ton. Ik wil jullie allemaal bedanken voor alle leuke jaren en de gezelligheid tijdens onze uitjes!

Hierbij wil ik ook alle CPS-collega's voor de leuke tijd bedanken. Truus, Jessie en Angela, jullie ondersteuning was geweldig! En niet te vergeten: een dikke merci voor mijn (oud-)collegaatjes, en inmiddels vrienden, van de andere secties: Carolien, Ellen, Esther, Jill, Loes, Saar en de mannen GJ, Hans, Hugo en Tim. Onze lunches, etentjes en feestjes waren altijd ontzettend gezellig, vaak hilarisch en vooral memorabel.

Als je al 10 jaar op de Faculteit werkt leer je een hoop leuke mensen kennen. Ik wil al deze mensen bedanken voor een leuke tijd die we samen hebben doorgebracht! Jet, jou wil ik even apart noemen, ik geniet altijd van jouw gezelschap en ik waardeer onze vriendschap heel erg. 
Ik ben ervan overtuigd dat een aio-project geen kans van slagen heeft zonder fijne kamergenootjes. Hugo, jij bent in één woord geweldig, vandaar dat je vandaag ook mijn paranimf bent! Henry en Elke, jullie zijn schatten. Er heerste altijd een fijne relaxte sfeer in onze kamer, dat maakte werken heel erg fijn. Henry, ik wil even uitgebreid bij jou stil staan. Jij was niet alleen maar een kamergenoot, maar ook een vriend. Je was mijn rots in de branding tijdens ons onverwachte langdurige verblijf in Duitsland. Ik ben dolgelukkig met de flexibiliteit die jij hebt getoond, zoals het halsoverkop overnemen van (stage-)studenten en het behandelen van belangrijke e-mails in de tijd dat ik daar zelf niet toe in staat was. Daarnaast heb ik onze brainstorms over onderzoek tussen de bedrijven door altijd erg gewaardeerd.

Ik wil hier ook alle studenten bedanken die me hebben geholpen met het verzamelen van data voor mijn studies in dit proefschrift. Bart, Eva, Francine, Heleen, Janneke, Marianne en Roos, heel erg bedankt voor jullie inzet!

Jill en Huug, wat fijn dat jullie vandaag, op deze belangrijke dag, mijn paranimfen willen zijn. Jill, mijn lieve schat, wat ben ik blij dat wij vriendinnetjes zijn! Bedankt voor alle gezellige lunches/etentjes, lieve knuffels, knusse theetjes, diepgaande analyses, heerlijke cheesecake-momenten, lieve kaartjes/e-mails en andere leuke dates! Huug, jij bent één van de fijnste personen die ik ken. Ik kijk met heel erg veel plezier terug op de tijd dat wij kamergenoten waren. Als (bijna) geen ander, lukt het jou altijd om me te laten lachen. En je knuffels zijn fantastisch! Lieverds, super bedankt!

Mama, papa, Patricia, Roger, Eric, Marie-Lisah, mijn allerliefste nichtjes, lieve vrienden en familie, ik wil jullie bedanken voor jullie eindeloze steun, vertrouwen en interesse. Jullie zijn het beste vangnet dat iemand zich kan wensen!

Robert, mijn steun en toeverlaat. Dit project heeft mij niet alleen een mooi proefschrift opgeleverd, maar ook mijn grote liefde! Wat ben ik blij dat wij elkaar hebben leren kennen. Elke dag is gewoon leuker met jou. Ik lief jou! Marit en Bente, jullie zijn schatjes en ik ben heel erg blij dat wij al 5 jaar een gezinnetje vormen. Kris, mijn kleine grote wonder, wat ben ik blij dat jij er bent! Door jou besef ik wat echt belangrijk in het leven is. Dankjewel daarvoor! 



\section{CURRICULUM VITAE}

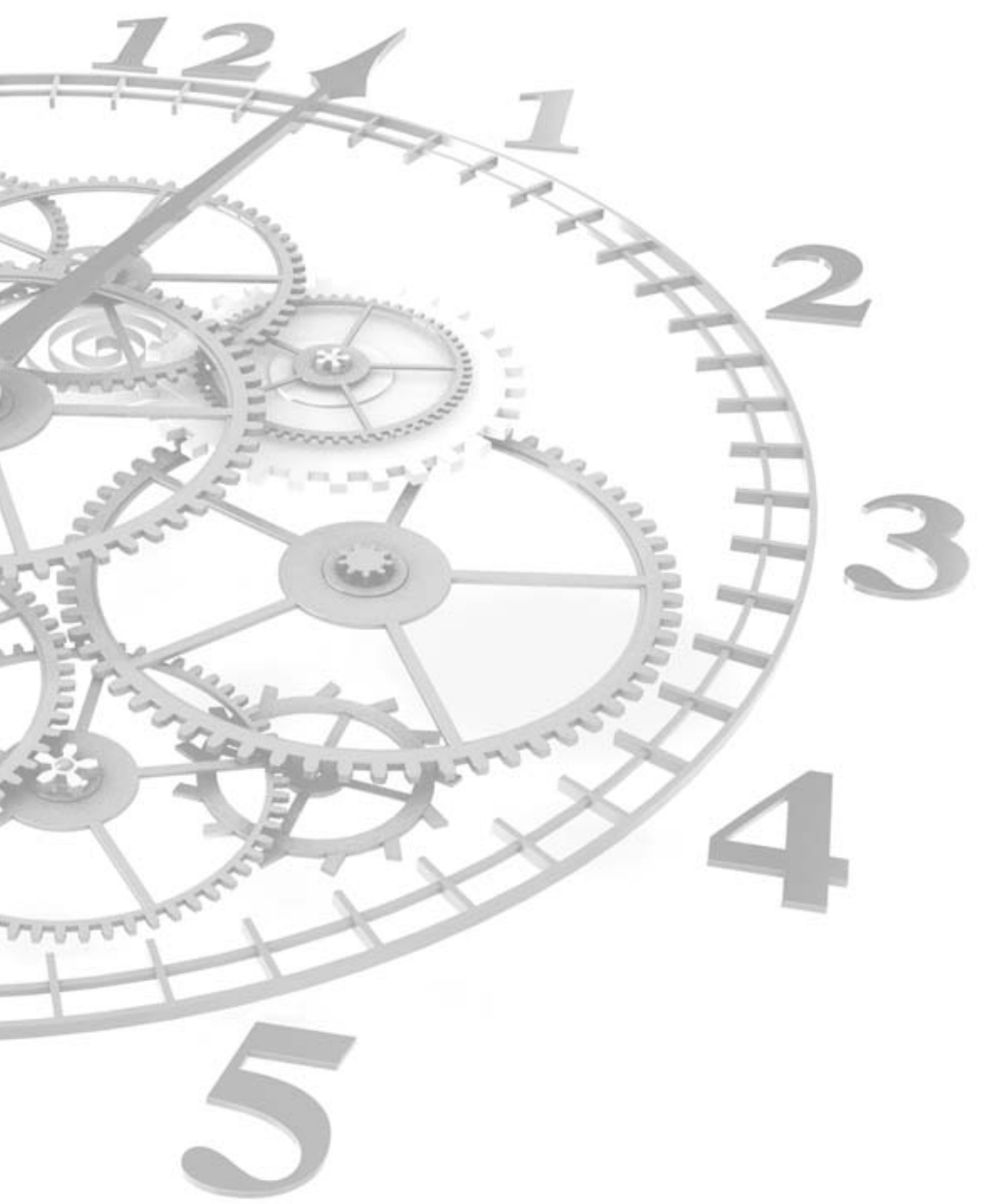



Saskia van Bergen werd geboren op 1 oktober 1980 te Bunde. In juli 1998 behaalde zij haar vwo-diploma aan het Stella Maris College te Meerssen. In hetzelfde jaar begon zij aan haar studie Psychologie aan de Universiteit Maastricht. Na extra keuzevakken in de criminologie gevolgd te hebben aan de University of Wales (Bangor, Verenigd Koninkrijk) en een extra klinische stage voltooid te hebben, studeerde ze in februari 2004 af en behaalde haar doctoraal diploma in de Cognitieve Psychologie. Van april 2004 tot en met april 2005 is zij werkzaam geweest als docent, onderzoeksmedewerker, en medewerker bestuurlijke informatievoorziening aan de Faculteit der Psychologie en Neurowetenschappen van de Universiteit Maastricht. Vanaf mei 2005 was zij aan dezelfde faculteit aangesteld als promovenda op een project over geheugenwantrouwen. Sinds maart 2011 werkt zij als beleidsadviseur bij Bureau Jeugdzorg Limburg.

Saskia van Bergen was born on October 1, 1980 in Bunde (The Netherlands). In July 1998, she finished her secondary school (Stella Maris College, Meerssen). In that same year, she started studying Psychology at Maastricht University. After extending her study with extracurricular criminology electives at the University of Wales (Bangor, United Kingdom), and a clinical internship, she graduated in February 2004 in Cognitive Psychology. From April 2004 until May 2005, she worked as a lecturer, research-assistant, and employee management information at the Faculty of Psychology and Neuroscience at Maastricht University. As from May 2005, she was appointed at the same Faculty as a PhD student on a project on memory distrust. Since March 2011, she works as a policy advisor at Bureau Jeugdzorg Limburg. 



\section{LIST OF PUBLICATIONS}

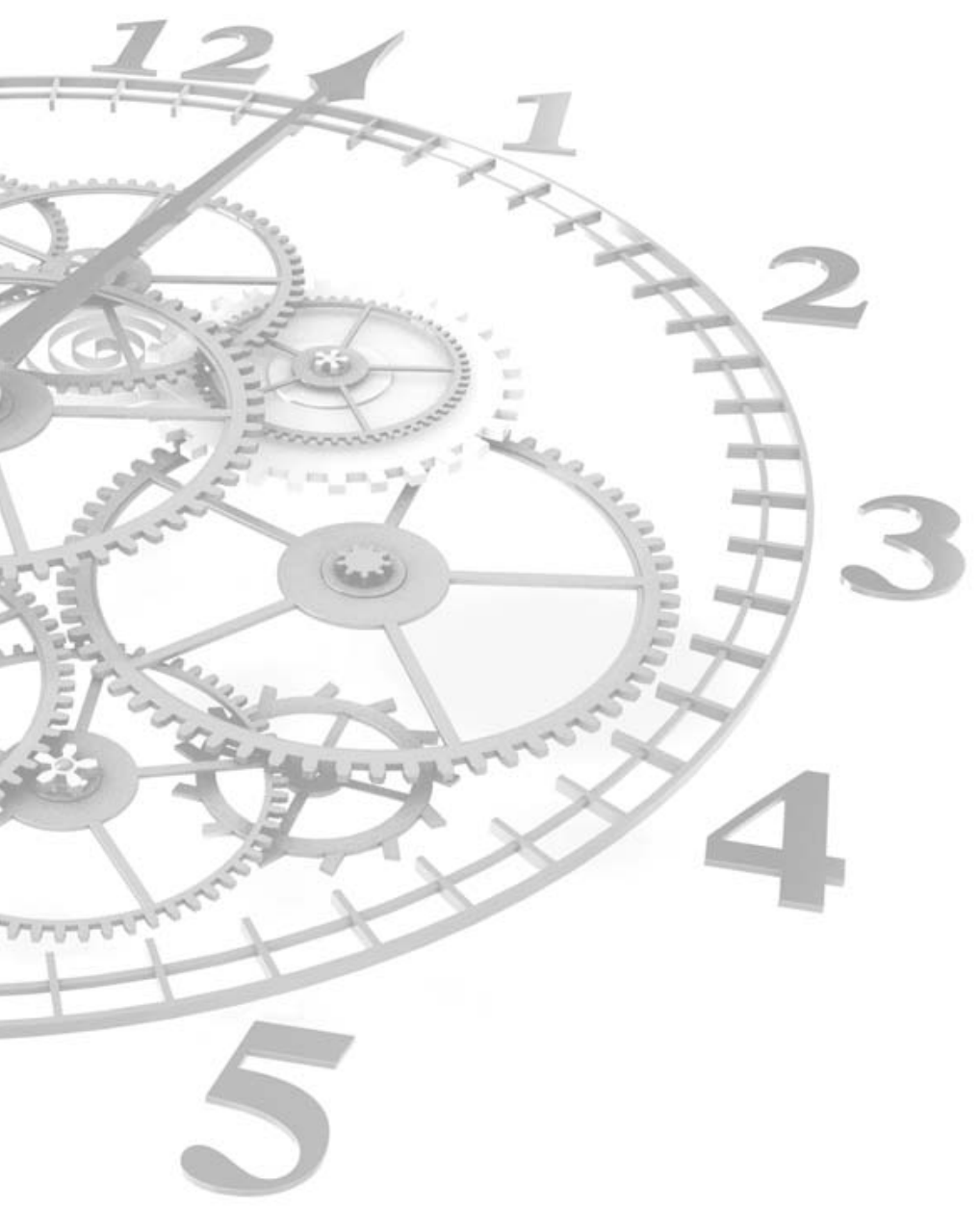




\section{International Journal Articles}

Cima, M., Van Bergen, S., \& Kremer, K. (2008). Development of the Supernormality Scale-Revised and its relationship with psychopathy. Journal of Forensic Sciences, 35, 975-981.

Jelicic, M., Merckelbach, H., \& Van Bergen, S. (2004). Symptom validity testing of feigned amnesia for a mock crime. Archives of Clinical Neuropsychology, 19, 525-531.

Jelicic, M., Merckelbach, H., \& Van Bergen, S. (2004). Symptom validity testing of feigned crime-related amnesia: A simulation study. Journal of Credibility Assessment and Witness Psychology, 5, 1-8.

Merckelbach, H., Zeles, G., Van Bergen, S., \& Giesbrecht, T. (2007). Trait dissociation and commission errors in memory reports. American Journal of Psychology, 120, 1-14.

Otgaar, H., Smeets, T., \& Van Bergen, S. (2010). Picturing survival memories: Enhanced memory after fitness-relevant processing occurs for verbal and visual stimuli. Memory \& Cognition, 38, 23-28.

Van Bergen, S., Brands, I., Jelicic, M., \& Merckelbach, H. (2010). Assessing trait memory distrust: Psychometric properties of the Squire Subjective Memory Questionnaire. Legal and Criminological Psychology, 15, 373384.

Van Bergen, S., Horselenberg, R., Merckelbach, H., Jelicic, M., \& Beckers, R. (2010). Memory distrust and acceptance of misinformation. Applied Cognitive Psychology, 24, 885-896.

Van Bergen, S., Jelicic, M., \& Merckelbach, H. (2008). Interrogation techniques and memory distrust. Psychology, Crime \& Law, 14, 425-434.

Van Bergen, S., Jelicic, M., \& Merckelbach, H. (2009). Are subjective memory problems related to suggestibility, compliance, false memories, and objective memory performance? American Journal of Psychology, 122, 249-257.

\section{National Journal Articles}

Van Bergen, S. (2009). Geheugenwantrouwen in de praktijk. Tijdschrift voor Neuropsychiatrie \& Gedragsneurologie, 8, 59-63.

Van Bergen, S., \& Jelicic, M. (2007). De rol van geheugenfeedback op imaginatie-inflatie. Directieve Therapie, 27, 5-16.

Van Bergen, S., Merckelbach, H., \& Jelicic, M. (2006). Je eigen geheugen wantrouwen: Een riskante zaak? De Psycholoog, 41, 664-669. 


\section{Book Contributions}

Horselenberg, R., Merckelbach, H., Crombag, H., \& Van Bergen, S. (2010). Getuigen helpen herinneren. In P. J. van Koppen, H. L .G. J. Merckelbach, M. Jelicic \& J. W. de Keijser (Eds.), Reizen met mijn Rechter: Psychologie van het Recht (pp. 487-508). Deventer: Kluwer.

Van Bergen, S. (2008). Squire Subjective Memory Questionnaire. In T. Giesbrecht, C. de Ruiter \& M. Jelicic (Eds.), Forensisch psychodiagnostisch gereedschap. Malingering, psychopathie en andere persoonlijkheidstrekken (pp. 137-142). Amsterdam: Harcourt.

Van Bergen, S. (2009). Memory distrust: Risky business? In L. Strömwall $\delta$ P. A. Granhag (Eds.), Memory: Reliability and personality. Proceedings of the Second Joint Nordic PhD course in Legal and Investigative Psychology (pp. 57-67). Göteborg: Göteborg University.

Van Koppen, P. J., Fernhout, F., \& Van Bergen, S. (2009). Het maagdenvlies als bewijs. Tegenstrijdige verklaringen in twee incestzaken. Den Haag: Boom Juridische Uitgevers.

\section{Submitted Article}

Van Bergen, S., Merckelbach, H., Horselenberg, R., Jelicic, M., \& Zuidberg, B. (2010). Did I do that? Memory distrust promotes internalised false confessions. Manuscript submitted for publication.

\section{Conference Presentations}

Van Bergen, S., Beckers, R., Jelicic, M., \& Merckelbach, H. (2008, July). Does memory distrust make you vulnerable in interrogations? Paper presented at the $18^{\text {th }}$ European Conference on Psychology and Law, Maastricht, The Netherlands.

Van Bergen, S., Jelicic, M., \& Merckelbach, H. (2007, July). Some police interrogation techniques elicit more memory distrust and false confessions than others. Paper presented at the $3^{\text {rd }}$ International Congress of Psychology and Law, Adelaide, Australia.

Van Bergen, S., Jelicic, M., \& Merckelbach, H. (2007, March). Distrusting your memory makes you in fact less suggestible. Poster presented at 'Off the witness stand: Using Psychology in the Practice of Justice', New York, USA. 
Van Bergen, S., Jelicic, M., \& Merckelbach, H. (2006, July). Distrusting your memory makes you in fact less suggestible. Paper presented at the $4^{\text {th }} \mathrm{In}$ ternational Conference on Memory, ICOM-4, Sydney, Australia.

Van Bergen, S., Jelicic, M., \& Merckelbach, H. (2005, June). Effects of memory distrust on imagination inflation. Poster presented at the $15^{\text {th }}$ European Conference on Psychology and Law, Vilnius, Lithuania. 